\author{
UNIVERSIDADE DE SÃO PAULO \\ FACULDADE DE MEDICINA DE RIBEIRÃO PRETO \\ DEPARTAMENTO DE FARMACOLOGIA
}

Vitória Carolina Rondon Pereira

Influência do tratamento de comorbidades sobre o sucesso da terapia da disfunção erétil: foco na via do óxido nítrico

Ribeirão Preto 


\author{
UNIVERSIDADE DE SÃO PAULO \\ FACULDADE DE MEDICINA DE RIBEIRÃO PRETO \\ DEPARTAMENTO DE FARMACOLOGIA
}

Vitória Carolina Rondon Pereira

\title{
Influência do tratamento de comorbidades sobre o sucesso da terapia da disfunção erétil: foco na via do óxido nítrico
}

Versão corrigida

Dissertação apresentada à Faculdade de Medicina de Ribeirão Preto da Universidade de São Paulo para obtenção do título de mestre em ciências

Área de concentração: Farmacologia

Orientador: Prof. Dr. Riccardo Lacchini

Ribeirão Preto 
Autorizo a reprodução e divulgação total ou parcial deste trabalho, por qualquer meio convencional ou eletrônico, para fins de estudo e pesquisa, desde que citada a fonte.

FICHA CATALOGRÁFICA

Pereira, Vitória Carolina Rondon

Influência de tratamento de comorbidades sobre o sucesso da terapia da disfunção erétil: foco na via do óxido nítrico.

Ribeirão Preto, 2020.

96 f. : il. ; $30 \mathrm{~cm}$

Dissertação de Mestrado, apresentada à Faculdade de Medicina de Ribeirão Preto / USP. Área de concentração: Farmacologia.

Orientador: Lacchini, Riccardo.

1.Disfunção erétil. 2. Inibidores da fosfodiesterase do tipo 5.

3. Dimetilarginina assimétrica. 4. Óxido nítrico. 


\section{FOLHA DE APROVAÇÃO}

PEREIRA, V. C. R. P. Influência de tratamento de comorbidades sobre o sucesso da terapia da disfunção erétil: foco na via do óxido nítrico. 96 f.

Dissertação (Mestrado em Farmacologia) - Faculdade de Medicina de Ribeirão Preto, Universidade de São Paulo, Ribeirão Preto, 2020.

Aprovado em:

BANCA EXAMINADORA

Prof. Dr.: Instituição:

Julgamento: Assinatura:

Prof. Dr.: Instituição: Julgamento: Assinatura:

Prof. Dr.: Instituição: Julgamento: Assinatura: 


\section{DEDICATÓRIA}

Dedico este trabalho aos meus pais, Patrícia e Nilton, por serem os melhores pais do universo e por me possibilaterem todas as conquistas da minha vida. Eu amo demais vocês dois, meus preciosos! 


\section{AGRADECIMENTOS}

Aos meus pais, por me apoiarem em tudo sempre, por estarem sempre comigo, mesmo que à distância, e por me amarem incondicionalmente. Às minhas madrinhas e meu padrinho, Nara, Rita e Angelo, por serem meus segundos pais e sempre me apoiarem e se preocuparem comigo. Ao meu noivo, Del, pelo apoio, amor e companhia durante essa jornada.

Ao meu orientador, Prof. Dr. Riccardo Lacchini, por me aceitar em seu grupo de pesquisa desde minha iniciação científica, pelos ensinamentos e pelas oportunidades. Aos meus colegas de laboratório, Aline, Anderson, Cezar, Fernanda, Leevan e Sherliane, e, especialmente, Ana e Letícia, por toda a ajuda durante a elaboração deste trabalho e amizade. À colaboradora dra. Fernanda Lacchini, por toda a ajuda durante o desenvolvimento deste projeto. Ao colaborador dr. Lucas Cezar Pinheiro, pela ajuda na elaboração deste trabalho. Aos membros da banca de qualificação, pelas contribuições neste trabalho.

Ao Prof. Dr. José Eduardo Tanus dos Santos, por fornecer gentilmente materiais e equipamentos necessários para realização deste trabalho, e aos membros do seu grupo de pesquisa, por toda ajuda sempre que preciso.

À Prof. Dra. Vera Lanchote, por aceitar essa colaboração e me receber de braços abertos em seu laboratório. Às doutoras Adriana e Maria Paula, por todos os ensinamentos e ajuda desde o início do projeto. Aos colegas do PKClin, Glauco, Igor, Leandro e Marta, e, especialmente, Fernanda, Jhohann e Tálita, por todas as lições, ajuda, companhia e amizade.

À Coordenação de Aperfeiçoamento de Pessoal de Nível Superior (Capes), pelo apoio financeiro. 


\section{RESUMO}

PEREIRA, V. C. R. Influência de tratamento de comorbidades sobre o sucesso da terapia da disfunção erétil: foco na via do óxido nítrico. 2020. $96 \mathrm{f}$. Dissertação (Mestrado em Farmacologia) - Faculdade de Medicina de Ribeirão Preto, Universidade de São Paulo, Ribeirão Preto, 2020.

A disfunção erétil (DE), definida como a inabilidade persistente em obter e/ou manter uma ereção que permita desempenho sexual satisfatório, pode afetar a saúde em seus aspectos físicos e psicossociais, e ter impacto importante na qualidade de vida dos portadores e de seus parceiros. A enzima óxido nítrico sintase endotelial (eNOS) utiliza L-arginina como substrato para sintetizar óxido nítrico (NO), que medeia o relaxamento da musculatura lisa vascular por meio de uma cascata de reações. A produção de NO pode ser inibida por substâncias endógenas como ADMA, SDMA e L-NMMA. A via alternativa de degradação da L-arginina depende de enzimas conhecidas como arginases. Diversos tratamentos farmacológicos impactam esta via e podem afetar o sucesso da terapia com inibidores de fosfodiesterase tipo 5 .

Investigamos a influência do diabetes mellitus (DM), do uso da insulina e dos fármacos omeprazol e alopurinol sobre o risco para DE e sobre a resposta ao tratamento com sildenafil em amostras oriundas de biorrepositório. Foi possível observar que, de forma geral, as concentrações de nitrito estão maiores nos portadores de DE; a presença do DM tem impacto negativo na função erétil; e, ainda, que as tendências dos indicadores estudados são opostas quando comparamos os grupos que utilizam omeprazol ou alopurinol.

Palavras-chave: disfunção erétil, inibidores da fosfodiesterase do tipo 5, dimetilarginina assimétrica, óxido nítrico. 


\section{ABSTRACT}

PEREIRA, V. C. R. The influence of cornorbidity treatments on the success of erectile dysfunction therapy: focus on nitric oxide pathway. 2020. $96 \mathrm{f}$. Dissertação (Mestrado em Farmacologia) - Faculdade de Medicina de Ribeirão Preto, Universidade de São Paulo, Ribeirão Preto, 2020.

Erectile dysfunction (ED), defined as the persistent inability to obtain and/or maintain an erection that permits satisfactory sexual performance, can affect health in its physical and psychosocial aspects, and it has an important impact on the quality of life of patients and their partners. The enzyme nitric oxide synthase endothelial (eNOS) uses the amino acid L-arginine as a substrate to synthesize nitric oxide (NO), which mediates the relaxation of vascular smooth muscle through a cascade of reactions. NO production can be inhibited by endogenous substances such as ADMA, SDMA and L-NMMA. The alternative L-arginine degradation pathway depends on enzymes known as arginases, culminating in the production of Lornithine and urea. Several pharmacological treatments impact this pathway and may affect the success of the therapy with phosphodiesterase 5 inhibitors.

We investigated the influence of diabetes mellitus (DM), the use of insulin and the drugs omeprazole and allopurinol on the risk of ED and on the response to treatment with sildenafil in samples from a biorepository. It was possible to observe that, in general, nitrite concentrations are higher in ED patients; the presence of DM has a negative impact on erectile function; and, furthermore, that the trends of the studied indicators are opposite when we compare the groups that use omeprazole or allopurinol.

Keywords: erectile dysfunction, type 5 phosphodiesterase inhibitors, asymmetric dimethylarginine, nitric oxide. 


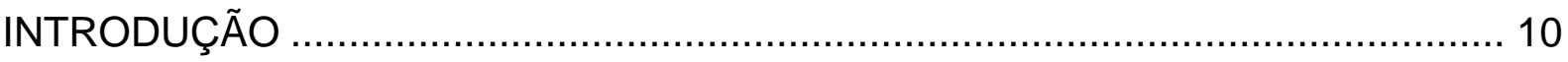



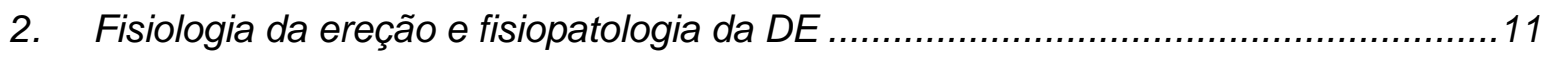

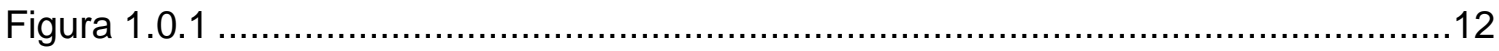



4. Disfunção endotelial e modulação do óxido nítrico …………..................................17

5. Tratamento farmacológico da DE - Inibidores da PDE-5 .....................................19

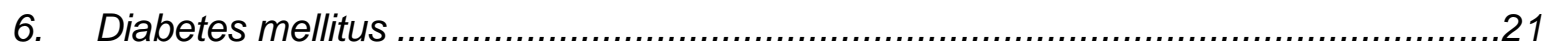

7. Inibidores da bomba de prótons (omeprazol), XOR e alopurinol ..............................24

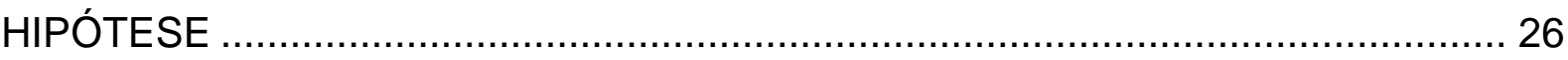

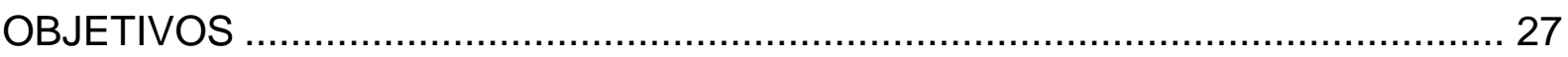





2. Avaliação da função erétil e da resposta ao tratamento com sildenafil .....................29

3. Determinação de nitrito.............................................................................

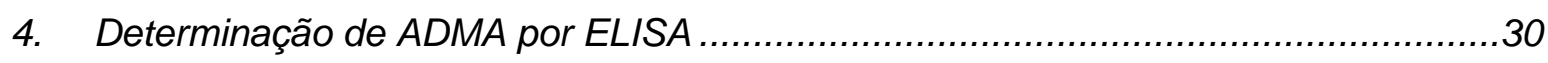

5. Determinação da atividade das arginases, arginase 1 e arginase 2.........................30

6. Determinação de ADMA, SDMA, L-NMMA, L-arginina, L-citrulina e L-ornitina por LCMS/MS

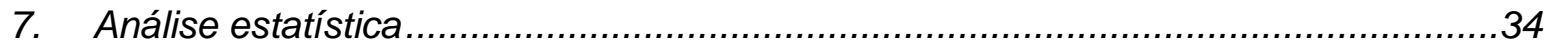



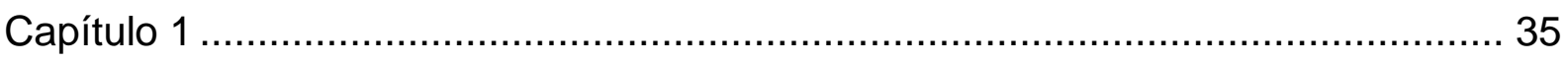

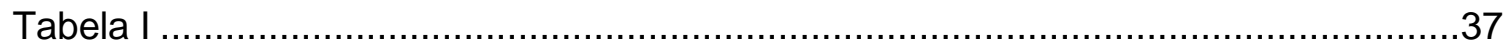

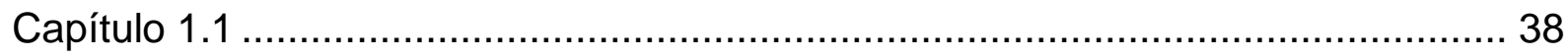

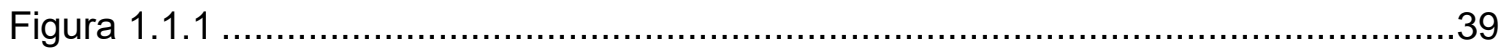

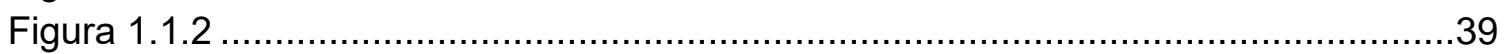

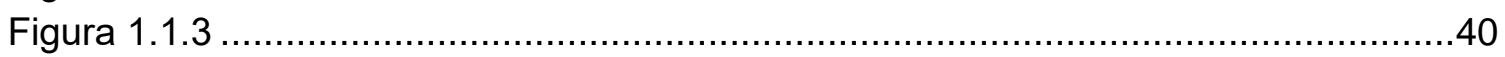

Figura 1.1.4

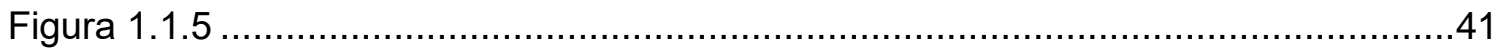

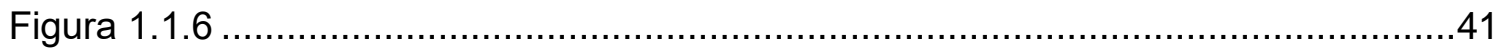




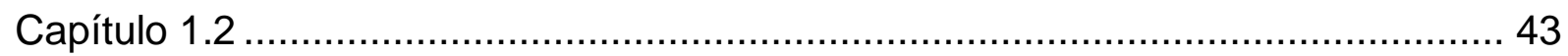

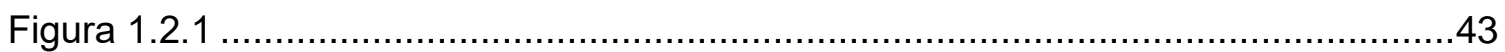

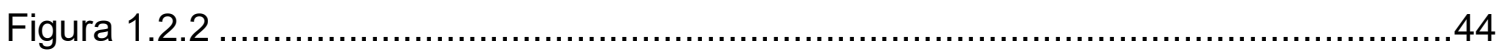

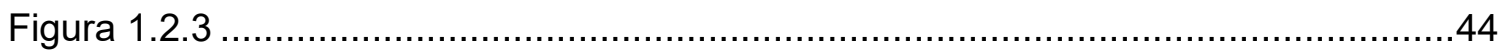

Figura 1.2.4

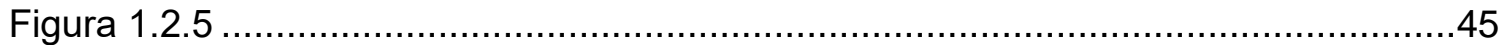

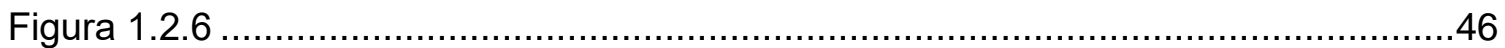

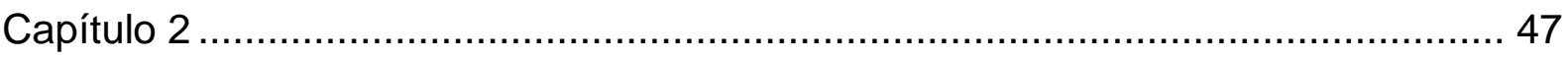



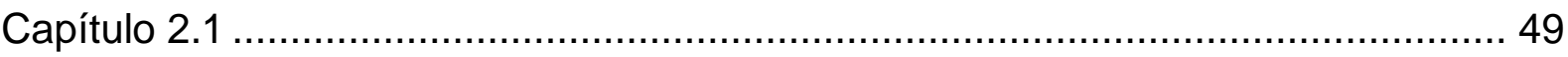

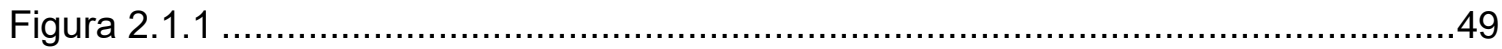

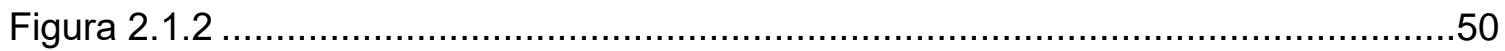



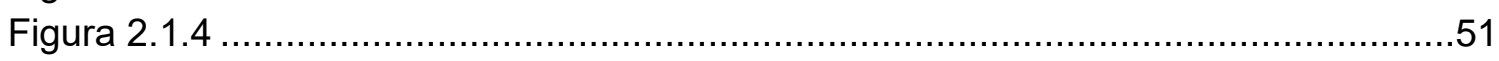

Figura 2.1.5



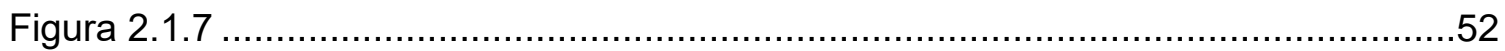

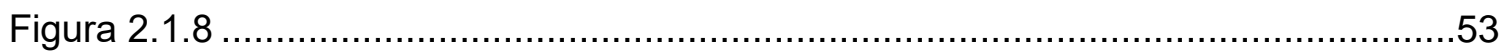

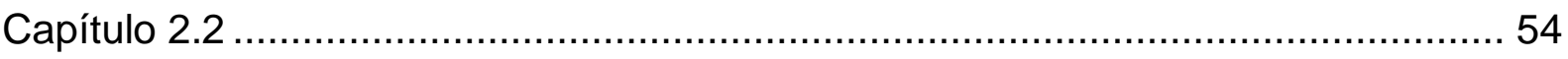

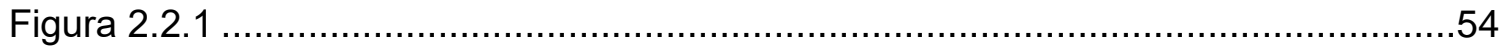

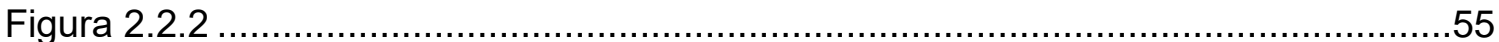

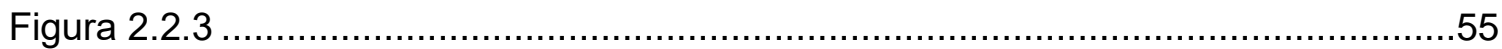

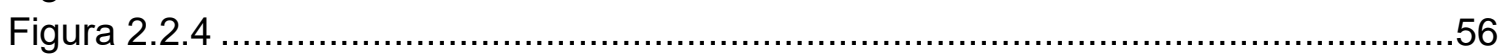

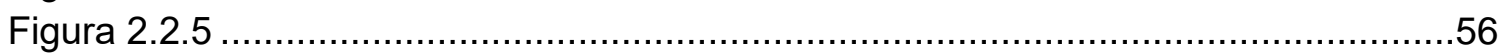

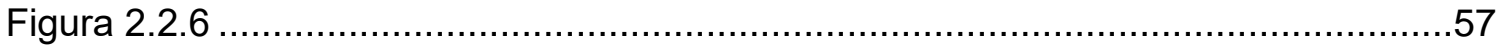

Figura 2.2.7

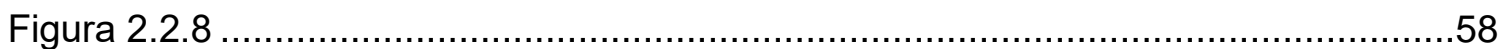

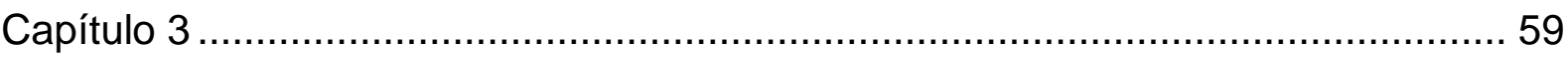

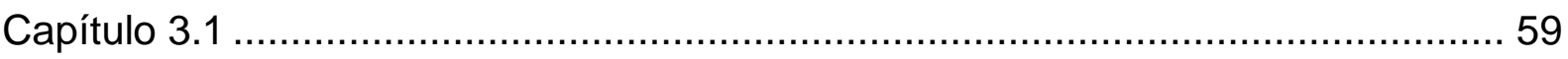

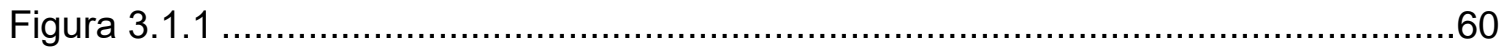

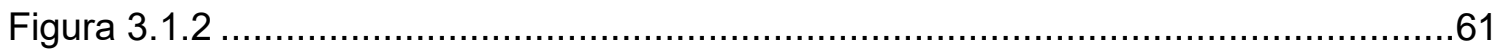



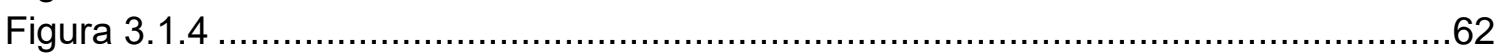

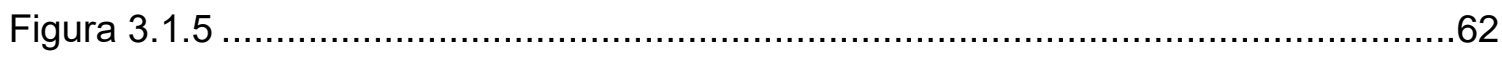

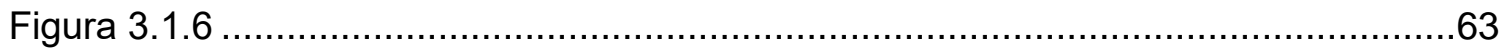

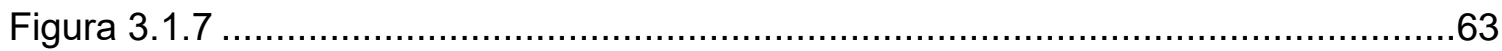

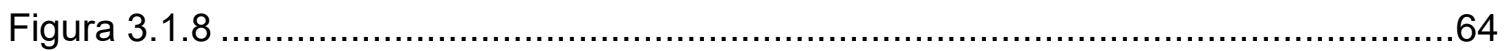

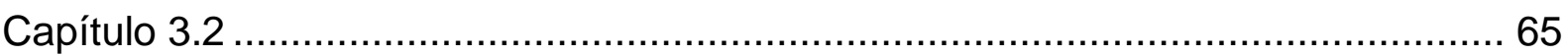

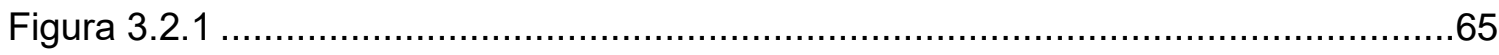

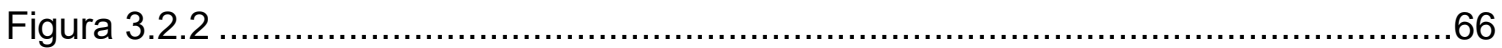






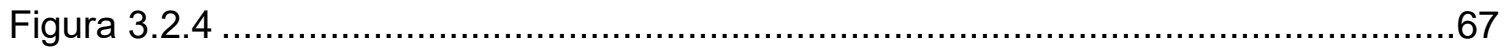

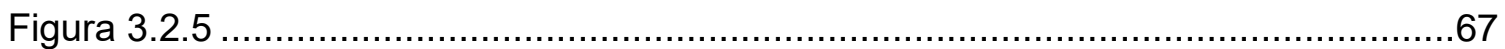

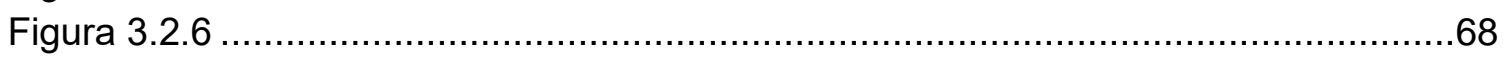



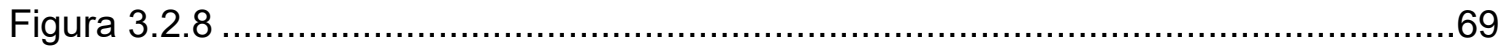

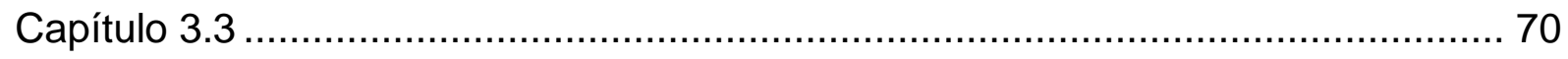





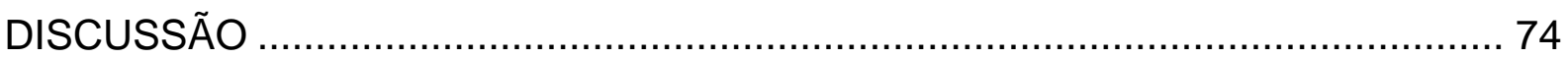

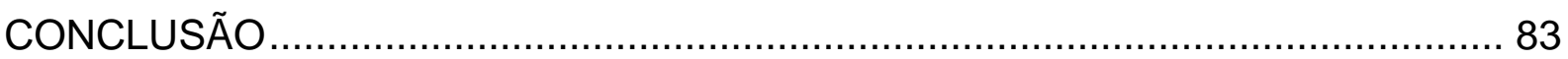

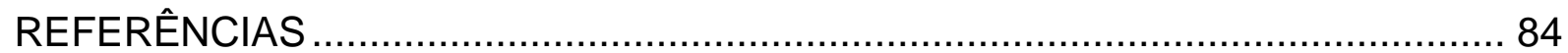




\section{INTRODUÇÃO}

\section{Disfunção erétil (DE)}

Disfunção erétil (DE) é definida como a inabilidade persistente em obter e/ou manter uma ereção que permita desempenho sexual satisfatório [1-3]. Essa condição pode afetar a saúde em seus aspectos físicos e psicossociais, e ter impacto importante na qualidade de vida dos portadores e de seus parceiros [2-5] Estudos demonstram que homens afetados pela disfunção erétil estão mais propensos a insatisfação física e emocional, além de uma diminuição da qualidade geral de vida [2-6].

De acordo com o European Male Aging Study, cerca de 30\% dos homens entre 40 e 79 anos apresentam DE moderada a severa [2], enquanto outro estudo (Massachusetts Male Aging Study) mostra que 52\% dos participantes, com idades entre 40 e 70 anos, relatam algum grau de DE (leve, moderada ou severa) [7]. Um estudo conduzido no Brasil com homens maiores de 18 anos descreve uma prevalência de $45,1 \%$ de DE [4]. A severidade da disfunção erétil aumenta com a idade: o grau moderado aumenta de 17 a $34 \%$ dos 40 aos 70 anos, enquanto o severo, de 5 a $15 \%$ nessa mesma faixa etária [7].

A ereção tem componentes reflexos e psicogênicos em sua gênese. Estimase que mais de $80 \%$ dos casos de disfunção erétil tenham origem orgânica, e não psíquica, como se pensava no passado [8].

De forma geral, os exames comumente usados para auxiliar no diagnóstico da disfunção erétil incluem testes de colesterol e glicemia, que avaliam fatores de risco para a doença, e exames de imagem - o ultrassom doppler peniano, que 
fornece informações importantes a respeito das condições dos vasos sanguíneos do órgão [3, 8, 9]. Uma forma de avaliar a presença e o grau de disfunção erétil consiste na aplicação do IIEF (International Index of Erectile Function), um questionário com quinze itens e cinco domínios da função sexual (função erétil, função orgásmica, desejo sexual, satisfação sexual e satisfação geral). As pontuações nos itens vão de zero ou um a cinco [10, 11]. Quanto menor a pontuação em cada item, pior a função estudada, isto é, pacientes com graus mais sérios de DE apresentam menores pontuações [10, 11].

\section{Fisiologia da ereção e fisiopatologia da DE}

O pênis é um órgão que possui basicamente três funções: urinária, sexual e reprodutiva. Ele apresenta três estruturas cilíndricas: dois corpos cavernosos, e um corpo esponjoso, que circunda a uretra. Os corpos cavernosos possuem duas porções: uma proximal, ou posterior, fixa no períneo, e outra distal, ou anterior, livre [12]. A base do corpo esponjoso é circundada pelo músculo bulbocavernoso, e as dos corpos cavernosos, pelos músculos isquiocavernosos. Esses músculos estão envolvidos na ejaculação e na fase rígida da ereção [13, 14].

O processo de ereção pode ser dividido em seis fases: flacidez, enchimento, tumescência, ereção completa, rigidez e detumescência. $O$ estado flácido caracteriza-se por baixo influxo de sangue e baixa pressão intracavernosa. Nesse momento, os músculos isquiocavernoso e bulbocavernoso estão relaxados, enquanto o músculo liso trabecular do pênis encontra-se contraído. O tônus desse músculo é controlado por uma combinação de ativação adrenérgica, controle miogênico e fatores contráteis derivados do endotélio, como endotelinas e 
prostaglandina $[15,16]$. Quando o mecanismo de ereção é iniciado, o sistema nervoso autônomo parassimpático envia sinais excitatórios ao pênis por meio de fibras eferentes localizadas na parte sacral da medula espinhal, especificamente entre S2 e S4. O músculo liso vascular das artérias helicinais e cavernosas relaxa, direcionando o fluxo sanguíneo para os espaços lacunares (também conhecidos como trabéculas ou sinusóides) $[16,17]$. É importante ressaltar a relevância da artéria pudenda interna, a principal responsável pelo suprimento sanguíneo dos corpos cavernosos [18].

Figura 1.0.1: Anatomia e mecanismo da ereção peniana

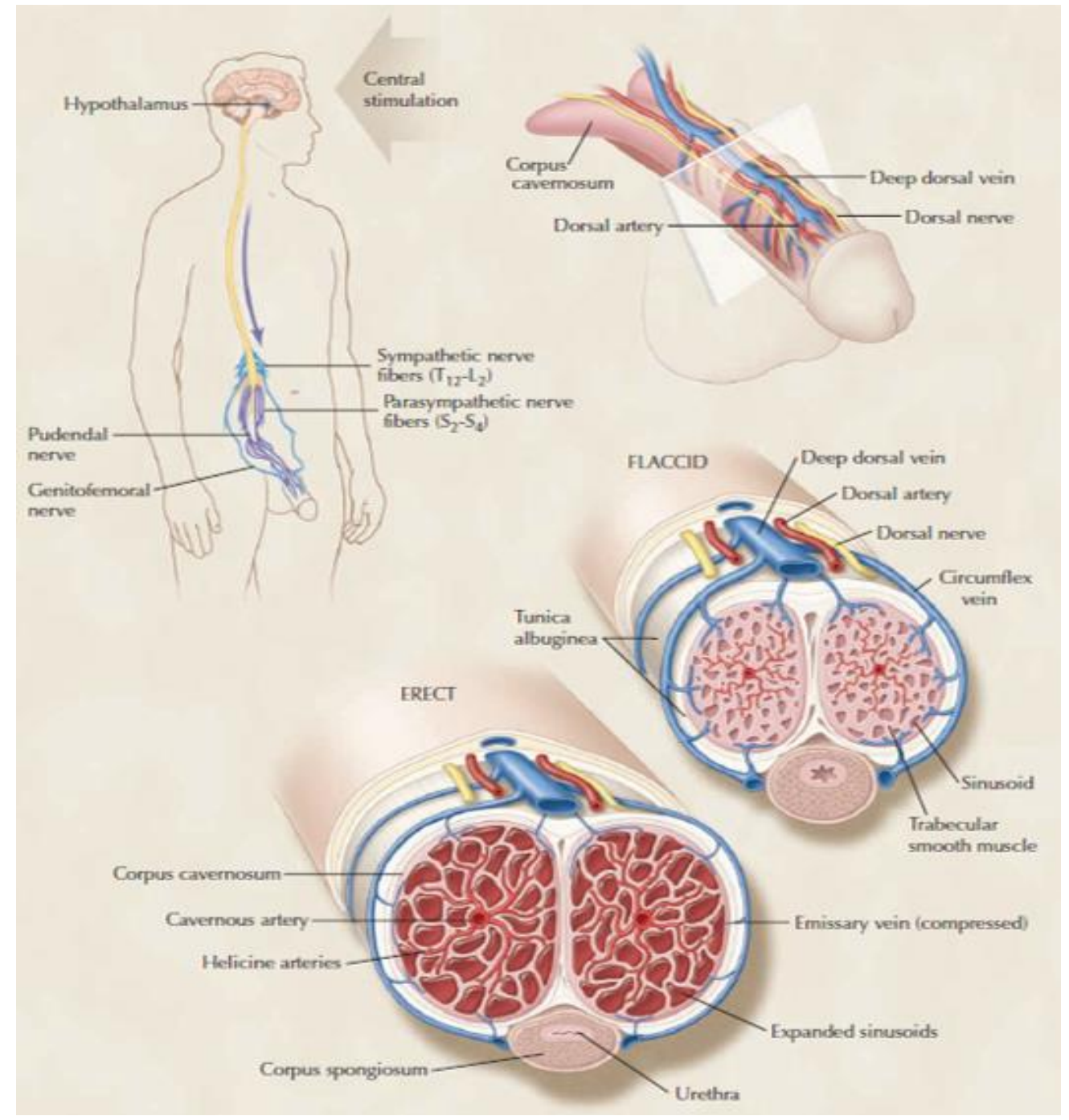

Fonte: Fazio, L.; Brock, 2004 [19]. 
Na tumescência, a compressão das veias subtúnicas pela túnica albugínea causa redução do efluxo venoso (mecanismo de veno-oclusão), o que ocasiona alongamento e aumento de volume do pênis, sem, entretanto, grande aumento da pressão intracavernosa [16, 17]. Durante a ereção completa, a pressão intracavernosa aumenta rapidamente, e na fase rígida da ereção, ultrapassa a pressão arterial diastólica, o que permite que o influxo sanguíneo ocorra durante a fase sistólica do pulso e possibilita uma rigidez completa. A contração dos músculos isquiocavernoso e bulbocavernoso durante a ejaculação também causa aumento na pressão intracavernosa $[16,17]$.

A detumescência é mediada pelo sistema nervoso autônomo simpático, por meio de nervos que emergem do segmento tóraco-lombar da medula, de T10 a L2. A contração do músculo liso do pênis e das artérias penianas ocasiona a diminuição do sangue nos espaços lacunares, e a contração do músculo liso trabecular leva ao colapso das trabéculas e à detumescência [20].

O óxido nítrico (NO), liberado pelo endotélio e pelas terminações nervosas parassimpáticas, é o principal mediador envolvido na ereção [17]. Resumidamente, o relaxamento do músculo liso cavernoso leva ao ingurgitamento dos sinusóides (isto é, essas estruturas enchem-se de sangue), e ocasiona a compressão de veias subtúnicas entre as trabéculas e a túnica albugínea, causando a oclusão do retorno venoso - o que culmina na ereção [16].

Fica claro, portanto, que quaisquer condições que afetem as vias neurais ou vasculares responsáveis pela ereção podem ocasionar disfunção erétil [18]. Estudos indicam, por exemplo, que apenas de 10 a $23 \%$ dos homens abaixo de 60 anos submetidos a prostatectomia radical bilateral poupadora de nervos recuperam sua função erétil basal [21], e a incidência de disfunção erétil pós-prostatectomia radical 
pode variar de 14 a $90 \%$ [22]. Além disso, os homens submetidos a prostatectomia radical, assim como outros indivíduos com danos neurológicos severos, constituem um grupo que sabidamente tem respostas piores ao tratamento farmacológico com inibidores de fosfodiesterases [23]. Outros fatores de risco que também podem contribuir para a patogênese da DE são diabetes mellitus, hipertensão, dislipidemia, obesidade, envelhecimento, tabagismo, sedentarismo e etilismo crônico [18, 24].

\section{Síntese endotelial de óxido nítrico (NO)}

As células endoteliais participam ativamente de atividades vasculares, como a secreção de mediadores químicos produzidos localmente e a regulação da permeabilidade vascular [12]. Diferentes estímulos podem desencadear a produção endotelial de óxido nítrico (NO), um radical livre gasoso. O óxido nítrico é sintetizado a partir do aminoácido L-arginina, numa reação catalisada pela enzima eNOS (óxido nítrico sintase endotelial), que formará, ainda, L-citrulina [25-29].

Há três isoformas de NOS: eNOS, ou NOS3, forma endotelial; nNOS, ou NOS1, neuronal; e iNOS, ou NOS2, forma induzível que é expressa, de forma geral, em resposta a estímulos patológicos [25, 27]. A eNOS, especificamente, encontra-se inativa, associada à proteína caveolina, nas cavéolas (microdomínios especializados, derivados do complexo de Golgi, presentes na membrana plasmática), e a dissociação da caveolina causa sua ativação. A estimulação por fatores de crescimento celular causa ativação de receptores na superfície celular e fosforilação de fosfoinositídeo-3 quinase (PI3K), tornando essa enzima ativa [26]. PI3K, então, fosforila lipídeos na membrana plasmática, formando fosfatidilinositol $(3,4,5)$ trisfosfato $\left(\mathrm{PIP}_{3}\right)$. Akt (proteína quinase $\mathrm{B}$ ou $\mathrm{PKB}$ ) é recrutada 
para a membrana pela interação com a via do $\mathrm{PIP}_{3}$, sendo ativada, e medeia respostas como sobrevivência celular, crescimento, proliferação, migração celular e angiogênese, por meio da fosforilação de proteínas intracelulares - incluindo a eNOS [26].

Outro elemento importante na via do NO é a calmodulina (CaM), uma proteína sensora de $\mathrm{Ca}^{2+}[30]$. Trata-se de um regulador essencial do fluxo de elétrons intra e interdomínio, um processo necessário para a geração de NO [31]. Todas as isoformas de NO sintase se ligam à calmodulina [32]. A CaM ativada por cálcio é importante para a regulação da atividade tanto da nNOS quanto da eNOS [32]. Devido às diferenças no domínio de ligação à CaM, nas isoformas neuronal e endotelial é necessário que haja um aumento no $\mathrm{Ca}^{2+}$ intracelular para que essa ligação seja efetivada, enquanto a NOS induzível se liga à calmodulina com alta afinidade, mesmo na ausência de íons cálcio [32].

A eNOS sintetiza NO de maneira variável, com sua atividade aumentando intensamente quando a concentração intracelular de cálcio aumenta [32]. O Ca ${ }^{2+}$ induz a ligação da calmodulina à enzima; entretanto, diversas outras proteínas também interagem com a eNOS e regulam sua atividade [32].

A biossíntese de NO ocorre em duas etapas: na primeira, há hidroxilação de um dos dois nitrogênios guanidinos da L-arginina, que é então convertida a N hidroxi-L-arginina (NHA); na segunda, há conversão da NHA a L-citrulina e NO. A primeira etapa do processo envolve nicotinamida adenina dinucleotídeo fosfato (NADPH) e oxigênio, enquanto a segunda depende dos cofatores flavina adenina dinucleotídeo (FAD), flavina mononucleotídeo (FMN) e tetra-hidrobiopterina $\left(\mathrm{BH}_{4}\right)$ [28]. 
O óxido nítrico produzido difunde-se rapidamente para o lúmen vascular e para o interior da célula muscular lisa, onde interage com o ferro do grupo heme da enzima guanilato ciclase solúvel (GCs), tornando-a ativa. A guanilato ciclase solúvel ativa catalisa a saída de dois grupamentos fosfato da molécula de guanosina trifosfato (GTP), culminando na síntese de guanosina monofosfato cíclico (GMPc) [33]. O aumento da concentração de GMPc na célula muscular lisa causa relaxamento. Basicamente, esse mecanismo envolve a diminuição da entrada de $\mathrm{Ca}^{2+}$ na célula, a inibição da liberação de $\mathrm{Ca}^{2+}$ do retículo sarcoplasmático e o aumento do sequestro de $\mathrm{Ca}^{2+}$ para o retículo sarcoplasmático [34].

O homodímero da eNOS pode se desacoplar sob condições patológicas, formando monômeros. Esse desacoplamento leva a produção de ânion superóxido em vez de NO, o que pode induzir estresse oxidativo [35]. As espécies reativas de oxigênio, em concentrações moderadas, agem como moléculas sinalizadoras e exercem função importante no controle do tônus vascular, detecção de oxigênio, crescimento e proliferação celular, apoptose e respostas inflamatórias [36].

As NOS constituem a principal fonte de óxido nítrico no organismo humano, e sua atividade é dependente de oxigênio; entretanto, há vias alternativas de produção do NO que não dependem de oxigênio, e envolvem, por exemplo, hemoglobina, mioglobina, xantina oxidoredutase (XOR), dentre outros [37-39]. Essas vias alternativas utilizam nitrito $\left(\mathrm{NO}_{2}^{-}\right)$e encontram-se especialmente ativadas em situações de hipóxia e acidose [37]. Os íons nitrito e nitrato $\left(\mathrm{NO}_{3}^{-}\right)$são produtos tanto da dieta quanto da oxidação do NO. Resumidamente, o íon nitrato é reduzido a nitrito, e o nitrito é reduzido a NO $[37,38]$. Por ser rapidamente metabolizado, o óxido nítrico tem uma meia-vida e um gradiente de difusão pequenos [37]. Devido a essas limitações, o marcador utilizado para medir de forma indireta as 
concentrações de óxido nítrico é o nitrito, formado pela reação de oxidação do NO $[37,40]$.

Por sua ação vasodilatadora, o NO tem função importante na manutenção da homeostase cardiovascular, especialmente pela atuação na regulação do tônus vascular basal, mantido pela liberação contínua de quantidades mínimas de NO estimulada pelo estresse de cisalhamento e pelo fluxo sanguíneo pulsátil [41, 42].

4. Disfunção endotelial e modulação do óxido nítrico

O endotélio desempenha um papel primordial na manutenção da homeostase vascular, pela liberação de diversas substâncias (dentre elas, o óxido nítrico) que regulam diversos processos, como vasoconstrição e vasodilatação, e os estados pró e antitrombótico, e pró e antiinflamatório [43]. A disfunção endotelial é caracterizada pelo aumento da vasoconstrição, da agregação plaquetária e da adesão, levando a um estado pró-trombótico, a uma maior proliferação de células musculares lisas e à inflamação vascular aumentada [43]. Trata-se de uma condição comum aos processos fisiopatológicos de diversas doenças, como o diabetes mellitus (DM), a hipertensão arterial e a disfunção erétil [15, 43].

As três isoformas de NO sintase podem ser inibidas por análogos da arginina, a exemplo de $\mathrm{N}^{\mathrm{G}}$-monometil-L-arginina (L-NMMA) e $\mathrm{N}^{\mathrm{G}}$-nitro-L-arginina-metil-éster (L-Name) [44, 45]. As formas dimetiladas de arginina, dimetil arginina assimétrica (ADMA) e dimetil arginina simétrica (SDMA), são produzidas pela metilação de resíduos de arginina das proteínas intracelulares [46].

ADMA e L-NMMA reduzem a síntese de NO por inibir tanto a enzima óxido nítrico sintase diretamente quanto a captação celular de L-arginina pelos 
transportadores de aminoácidos catiônicos (CAT) [46]. A degradação dessas substâncias é catalisada pela enzima dimetil arginina dimetilamina hidrolase (DDAH), que existe em duas isoformas em humanos: DDAH1 e DDAH2 [47]. Já SDMA atua apenas inibindo a captação celular de L-arginina pelos CATs, não sendo capaz de inibir diretamente a atividade das óxido nítrico sintases [46]. A eliminação de SDMA depende majoritariamente de excreção renal, mas essa substância pode ser metabolizada pela enzima alanina-glioxilato aminotransferase 2 (AGXT2) (também capaz de metabolizar ADMA e L-NMMA) [48].

O padrão ouro para quantificação de arginina e suas formas metiladas é a cromatografia líquida acoplada a espectrometria de massas (LC-MS) [49-52]. Há diversos métodos de LC-MS descritos na literatura para essas substâncias, mas, de forma geral, o preparo de amostra é feito por precipitação proteica ou extração em fase sólida (SPE) [51, 52]. Quando a separação cromatográfica é feita por colunas de fase normal ou HILIC (cromatografia líquida de interação hidrofílica), não é necessário fazer a reação de derivatização; entretanto, no caso de colunas de fase reversa, é preciso derivatizar os compostos para torná-los menos polares e aumentar os tempos de retenção e, assim, facilitar a separação cromatográfica [52].

Embora, de forma geral, haja excesso de L-arginina no citoplasma da célula endotelial e a taxa de produção de NO seja determinada pela atividade de enzima, em determinadas situações, a síntese desse mediador pode ser limitada pela biodisponibilidade de substrato. A enzima arginase utiliza a L-arginina para produzir L-ornitina e ureia $[53,54]$. Por competirem pelo mesmo substrato, a expressão aumentada da arginase pode interferir na síntese de óxido nítrico pelas NO sintases. Em mamíferos, foram identificadas duas isoformas de arginases: arginase 1 (ARG1), localizada no citosol, predominantemente nos hepatócitos, e arginase 2 (ARG2), 
presente nas mitocôndrias em diversos tecidos, dentre eles, os corpos cavernosos [47, 53-55]. Ambas isoformas estão presentes no endotélio vascular [47, 53, 54].

As duas principais funções das arginases são eliminar o amônio do organismo (pela síntese de ureia) e produzir ornitina - precursora de poliaminas (necessárias para a proliferação celular e a regulação de diversos canais iônicos) e prolinas (envolvidas na produção de colágeno) [53, 56]. Embora as ações das duas isoformas sejam redundantes, alterações na isoforma 1 podem levar a problemas graves ou mesmo letais de saúde [53]. A atividade aumentada da ARG1 foi associada a diabetes, HA e hipertensão pulmonar [47]. Diferentemente de ARG1. A isoforma ARG2 tem como principal função manter a homeostase vascular da Larginina [55].

O fim da sinalização da via das NOS se dá pela degradação do GMPc por enzimas chamadas fosfodiesterases (PDEs) [25, 26]. Há diferentes subtipos de PDEs, e cada um é seletivo para AMPc (3',5'-adenosina monofosfato cíclico, substância produzida numa reação catalisada pela enzima adenilato ciclase), GMPc, ou ambas. As PDEs, que atuam como reguladoras dos níveis de GMPc, foram identificadas, até o presente momento, em onze isoformas [57]. Dessas isoformas, a mais relevante no tecido peniano humano em termos de função é a PDE-5, específica para GMPc [23].

5. Tratamento farmacológico da DE - Inibidores da PDE-5

O inibidor de fosfodiesterases mais conhecido atualmente é o sildenafil, que inibe seletivamente o subtipo 5 da enzima, específico para GMPc. Esse fármaco foi originalmente desenhado para tratar angina, mas durante a fase inicial dos testes, 
percebeu-se que seus efeitos na pressão arterial sistêmica de voluntários sadios foram modestos [58]. Além disso, participantes descreveram efeitos positivos na ereção, por isso seu uso mais difundido atualmente consiste no tratamento na disfunção erétil - embora também esteja aprovado pelo FDA (Food and Drug Administration, departamento do governo dos EUA) para uso em hipertensão arterial pulmonar, assim como o tadalafil e o vardenafil [59]. Esses últimos (tadalafil e vardenafil) também são inibidores da PDE-5, com características farmacocinéticas diferentes do sildenafil (o tadalafil, por exemplo, apresenta um tempo de ação mais prolongado) $[26,60]$.

Por sua administração simples (via oral), segurança, eficácia clínica e aceitação dos pacientes, os inibidores da fosfodiesterases-5 são os fármacos de primeira escolha no tratamento da disfunção erétil $[18,61,62]$. Ao inibir a atividade das PDEs, esses fármacos causam um aumento da concentração intracelular de GMPc, o que facilita o relaxamento do músculo liso trabecular dos corpos cavernosos do pênis [26, 58, 61]. Assim, o uso dessa classe de medicamentos facilita o processo de tumescência, mas o estímulo sexual continua sendo necessário para que ele se inicie [61].

Apesar de sua eficácia clínica alta, citada anteriormente, um estudo conduzido na América Latina revela que $19 \%$ dos homens submetidos ao tratamento com sildenafil não tiveram melhora em suas ereções, e $29 \%$ não conseguiram ter relações sexuais satisfatórias [63]. Esses dados mostram que uma parcela considerável dos homens que utilizam inibidores de PDEs não responde ao tratamento [23, 64]. Sabe-se, por exemplo, que homens com diabetes mellitus respondem menos ao tratamento com sildenafil em decorrência da função vascular deficiente $[23,64,65]$. 


\section{Diabetes mellitus}

Diabetes mellitus é o termo utilizado para definir distúrbios metabólicos que têm a hiperglicemia crônica como principal manifestação [66, 67]. Pode ocorrer ainda, simultaneamente, deficiência de insulina e resistência a esse hormônio, além de níveis elevados de glicose circulante $[67,68]$. De acordo com a Sociedade Brasileira de Diabetes, em 2015, cerca de 14,3 milhões de pessoas entre 20 e 79 anos tinham DM no Brasil, e a projeção para o ano 2040 no país é de 23,3 milhões de afetados [69]. Em 2015, o diabetes mellitus foi a quarta doença não transmissível que mais causou mortes ao redor do mundo [70].

A insulina é secretada pelas células $\beta$ nas ilhotas de Langerhans do pâncreas, de acordo com os níveis circulantes de glicose no organismo [66, 67]. Esse hormônio possui uma série de funções em diferentes tipos celulares, facilitando a absorção de componentes da alimentação para as células (em especial, a glicose, para fornecimento de energia) e seu armazenamento [71], estimulando as enzimas que produzem glicogênio e gordura, e suprimindo as enzimas que degradam essas duas substâncias [67]. Além disso, ela também atua nas células endoteliais para promover tanto vasodilatação (mediada por NO) quanto vasoconstrição (mediada por MAPK - proteína quinase ativada por mitogênio) [72]. Diversos fatores podem resultar numa perda progressiva de células $\beta$ pancreáticas, como polimorfismos genéticos, sedentarismo, alimentação inadequada e outros fatores ambientais [68].

O diabetes mellitus pode ser classificado em diversos tipos, mas os mais recorrentes são o diabetes tipo 1 e o diabetes tipo 2 [71]. O tipo 1, resumidamente, resulta da destruição das células $\beta$ pancreáticas mediada pelo sistema imunológico, 
enquanto o tipo 2 está relacionado à diminuição da produção de insulina e resistência ao hormônio secretado [68, 71].

A hiperglicemia causada pela diminuição da produção de insulina e a resistência à insulina produzida ocasiona doença microvascular, por meio de diferentes mecanismos, dentre eles, o de glicosilação (isto é, a glicose interage com estruturas / proteínas presentes nesses tecidos e os torna disfuncionais) [67]. Isso ocorre devido ao fato de os tecidos vascular e nervoso serem permeáveis à glicose, sem a necessidade da presença de insulina [73]. Essa via de dano tecidual, especificamente, pode explicar a associação entre DM e doenças cardiovasculares, visto que a disfunção vascular e endotelial está presente em ambos os processos fisiopatológicos [67]. Há diversos mecanismos propostos para explicar a relação entre DM e doenças cardiovasculares, e acredita-se que eles sejam mediados pelo papel do sistema adrenérgico tanto no diabetes mellitus quanto na hipertensão [73]. O controle mediado pela incretina do sistema renina-angiotensina-aldosterona, e alterações na via cálcio-calmodulina são exemplos desses mecanismos [73]. Essas alterações no sistema cálcio-calmodulina, por sua vez, ocasionam um aumento das concentrações intracelulares de cálcio que, por sua vez, culmina na inibição da transcrição do gene da insulina nas células $\beta$ pancreáticas [73].

No diabetes, assim como em outras doenças vasculares, há formação de espécies reativas de oxigênio, que podem reagir com o NO, por exemplo, diminuindo sua biodisponibilidade e impedindo-o de exercer seus efeitos vasodilatadores [23]. Além disso, tanto a hiperglicemia quanto a hiperinsulinemia (resultado da resistência à insulina) geradas pelo diabetes estimulam enzimas envolvidas no estresse oxidativo e desacoplamento da eNOS $[72,74]$. 
O tratamento do diabetes pode ser baseado em mudança de comportamentos (como por exemplo, adoção de hábitos alimentares mais saudáveis e prática de atividades físicas), ou aliar essa abordagem à terapia medicamentosa [68, 71]. De forma geral, a insulina é a substância mais usada no tratamento do DM tipo 1, enquanto os hipoglicemiantes orais representam a primeira escolha na terapia medicamentosa do DM tipo $2[68,71]$. Ainda assim, quando a abordagem não medicamentosa aliada aos hipoglicemiantes orais falha no controle da glicose no tratamento do DM tipo 2, pode ser necessário utilizar a insulina, ou seja, trata-se de uma terapia para formas mais graves de DM [68, 71].

Algumas desvantagens do uso de insulina residem em sua forma de administração (por injeções, o que aumenta o risco de problemas quando comparada à administração por via oral), além do risco de hipoglicemia (que, em menor grau, também pode ser um efeito adverso do uso de hipoglicemiantes orais) $[71,75,76]$

O diabetes mellitus consiste num dos fatores de risco para DE $[18,24,65]$. Além de culminar em lesões microvasculares, um estudo conduzido em tecido de corpos cavernosos humanos também demonstrou que entre pacientes com disfunção erétil, a ocorrência de DM resulta em maiores prejuízos no relaxamento dependente do endotélio tanto no tecido dos corpos cavernosos quanto nas artérias penianas de resistência [65]. O mesmo estudo revelou também que, embora a função endotelial estivesse diminuída em todos os sujeitos, aqueles com diabetes possuíam um nível de disfunção endotelial maior que os outros, maior até mesmo que aqueles com hipercolesterolemia e hipertensão arterial (sabidamente relacionadas à disfunção endotelial e ao desenvolvimento da DE) [65]. Segundo os 
autores, esses dados ajudam a explicar o motivo pelo qual homens diabéticos apresentam respostas piores à terapia convencional (com inibidores de PDE-5) [65].

7. Inibidores da bomba de prótons (omeprazol), XOR e alopurinol

Os inibidores da bomba de prótons formam uma classe de fármacos vastamente utilizada para inibir ou neutralizar a ácido gástrico em situações como ulceração péptica (duodenal e gástrica) e doença do refluxo gastroesofágico [26]. O fármaco mais conhecido dessa classe é o omeprazol, administrado por via oral, que inibe irreversivelmente a $\mathrm{H}^{+}-\mathrm{K}^{+}-$ATPase (a bomba de prótons), reduzindo assim a secreção de ácido basal e a estimulada por alimentos [26].

Estudos recentes demonstraram que o omeprazol possui ações que interferem na via do óxido nítrico, podendo ter impactos tanto na piora da função endotelial [77] quanto na diminuição dos efeitos da terapia anti-hipertensiva com nitrito de sódio [78-80]. Foi proposto que o efeito na função endotelial seria mediado por um aumento das concentrações de ADMA, que por sua vez aumenta a atividade de uma enzima chamada xantina oxidoredutase (XOR) [77], responsável por converter hipoxantina em xantina, e xantina em ácido úrico, e uma grande responsável pelo estresse oxidativo e nitrosativo em diversas doenças cardiovasculares $[77,81]$. Já os efeitos negativos na terapia anti-hipertensiva podem ser resultado do aumento de pH do suco gástrico, uma vez que a reação de redução de nitrito a óxido nítrico no estômago requer um ph baixo (ácido) [78-80].

A XOR pode ter diferentes atividades enzimáticas, a depender da situação, e seus produtos podem apresentar tanto atividade oxidante quanto antioxidante [74, 82]. Essas substâncias estão envolvidas na regulação do tônus vascular e da 
pressão arterial, assim como na indução do processo inflamatório e na resposta reparadora [82]. Essa enzima tem baixa especificidade para substratos, sendo capaz de metabolizar diversos compostos endógenos e exógenos [82].

Em situações de hipóxia, por exemplo, a XOR pode atuar na produção NO a partir de nitrito [37-39]. Contudo, considerando a importância da produção de espécies reativas de oxigênio e de nitrogênio por essa enzima e a capacidade dessas substâncias em lesionar tecidos, fica claro que a atividade aumentada da XOR tem mais efeitos negativos do que positivos [74, 83]. Assim, pode-se esperar um efeito benéfico do uso de fármacos que inibam a atividade da XOR, tendo em vista a diminuição da produção de espécies reativas tanto de oxigênio quanto de nitrogênio pela enzima [38].

O alopurinol é um análogo de hipoxantina, utilizado no tratamento da gota, que reduz a síntese de ácido úrico por inibir competitivamente a XOR [26, 81]. Por diminuir urato, medicamentos como o alopurinol podem ter um papel relevante na prevenção e no tratamento de doenças cardiovasculares [84-86]. Além da ação na XOR, há evidências de que tanto o alopurinol quanto seu metabólito ativo, o oxipurinol, podem atuar eliminando diretamente os radicais livres [87-89], o que contribui para possíveis ações benéficas de seu uso no tratamento de doenças cardiovasculares (que, de forma geral, estão associadas a disfunção endotelial) [84, 85]. 


\section{HIPÓTESE}

A hipótese do presente trabalho é de que fatores como a ocorrência de diabetes mellitus e tratamentos farmacológicos como o uso de insulina, omeprazol e alopurinol podem influenciar positiva ou negativamente a terapia da disfunção erétil. 


\section{OBJETIVOS}

Objetivo geral

Investigar fatores que influenciam o risco para disfunção erétil e o sucesso da terapia da disfunção erétil.

Objetivos específicos

- Verificar o efeito do diabetes mellitus sobre o risco para disfunção erétil e sua influência sobre marcadores da via do óxido nítrico.

- Verificar, nos diabéticos, o efeito da terapia com insulina sobre o risco para disfunção erétil e sua influência sobre marcadores da via do óxido nítrico.

- Verificar o efeito do diabetes mellitus sobre a resposta ao tratamento da disfunção erétil com sildenafil.

- Verificar, nos diabéticos, o efeito do tratamento com insulina sobre a resposta ao tratamento da disfunção erétil com sildenafil.

- Verificar o efeito do tratamento com omeprazol sobre a resposta ao tratamento da disfunção erétil com sildenafil.

- Verificar o efeito do tratamento com alopurinol sobre a resposta ao tratamento da disfunção erétil com sildenafil. 


\section{MATERIAIS E MÉTODOS}

1. Abordagem experimental

Os dados e amostras dos participantes deste estudo são oriundos do biorrepositório de um estudo maior: "Bases genéticas da disfunção erétil: da resposta ao stress à produção de óxido nítrico", sob coordenação do Prof. Dr. Riccardo Lacchini, aprovado pelo CEP sob o número CAAE 51408515.9.0000.5393. As amostras de pacientes foram coletadas entre 2009 e 2019, no Ambulatório de Urologia do Hospital das Clínicas da Faculdade de Medicina de Ribeirão Preto (HCFMRP), sob coordenação do Prof. Dr. Sílvio Tucci Junior da FMRP-USP, e as amostras de controles, da população em geral de Ribeirão Preto. Para o grupo controle, foram selecionados homens saudáveis da população de Ribeirão Preto, pareados por idade, etnia, e índice de massa corporal com os pacientes de DE. Todos os participantes assinaram o termo de consentimento livre e esclarecido (TCLE) referente ao projeto anteriormente descrito. O presente estudo foi submetido para análise pelo CEP da EERP/USP e aprovado sob o número CAAE 30472620.8.0000.5393. A proposta inclui 278 participantes, entre 18 e 80 anos, sendo 177 com diagnóstico médico de disfunção erétil e 101 controles pareados por idade, etnia e índice de massa corporal com os pacientes.

Os critérios de inclusão dos pacientes foram: idade entre 18 e 80 anos; queixas envolvendo a atividade sexual; e diagnóstico médico de disfunção erétil. Os critérios de exclusão comuns para os dois grupos foram: presença de hipogonadismo, bexiga neurogênica; ejaculação precoce; implantes penianos; acidentes cerebrovasculares; traumas no sistema nervoso central; e anormalidades 
anatômicas, como a doença de Peyronie. Para o grupo controle, ainda foram excluídos os participantes com IIEF igual ou menor a 25, e para o grupo de pacientes, foram excluídos os participantes com IIEF maior que 25 quando não tratados. Nenhuma prescrição médica ou qualquer outro procedimento foram alterados por causa do estudo, que é estritamente observacional.

Os sujeitos do estudo foram submetidos a punção intravenosa para coleta de sangue em tubos a vácuo de heparina de sódio, utilizando procedimentos adequados. O sangue foi processado para obtenção de plasma. As amostras de plasma foram aliquotadas em tubos de $2,0 \mathrm{~mL}$ previamente identificados, e congeladas imediatamente em gelo seco no local de coleta, sendo posteriormente armazenadas em biorrepositório em freezer $-80^{\circ} \mathrm{C}$.

2. Avaliação da função erétil e da resposta ao tratamento com sildenafil

A função erétil dos pacientes foi avaliada pelo score do domínio função erétil (FE) do questionário IIEF, antes e após o tratamento com sildenafil. Para avaliação da reposta ao fármaco, sendo o valor máximo de pontuação no domínio FE do IIEF (score IIEF) igual a 30, foram feitos os seguintes cálculos para cada paciente:

a) score IIEF pós-tratamento - score IIEF pré-tratamento = $\triangle \mathrm{IIEF}$;

b) 30 - score IIEF pré-tratamento = MRP; e

c) $(\triangle \mathrm{IIEF} / \mathrm{MRP}) \times 100=\Delta \mathrm{IIEF} \%$.

Onde MRP = máxima resposta possível e $\triangle \mathrm{IIEF} \%$ = porcentagem da MRP atingida pelo paciente.

Os valores de $\triangle \mathrm{IIEF}, \triangle \mathrm{IIEF} \%$ e score IIEF pós-tratamento foram utilizados para medir as respostas dos pacientes ao sildenafil. 


\section{Determinação de nitrito}

As alíquotas de plasma e de sangue total foram analisadas em duplicata pelo método de quimiluminescência através de ozônio. Resumidamente, $300 \mu \mathrm{l}$ de amostra de plasma foram injetados no aparelho contendo solução de iodo acidificada. O óxido nítrico formado, então, é carreado pelo gás nitrogênio até o analisador de NO. (Sievers Modelo 280 NO analyzer, Boulder, CO). Aproximadamente $8 \mathrm{ml}$ de solução ácida de iodo foram colocadas no purge vessel, onde as amostras foram injetadas. Os dados obtidos foram analisados pelo programa Origin 6.1 (OriginLab, Northampton, MA, EUA).

\section{Determinação de ADMA por ELISA}

Os níveis de ADMA foram quantificados por ELISA, usando kit comercialmente disponível (Elabscience, cat\# E-EL-0042, Wuhan, China). A absorbância a $450 \mathrm{~nm}$ foi medida usando o espectrofotômetro $\mu$ Quant microplate (BioTek, Winooski,USA), e o ajuste de 4 parâmetros foi realizado usando uma ferramenta gratuita disponível online (www.elisaanalysis.com).

5. Determinação da atividade das arginases, arginase 1 e arginase 2

Para avaliar a atividade das arginases, amostras de plasma foram depletadas de ureia usando colunas com filtro de membrana $10 \mathrm{KDa}$ (Vivaspin 500 model VS0102, Sartorius, Goettingen, Germany), que foram centrifugadas a $14.000 \mathrm{~g}$ por 30 minutos a $4^{\circ} \mathrm{C}$. As amostras foram então reconstituídas em água Mili-Q e 
analisadas pelo kit QuantiChrom Arginase Assay (BioAssay Systems, Hayward, CA, USA), de acordo com instruções do fabricante. As concentrações de arginase 1 e arginase 2 foram medidas em amostras de plasma, usando kits de ELISA disponíveis comercialmente (MBS912500 e MBS2021960 respectivamente, adquiridos da empresa MyBioSource; San Diago, CA, USA), de acordo com instruções do fabricante.

6. Determinação de ADMA, SDMA, L-NMMA, L-arginina, L-citrulina e Lornitina por LC-MS/MS

L-arginina, L-citrulina, L-ornitina, ADMA, SDMA e L-NMMA seriam analisados em plasma, empregando cromatografia líquida acoplada a espectrometria de massas em tandem (LC-MS/MS), em colaboração com a professora doutora Vera Lúcia Lanchote, docente da Faculdade de Ciências Farmacêuticas de Ribeirão Preto da USP (FCFRP). Os padrões analíticos (L-arginina; L-citrulina; cloridrato de Lornitina; dicloridrato de $N^{G}, N^{G}$-dimetilarginina; sal de di(p-hidroxi-azobenzeno-p'sulfonato) de $\mathrm{N}^{\mathrm{G}}, \mathrm{N}^{\mathrm{G}}$-dimetilarginina; acetato de $\mathrm{N}^{\mathrm{G}}$-monometil-L-arginina; cloridrato de L-arginina- ${ }^{13}-\mathrm{C}_{6}$; L-citrulina-d 7 ; L-ornitina- $\mathrm{d}_{6} ;$ ADMA- $\mathrm{d}_{6}$; SDMA-d $\mathrm{d}_{6}$ ) foram obtidos de Sigma-Aldrich (EUA) ou Toronto Research Chemicals (Canadá). Os sais formiato de amônio e acetato de amônio foram obtidos de Sigma-Aldrich (EUA) ou J.T. Baker, e os solventes metanol e acetonitrila, de J.T. Baker ou Honeywell (EUA).

Foi possível realizar a separação cromatográfica das seis substâncias de interesse por HPLC-MS/MS no equipamento Micromass Quattro Micro API equipado com MassLynx (Waters, EUA), empregando-se a coluna Luna Silica (100 x 4,6 mm, $3 \mu \mathrm{m})$, pré-coluna Luna Silica $(4 \times 3,0 \mathrm{~mm})$ (Phenomenex, EUA), e fase móvel (FM) 
composta por acetato de amônio $05 \mathrm{mM}, 95 \%$, e acetonitrila $(\mathrm{ACN}), 05 \%$. As amostras foram preparadas por precipitação proteica. Alíquotas de $100 \mu \mathrm{L}$ de plasma ou solução de padrões foram adicionadas de $25 \mu \mathrm{L}$ de solução de padrões internos (cloridrato de L-arginina- ${ }^{13}-\mathrm{C}_{6}, 40,55 \mu \mathrm{M}$; L-citrulina-d7, $11 \mu \mathrm{M}$; L-ornitina-d6, 286,27 $\mu \mathrm{M}$; ADMA-d6, 17,73 $\mu \mathrm{M}$; SDMA- $\left.\mathrm{d}_{6}, 9,62 \mu \mathrm{M}\right), 100 \mu \mathrm{L}$ de água ultrapura e $200 \mu \mathrm{L}$ de metanol. Após agitação vigorosa e 30 minutos de descanso, as amostras foram submetidas a centrifugação, e $20 \mu \mathrm{L}$ do sobrenadante foram submetidos à análise cromatográfica, num fluxo de $1 \mathrm{~mL} / \mathrm{min}$ (sendo $0,3 \mathrm{~mL} / \mathrm{min}$ direcionados ao espectrômetro de massas e $0,7 \mathrm{~mL} / \mathrm{min}$ ao lixo). As análises no espectrômetro de massas foram conduzidas no modo de ionização positivo, com temperatura da fonte de $130^{\circ} \mathrm{C}$, e dessolvatação de $350^{\circ} \mathrm{C}$ [90]. Foi possível avaliar de forma preliminar a estabilidade de ciclos de congelamento e descongelamento, bancada (4h) e auto injetor (48 horas) das seis substâncias analisadas. Todas mostraram-se estáveis nas condições analisadas.

Devido a problemas com a coluna cromatográfica em agosto de 2019, foi necessário padronizar outro método de quantificação para as substâncias de interesse, que será descrito a seguir.

Outro método de quantificação para quatro dessas substâncias (L-arginina, Lcitrulina, ADMA e SDMA) foi desenvolvido. As amostras foram preparadas por precipitação proteica, seguida de derivatização. $25 \mu \mathrm{L}$ de amostras de plasma, controles de qualidade ou padrões (reconstituídos e diluídos em água ultrapura) foram adicionados de $10 \mu \mathrm{L}$ de solução de padrões internos (cloridrato de L-arginina${ }^{13}-\mathrm{C}_{6}, 40,55 \mu \mathrm{M}$; L-citrulina-d7, $11 \mu \mathrm{M} ;$ ADMA-d6, 17,73 $\mu \mathrm{M}$; SDMA-d6, 9,62 $\mu \mathrm{M}$; diluídos em água ultrapura), $25 \mu \mathrm{L}$ de água ultrapura e $400 \mu \mathrm{L}$ de $\mathrm{ACN}$, submetidos a intensa agitação e centrifugados. $400 \mu \mathrm{L}$ do sobrenadante foram coletados e 
adicionados de $50 \mu \mathrm{L}$ de tampão borato $\left(\mathrm{Na}_{2} \mathrm{~B}_{4} \mathrm{O}_{7} .10 \mathrm{H}_{2} \mathrm{O} \quad 0,025 \mathrm{M}\right.$; $\mathrm{NaOH} 1,77 \mathrm{M}$, pH9.2) e $10 \mu \mathrm{L}$ de $\mathrm{BCl} 10 \%$ em $\mathrm{ACN}$, agitados, incubados por cinco minutos a temperatura ambiente, diluídos $20 x$ e submetidos a análise cromatográfica, com volume de injeção de $2 \mu \mathrm{L}$ e taxa de infusão de $0,25 \mathrm{~mL} / \mathrm{min}$. A separação cromatográfica foi conduzida na coluna de UPLC (cromatografia líquida de ultra eficiência) Acquity HSS T3 (2,1 x 100 mm, 1,8 $\mu \mathrm{m})$ (Waters, EUA), a $30^{\circ} \mathrm{C}$, enquanto a análise por espectrometria de massas em tandem ocorreu no aparelho Xevo TQ-S (Waters, EUA) operando em modo de ionização positivo, com temperatura de fonte de $130^{\circ} \mathrm{C}$ e de dessolvatação de $350^{\circ} \mathrm{C}$. A temperatura do injetor e do organizador de amostras foi mantida em $15^{\circ} \mathrm{C}$ [91]. A curva analítica possui oito pontos (concentrações) diferentes para cada substância analisada, sendo os limites inferior (LIQ) e superior (LSQ) de quantificação os seguintes: 3,90 a $250 \mu \mathrm{M}$ para L-arginina; 5,65 a 361,93 $\mu \mathrm{M}$ para L-citrulina; 0,08 a 5,33 $\mu \mathrm{M}$ para ADMA, e 0,10 a 6,84 $\mu \mathrm{M}$ para SDMA. O tempo de retenção para cada uma dessas substâncias, em minutos, foi de 3,66 para ARG; 6,69 para CIT; 5,19 para ADMA, e 5,97 para SDMA. A validação do método segue as diretrizes do FDA (Food and Drug Administration, EUA). Foram realizados os testes de linearidade (a curva analítica proposta é linear nas concentrações testadas), precisão e exatidão (o método é reprodutível de maneira precisa e exata) e paralelismo (avaliamos se a faixa de ângulos das curvas em plasma é semelhante à das curvas em água; as faixas foram similares, com desvios menores que $15 \%$, para as quatro substâncias analisadas, o que permite que as curvas de calibração de todo o estudo sejam feitas em água). Todos os testes realizados atenderam aos parâmetros estabelecidos. 
Houve um problema no aparelho no fim de 2019 , solucionado na semana do dia 16 de março de 2020, quando o laboratório foi fechado em decorrência da pandemia da COVID-19. Assim, não foi possível concluir as análises pelo método de LC-MS/MS para incluí-las neste trabalho. Essas quantificações serão finalizadas assim que possível.

\section{Análise estatística}

Dados quantitativos com distribuição paramétrica foram comparados com teste $\mathrm{T}$ pareado. Dados quantitativos com distribuição não paramétrica foram comparados com teste Mann-Whitney. Anova de uma via e regressão linear multivariada também foram utilizadas. Todos os testes foram bicaudais e assumiram um valor de alfa de 5\% para determinação da significância estatística. 


\section{RESULTADOS}

Capítulo 1

Nesta primeira seção, os dados apresentados avaliam fatores que possam interferir no risco para o desenvolvimento da disfunção erétil. Na primeira parte do capítulo (1.1), investigamos a influência do diabetes mellitus sobre o risco para DE, e na segunda (capítulo 1.2), o efeito da terapia do diabetes com insulina sobre o risco para disfunção erétil.

A tabela I sumariza as características clínicas e laboratoriais dos 204 indivíduos envolvidos no estudo, divididos entre controles e portadores de disfunção erétil clínica (DEC). Houve diferença significativa nos parâmetros idade, tabagismo, pressão arterial sistólica, glicemia, percentual de hipertensos e diabéticos, e score função erétil do IIEF. A diferença neste último (IIEF) já era esperada, tendo em vista que comparamos um grupo de homens saudáveis a um grupo com disfunção erétil, e mostra o quanto a função erétil é prejudicada nos pacientes em relação aos controles. Como é sabido, a prevalência de DE aumenta com a idade. Sendo assim, a maior média de idade para o grupo DEC já era esperada. Além disso, durante as coletas para o estudo, foi bastante difícil encontrar indivíduos idosos saudáveis ou jovens com DE, dificultando o pareamento entre os grupos para esta variável. $\mathrm{O}$ responsável pela diferença observada no tabagismo é o maior percentual de exfumantes em relação ao de não fumantes no grupo DEC quando comparado aos percentuais do grupo Controle. Entretanto, grande parte dos ex-fumantes incluídos no estudo deixaram de fumar há mais de 10 anos, fato que pode minimizar os efeitos maléficos causados pelo tabagismo que podem ter associação com a DE. Quanto à pressão arterial sistólica (PAS) e à dosagem de glicose, como os pacientes 
têm grande percentual de hipertensos e diabéticos, as diferenças nos valores médios desses fatores entre os grupos também já eram esperadas. 
Tabela I: Características clínicas e laboratoriais dos grupos estudados

\begin{tabular}{|c|c|c|c|}
\hline Características & Controle $(n=101)$ & DEC $(n=103)$ & $\mathbf{P}$ \\
\hline Idade (anos) & $47,42 \pm 9,31$ & $55,66 \pm 10,83$ & $<0,0001^{*}$ \\
\hline Etnia (brancos / não brancos) & $63 / 37$ & $56 / 46$ & 0,242 \\
\hline IMC $\left(\mathrm{Kg} / \mathrm{m}^{2}\right)$ & $27,84 \pm 4,39$ & $28,05 \pm 4,79$ & 0,690 \\
\hline Praticam atividade física (\%) & 60 & 53 & 0,318 \\
\hline Tabagismo (\%) & & & $<0,0001^{*}$ \\
\hline Não fumantes & 58 & 31 & - \\
\hline Ex-fumantes & 25 & 55 & $<0,0001^{*}$ \\
\hline Fumantes & 17 & 14 & 0,306 \\
\hline Etilismoa (\%) & 9 & 5 & 0,268 \\
\hline PAS $(\mathrm{mmHg})$ & $130,70 \pm 19,20$ & $139,20 \pm 19,74$ & $0,001^{*}$ \\
\hline PAD $(\mathrm{mmHg})$ & $87,87 \pm 12,75$ & $90,49 \pm 12,25$ & 0,140 \\
\hline Colesterol total (mg/dL) & $203,10 \pm 48,63$ & $181,50 \pm 39,90$ & 0,060 \\
\hline Colesterol HDL (mg/dL) & $36,58 \pm 10,12$ & $41,19 \pm 9,22$ & 0,092 \\
\hline Colesterol LDL (mg/dL) & $125,50 \pm 40,02$ & $112,40 \pm 37,09$ & 0,255 \\
\hline Triglicerídeos (mg/dL) & $162,20 \pm 86,11$ & $155,00 \pm 108,00$ & 0,840 \\
\hline Glicose (mg/dL) & $93,06 \pm 23,81$ & $124,20 \pm 54,51$ & $0,016^{*}$ \\
\hline Ureia (mg/dL) & $35,06 \pm 7,19$ & $32,47 \pm 12,40$ & 0,410 \\
\hline Creatinina (mg/dL) & $1,03 \pm 0,294$ & $1,04 \pm 0,31$ & 0,780 \\
\hline Hipertensos (\%) & 0 & 50 & $<0,0001^{*}$ \\
\hline Diabéticos (\%) & 0 & 40 & $<0,0001^{*}$ \\
\hline Score IIEF domínio FE & \pm & $10,62 \pm 7,92$ & $<0,0001^{*}$ \\
\hline
\end{tabular}

DEC, pacientes com disfunção erétil clínica; IMC, índice de massa corporal; PAS, pressão arterial sistólica; PAD, pressão arterial diastólica; HDL, lipoproteína de alta densidade; LDL, lipoproteína de baixa densidade; IIEF, Índice Internacional de Função Erétil; FE, função erétil. a Consumo de etanol > $30 \mathrm{~g} / \mathrm{dia}$. Dados expressos como média \pm desvio padrão, valores absolutos ou frequências relativas (\%). ${ }^{*} \mathrm{P}<0,05$. 


\section{Capítulo 1.1}

Inicialmente, avaliamos o efeito do diabetes sobre o risco para disfunção erétil. Separamos os indivíduos afetados pelo DM dos não afetados e analisamos a função erétil e os dados bioquímicos de substâncias relacionadas à via do óxido nítrico (nitrito, ADMA, atividade das arginases, arginase 1 e arginase 2).

Analisamos o risco para desenvolvimento da disfunção erétil utilizando o score IIEF do domínio função erétil (figura 1.1.1), que avalia tanto a presença quanto o grau de DE, e marcadores bioquímicos relacionados à via do óxido nítrico (figuras 1.1.2 a 1.1.6). Os parâmetros bioquímicos escolhidos para essa investigação foram as concentrações plasmáticas de nitrito (figura 1.1.2), utilizado como marcador da atividade recente de NO; ADMA (figura 1.1.3), um dos inibidores endógenos da síntese de óxido nítrico; a atividade das arginases (figura 1.1.4), que podem utilizar a L-arginina como substrato na produção de L-ornitina; e as concentrações plasmáticas das isoformas ARG1 (figura 1.1.5) e ARG2 (figura 1.1.6) da enzima. 
Figura 1.1.1: Score IIEF domínio FE nos grupos controle, disfunção erétil clínica e disfunção erétil clínica com diabetes mellitus

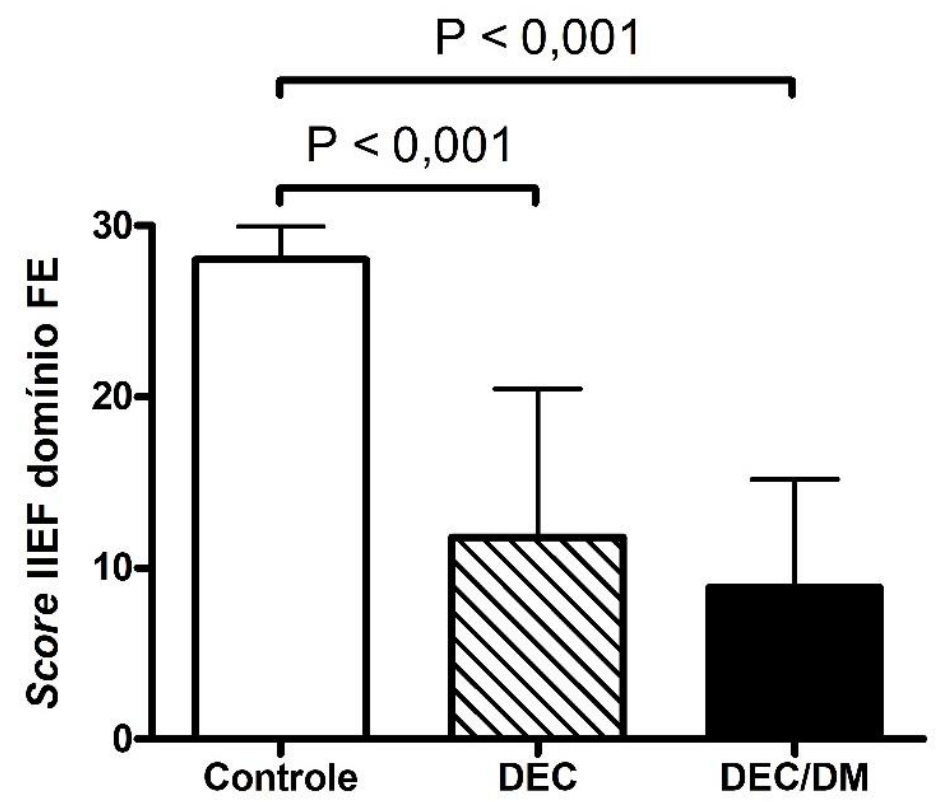

IIEF, Índice Internacional de Função Erétil; FE, função erétil; DEC, disfunção erétil clínica; DEC/DM, disfunção erétil clínica com diabetes mellitus. $n$ por grupo: Controle $=101$, $D E C=62$, $\mathrm{DEC} / \mathrm{DM}=41$. Teste Kruskal-Wallis, com valor de $\mathrm{P}$ global $<0,0001$, e pós teste de Dunn. Para a comparação DEC x DEC/DM, $P>0,05$. Valores expressos como média \pm desvio padrão.

Figura 1.1.2: Nitrito nos grupos controle, DEC e DEC/DM

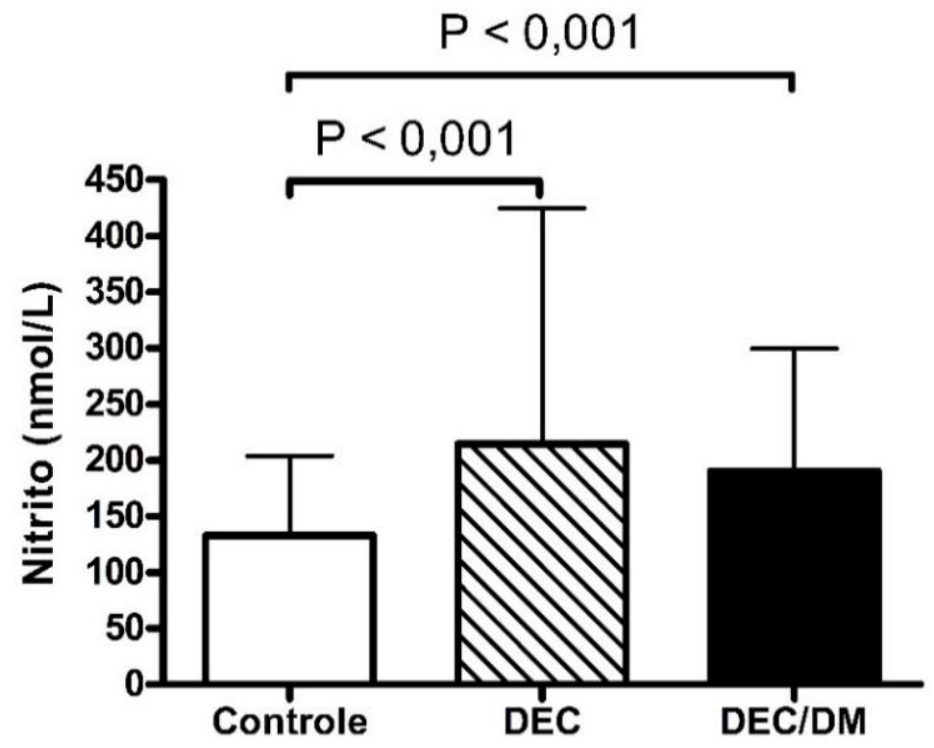

DEC, disfunção erétil clínica; DEC/DM, disfunção erétil clínica com diabetes mellitus. $\mathrm{n}$ por grupo: Controle $=100, \mathrm{DEC}=62, \mathrm{DEC} / \mathrm{DM}=41$. Teste Kruskal-Wallis, com valor de $\mathrm{P}$ global $<0,0001$, e pós teste de Dunn. Para a comparação DEC x DEC/DM, P > 0,05. Valores expressos como média \pm desvio padrão. 
Figura 1.1.3: ADMA nos grupos controle, DEC e DEC/DM

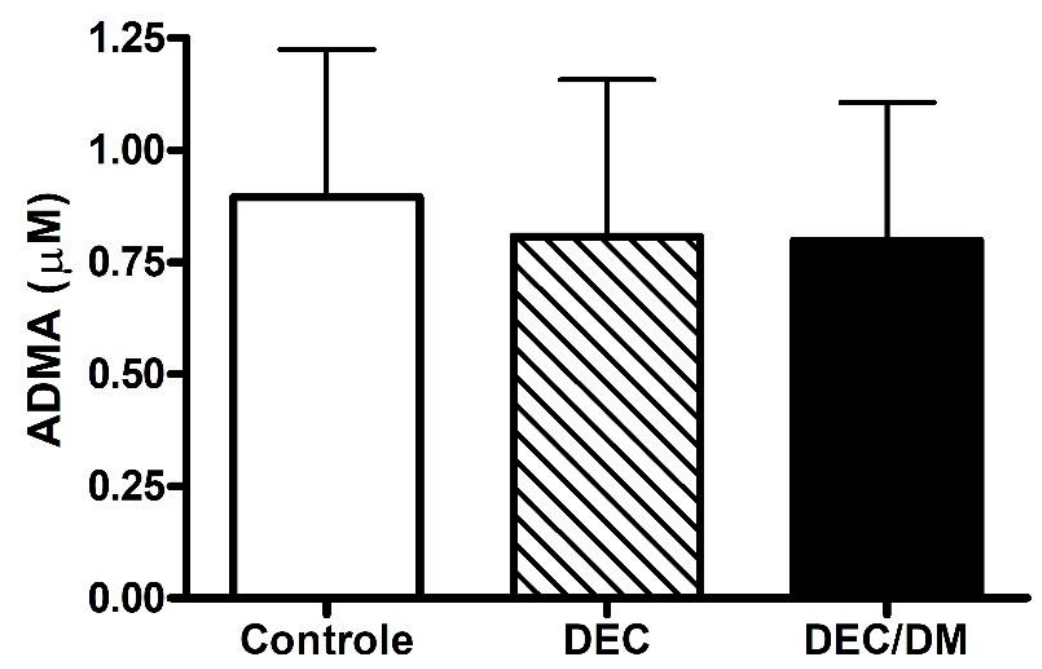

ADMA, dimetilarginina assimétrica; DEC, disfunção erétil clínica; DEC/DM, disfunção erétil clínica com diabetes mellitus. $n$ por grupo: Controle $=88, \mathrm{DEC}=44, \mathrm{DEC} / \mathrm{DM}=36$. ANOVA de uma via, com valor de $\mathrm{P}$ global = 0,204, e pós teste de Tukey. Para as três comparações (Controle $\mathrm{x}$ DEC, Controle x DEC/DM e DEC x DEC/DM), P > 0,05. Valores expressos como média \pm desvio padrão.

Figura 1.1.4: Atividade das arginases nos grupos controle, DEC e DEC/DM

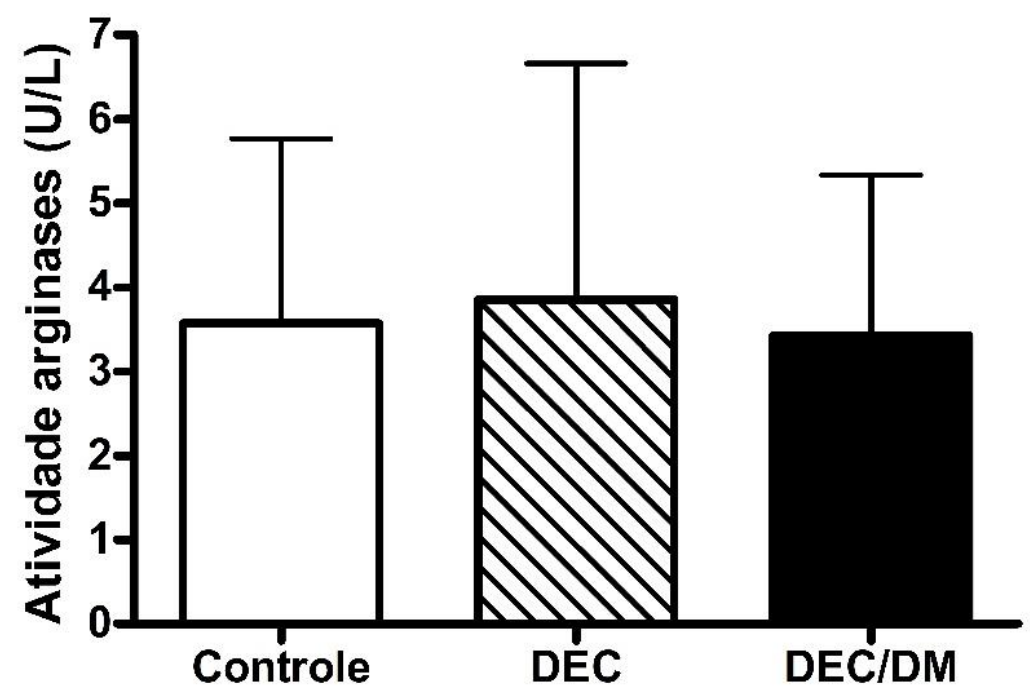

DEC, disfunção erétil clínica; DEC/DM, disfunção erétil clínica com diabetes mellitus. $\mathrm{n}$ por grupo: Controle $=101, \mathrm{DEC}=62, \mathrm{DEC} / \mathrm{DM}=41$. Teste Kruskal-Wallis, com valor de $\mathrm{P}$ global $=0,988$, e pós teste de Dunn. Para as três comparações (Controle x DEC, Controle x DEC/DM e DEC x DEC/DM), $P>0,05$. Valores expressos como média \pm desvio padrão. 
Figura 1.1.5: Arginase 1 nos grupos controle, DEC e DEC/DM

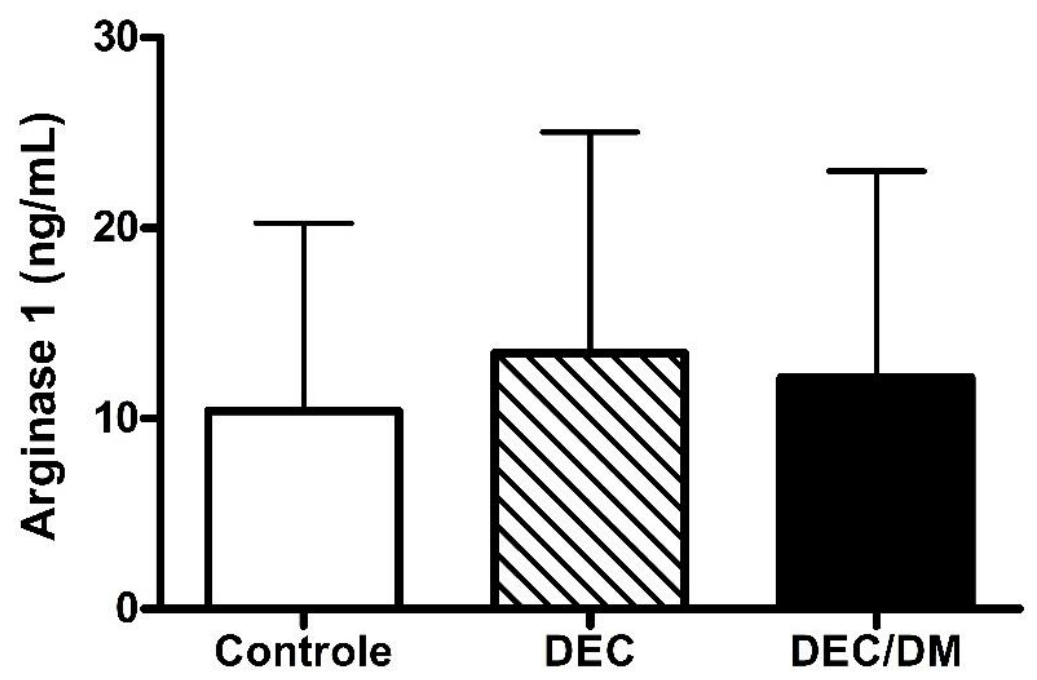

DEC, disfunção erétil clínica; DEC/DM, disfunção erétil clínica com diabetes mellitus. $\mathrm{n}$ por grupo: Controle $=89, \mathrm{DEC}=54, \mathrm{DEC} / \mathrm{DM}=38$. Teste Kruskal-Wallis, com valor de $\mathrm{P}$ global $=0,384$, e pós teste de Dunn. Para as três comparações (Controle $x$ DEC, Controle $x$ DEC/DM e DEC $x$ $\mathrm{DEC} / \mathrm{DM}), \mathrm{P}>0,05$. Valores expressos como média \pm desvio padrão.

Figura 1.1.6: Arginase 2 nos grupos controle, DEC e DEC/DM

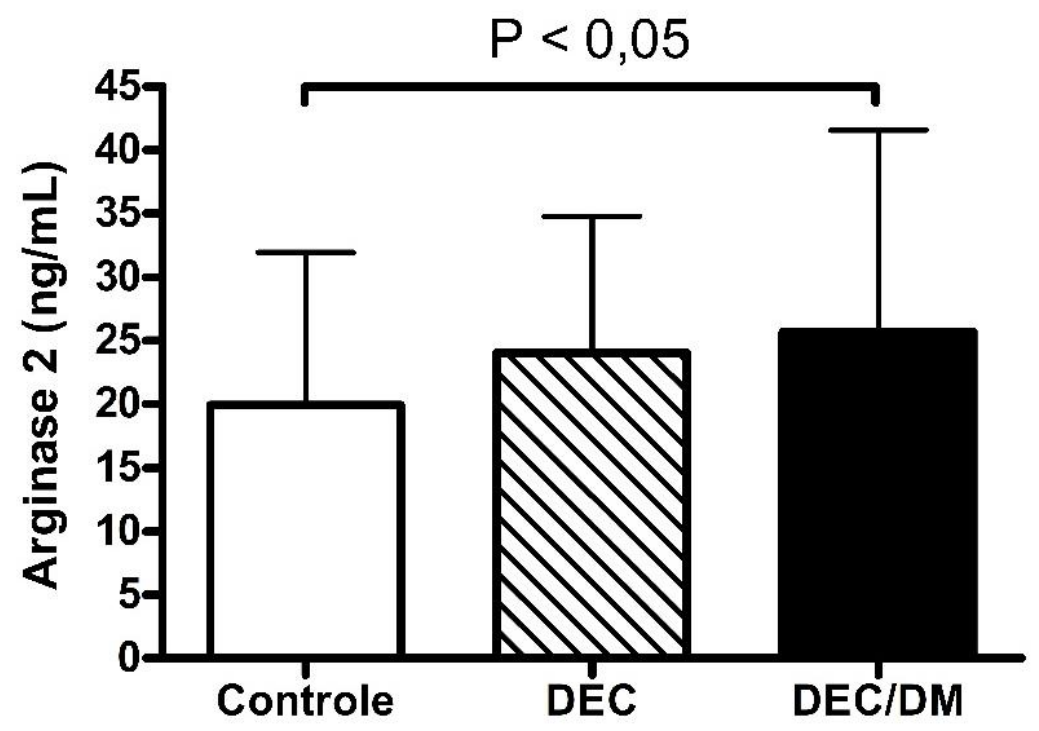

DEC, disfunção erétil clínica; DEC/DM, disfunção erétil clínica com diabetes mellitus. $\mathrm{n}$ por grupo: Controle $=101, \mathrm{DEC}=62, \mathrm{DEC} / \mathrm{DM}=41$. ANOVA de uma via, com valor de $\mathrm{P}$ global $=0,021, \mathrm{e}$ pós teste de Tukey. Para as comparações Controle $\times$ DEC e DEC x DEC/DM, $P>0,05$. Valores expressos como média \pm desvio padrão. 
Conforme esperado, houve diferença significativa entre o score IIEF dos controles tanto em relação ao grupo DE clínica quanto ao grupo DE clínica com diabetes. Apesar de não ser estatisticamente significativa, nota-se que a média desse parâmetro parece menor no grupo DE com diabetes. As concentrações de nitrito também foram significativamente maiores nos grupos DEC e DEC/DM quando comparados aos controles, embora não haja diferença entre eles. Quando comparado aos controles, o grupo DEC/DM apresentou concentrações significativamente maiores de arginase 2. Apesar de não haver diferença entre o grupo DEC e os outros dois grupos estudados (controles e DEC/DM), é possível observar que suas concentrações de arginase 2 são intermediárias àquelas encontradas nos controles (a menor nos grupos estudados) e no grupo DEC/DM (a maior nos três grupos). 


\section{Capítulo 1.2}

Num segundo momento, decidimos avaliar se a terapia com insulina nos diabéticos influencia o risco para disfunção erétil, comparando a função erétil e os dados bioquímicos das mesmas substâncias relacionadas à via do óxido nítrico analisadas anteriormente (nitrito, ADMA, atividade das arginases, arginase $1 \mathrm{e}$ arginase 2). Para tanto, selecionamos os portadores de DE que também possuem diabetes mellitus e os separamos de acordo com o uso ou não de insulina, comparando-os ao grupo controle.

Figura 1.2.1: Score IIEF domínio FE nos grupos controle, DEC com diabetes mellitus e DEC com diabetes mellitus tratado com insulina

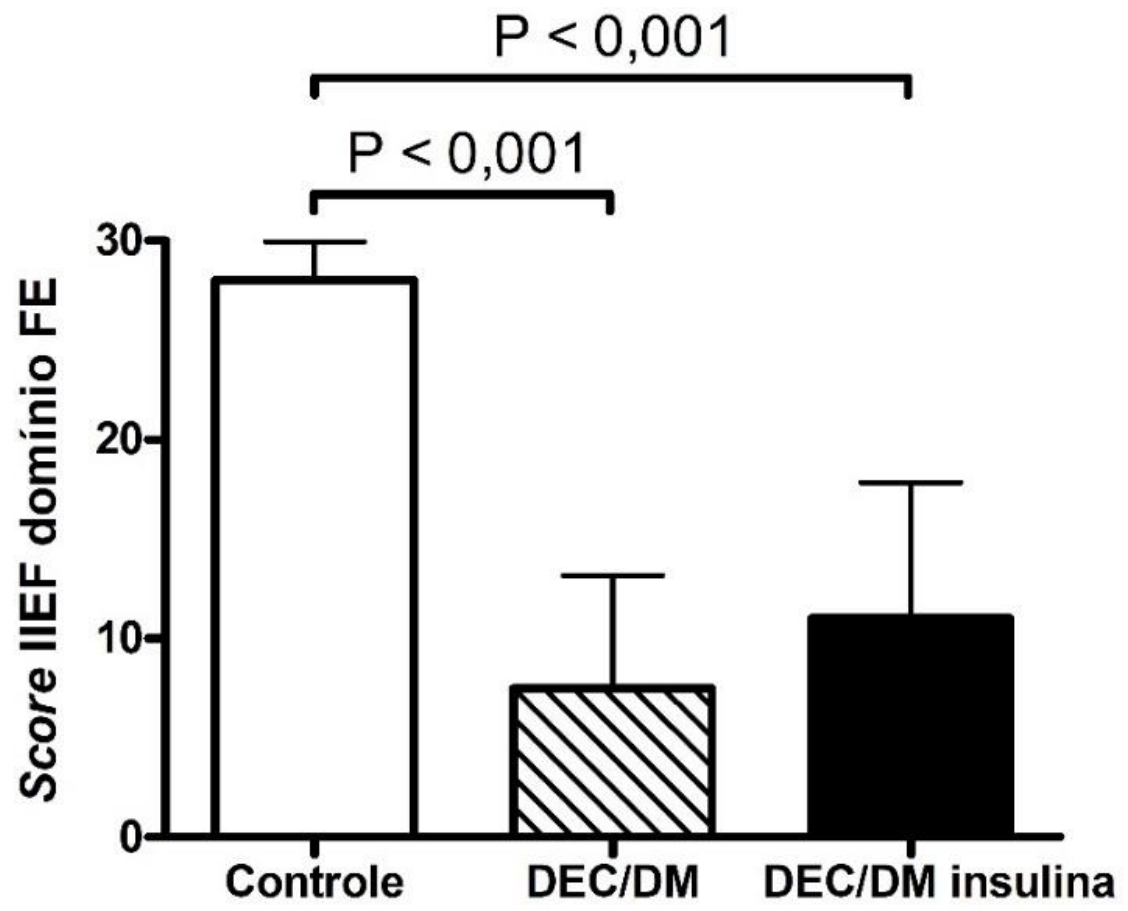

IIEF, Índice Internacional de Função Erétil; FE, função erétil; DEC/DM, disfunção erétil clínica com diabetes mellitus; DEC/DM insulina, disfunção erétil clínica com diabetes mellitus tratado com insulina. $\mathrm{n}$ por grupo: Controle $=101, \mathrm{DEC} / \mathrm{DM}=25, \mathrm{DEC} / \mathrm{DM}$ insulina $=16$. Teste Kruskal-Wallis, com valor de $\mathrm{P}$ global <0,0001, e pós teste de Dunn. Para a comparação DEC/DM x DEC/DM insulina, $\mathrm{P}>$ 0,05 . Valores expressos como média \pm desvio padrão. 
Figura 1.2.2: Nitrito nos grupos controle, DEC com diabetes mellitus e DEC com diabetes mellitus tratado com insulina

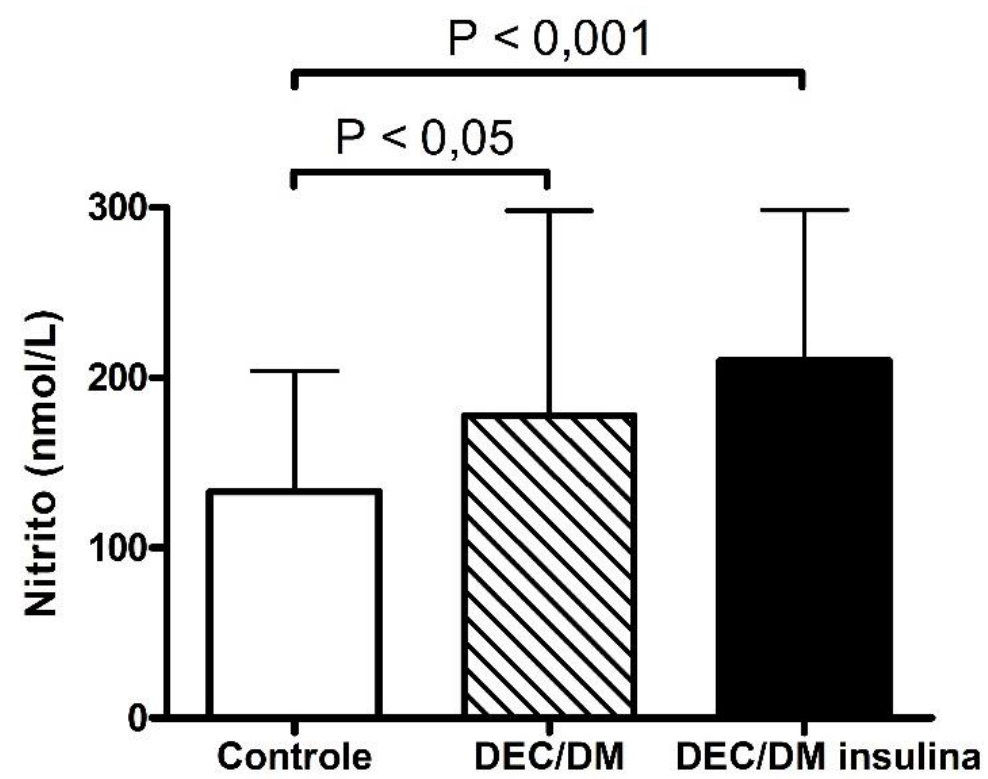

DEC/DM, disfunção erétil clínica com diabetes mellitus; DEC/DM insulina, disfunção erétil clínica com diabetes mellitus tratado com insulina. $n$ por grupo: Controle $=100, D E C / D M=25$, $\mathrm{DEC} / \mathrm{DM}$ insulina $=16$. Teste Kruskal-Wallis, com valor de $\mathrm{P}$ global = 0,0001, e pós teste de Dunn. Para a comparação DEC/DM x DEC/DM insulina, $P>0,05$. Valores expressos como média \pm desvio padrão.

Figura 1.2.3: ADMA nos grupos controle, DEC com diabetes mellitus e DEC com diabetes mellitus tratado com insulina

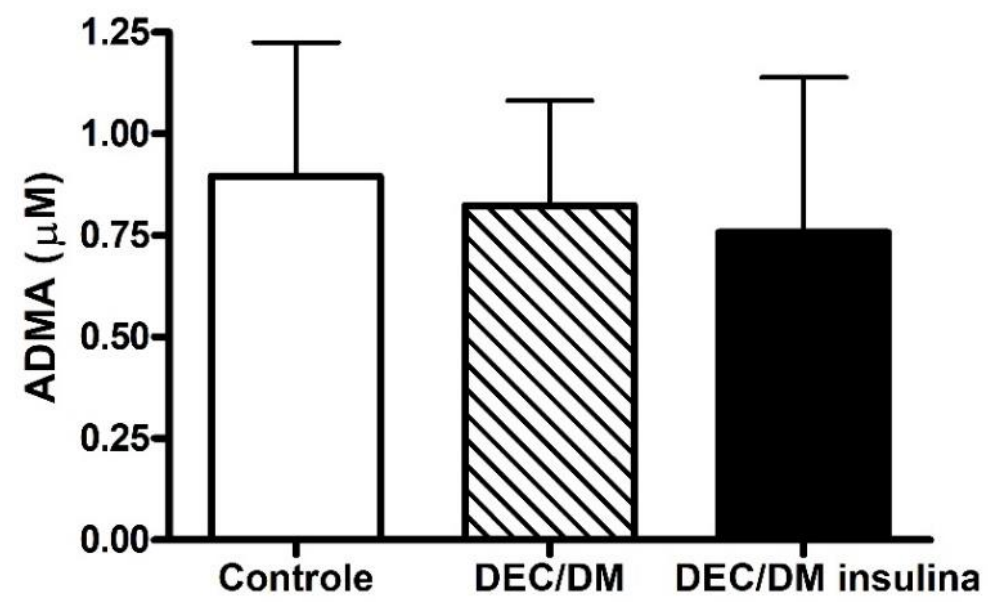

ADMA, dimetilarginina assimétrica; DEC/DM, disfunção erétil clínica com diabetes mellitus; DEC/DM insulina, disfunção erétil clínica com diabetes mellitus tratado com insulina. $\mathrm{n}$ por grupo: Controle $=88, \mathrm{DEC} / \mathrm{DM}=22$, DEC/DM insulina $=14$. ANOVA de uma via, com valor de $\mathrm{P}$ global = 0,276, e pós teste de Tukey. Para as três comparações (Controle x DEC/DM, Controle x DEC/DM insulina e DEC/DM x DEC/DM insulina), $\mathrm{P}>0,05$. Valores expressos como média \pm desvio padrão. 
Figura 1.2.4: Atividade das arginases nos grupos controle, DEC com diabetes mellitus e DEC com diabetes mellitus tratado com insulina

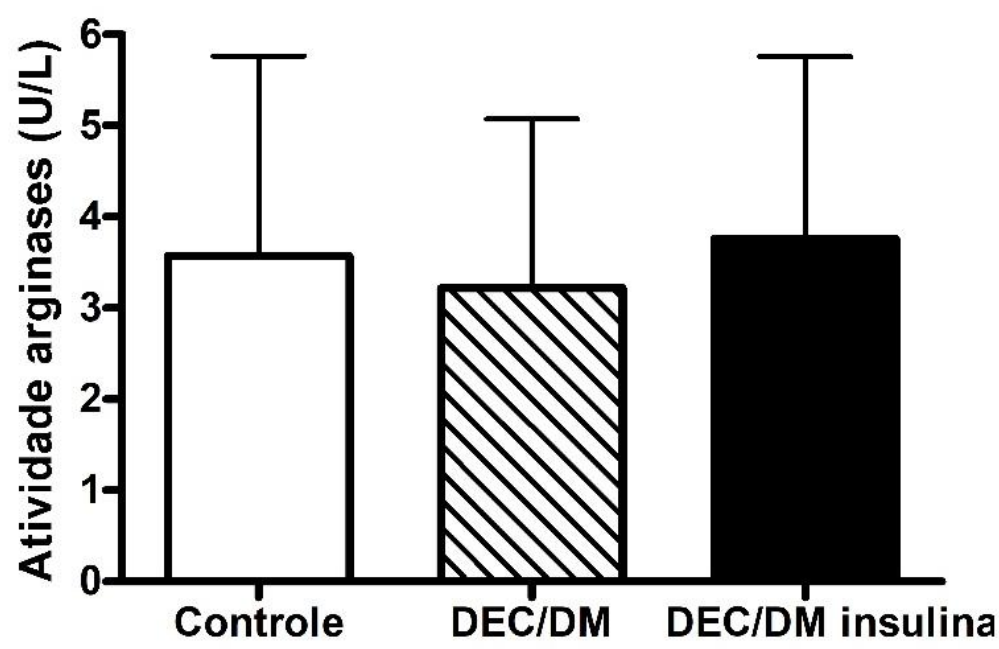

DEC/DM, disfunção erétil clínica com diabetes mellitus; DEC/DM insulina, disfunção erétil clínica com diabetes mellitus tratado com insulina. $n$ por grupo: Controle $=101, D E C / D M=25$, $D E C / D M$ insulina $=16$. ANOVA de uma via, com valor de $P$ global $=0,686$, e pós teste de Tukey. Para as três comparações (Controle $\times$ DEC/DM, Controle $\times$ DEC/DM insulina e DEC/DM $\times$ DEC/DM insulina), $\mathrm{P}>0,05$. Valores expressos como média \pm desvio padrão.

Figura 1.2.5: Arginase 1 nos grupos controle, DEC com diabetes mellitus e DEC com diabetes mellitus tratado com insulina

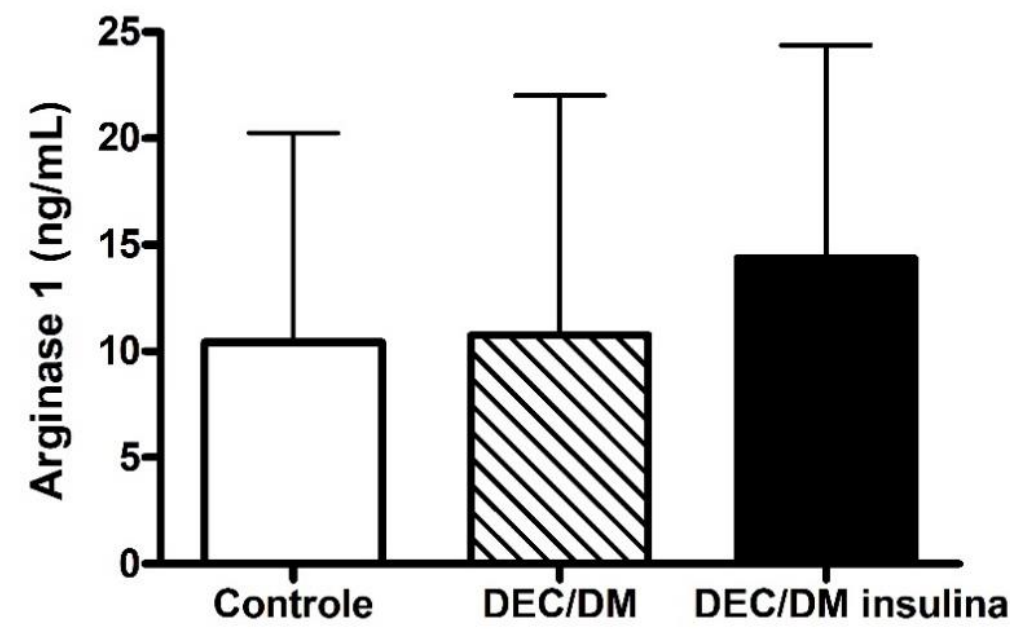

DEC/DM, disfunção erétil clínica com diabetes mellitus; DEC/DM insulina, disfunção erétil clínica com diabetes mellitus tratado com insulina. $n$ por grupo: Controle $=89, D E C / D M=23$, $D E C / D M$ insulina $=15$. Teste Kruskal-Wallis, com valor de $P$ global $=0,174$, e pós teste de Dunn. Para as três comparações (Controle $\times$ DEC/DM, Controle $\times$ DEC/DM insulina e DEC/DM $x$ DEC/DM insulina), $\mathrm{P}>0,05$. Valores expressos como média \pm desvio padrão. 
Figura 1.2.6: Arginase 2 nos grupos controle, DEC com diabetes mellitus e DEC com diabetes mellitus tratado com insulina



DEC/DM, disfunção erétil clínica com diabetes mellitus; DEC/DM insulina, disfunção erétil clínica com diabetes mellitus tratado com insulina. $n$ por grupo: Controle $=101, D E C / D M=25$, $\mathrm{DEC} / \mathrm{DM}$ insulina $=16$. Teste Kruskal-Wallis, com valor de $\mathrm{P}$ global $=0,133$, e pós teste de Dunn. Para as três comparações (Controle $\times$ DEC/DM, Controle $\times$ DEC/DM insulina e DEC/DM $\times$ DEC/DM insulina), $\mathrm{P}>0,05$. Valores expressos como média \pm desvio padrão.

Assim como na seção anterior, os valores do score IIEF são significativamente maiores nos controles do que nos grupos DEC/DM e DEC/DM insulina. As concentrações de nitrito também foram significativamente maiores nos grupos DEC/DM e DEC/DM insulina quando comparados aos controles, e embora não haja diferença entre eles, é possível observar que as concentrações de nitrito aumentam gradualmente nos grupos três grupos, tendo os controles os menores valores, e o grupo DEC/DM insulina os maiores valores. Outro ponto importante a ser destacado, apesar de não haver diferença estatística, é que as concentrações de ADMA parecem diminuir gradualmente nos grupos (inversamente ao que ocorre com o nitrito), tendo os controles os maiores valores, enquanto o grupo DEC/DM apresenta os menores valores dos três grupos estudados. 


\section{Capítulo 2}

Nesta segunda seção, os dados apresentados avaliam os efeitos do diabetes mellitus e de seu tratamento sobre a terapia da disfunção erétil com sildenafil. $\mathrm{Na}$ primeira parte do capítulo (2.1), investigamos a influência do diabetes mellitus no desfecho da terapia com sildenafil, e na segunda (capítulo 2.2), o efeito do uso de insulina sobre o tratamento da disfunção erétil.

$\mathrm{Na}$ tabela II, temos as características clínicas e laboratoriais dos 148 indivíduos tratados com sildenafil divididos nos grupos disfunção erétil clínica (DEC) e disfunção erétil pós-prostatectomia (DEPP). Houve diferença entre os grupos em: idade, creatinina, percentual de diabéticos, score IIEF pós-tratamento com sildenafil e $\triangle I I E F \%$. Esses últimos dados (IIEF) são coerentes com o fato de pacientes submetidos à cirurgia de prostatectomia radical terem menor sucesso na terapia para DE. As outras diferenças encontradas não são relevantes, visto que os grupos não são comparados entre si neste estudo. 
Tabela II: Características clínicas e laboratoriais dos grupos estudados

\begin{tabular}{|c|c|c|c|}
\hline Características & DEC $(n=74)$ & DEPP $(n=74)$ & $\mathbf{P}$ \\
\hline Idade (anos) & $54,65 \pm 10,77$ & $64,78 \pm 6,65$ & $<0,0001^{*}$ \\
\hline Etnia (brancos / não brancos) & $42 / 31$ & $38 / 36$ & 0,452 \\
\hline $\mathrm{IMC}\left(\mathrm{Kg} / \mathrm{m}^{2}\right)$ & $28,35 \pm 4,60$ & $28,03 \pm 4,34$ & 0,663 \\
\hline Praticam atividade física (\%) & 53 & 55 & 0,777 \\
\hline Tabagismo (\%) & & & 0,148 \\
\hline Não fumantes & 30 & 41 & - \\
\hline Ex-fumantes & 54 & 50 & 0,209 \\
\hline Fumantes & 16 & 9 & 0,061 \\
\hline Etilismoa (\%) & 7 & 9 & 0,602 \\
\hline PAS (mmHg) & $138,50 \pm 17,91$ & $144,70 \pm 21,84$ & 0,079 \\
\hline PAD (mmHg) & $90,82 \pm 10,96$ & $93,11 \pm 12,29$ & 0,361 \\
\hline Colesterol total (mg/dL) & $181,00 \pm 37,96$ & $174,00 \pm 44,26$ & 0,574 \\
\hline Colesterol HDL (mg/dL) & $40,96 \pm 8,26$ & $39,00 \pm 5,58$ & 0,432 \\
\hline Colesterol LDL (mg/dL) & $111,00 \pm 34,96$ & $100,10 \pm 38,23$ & 0,388 \\
\hline Triglicerídeos (mg/dL) & $139,90 \pm 79,93$ & $155,70 \pm 81,29$ & 0,569 \\
\hline Glicose (mg/dL) & $116,00 \pm 40,06$ & $119,00 \pm 39,01$ & 0,229 \\
\hline Ureia (mg/dL) & $32,55 \pm 12,33$ & $31,90 \pm 13,17$ & 0,831 \\
\hline Creatinina (mg/dL) & $1,04 \pm 0,35$ & $1,15 \pm 0,44$ & $0,029^{*}$ \\
\hline Hipertensos (\%) & 46 & 57 & 0,120 \\
\hline Diabéticos (\%) & 41 & 20 & $0,001^{*}$ \\
\hline \multicolumn{4}{|l|}{ Score IIEF domínio FE } \\
\hline Pré-tratamento & $10,59 \pm 7,62$ & $8,51 \pm 5,47$ & 0,181 \\
\hline Pós-tratamento & $17,28 \pm 9,22$ & $13,31 \pm 7,84$ & $0,009^{*}$ \\
\hline$\Delta \mathrm{IIEF} \%$ & $39,62 \pm 37,05$ & $23,34 \pm 29,72$ & $0,012^{*}$ \\
\hline
\end{tabular}

DEC, pacientes com disfunção erétil clínica; DEPP, pacientes com disfunção erétil pósprostatectomia; IMC, índice de massa corporal; PAS, pressão arterial sistólica; PAD, pressão arterial diastólica; HDL, lipoproteína de alta densidade; LDL, lipoproteína de baixa densidade; IIEF, Índice Internacional de Função Erétil; FE, função erétil. a Consumo de etanol $>30 \mathrm{~g} /$ dia. Dados expressos como média \pm desvio padrão, valores absolutos ou frequências relativas (\%). ${ }^{*} P<0,05$. 


\section{Capítulo 2.1}

Inicialmente, avaliamos o efeito do diabetes sobre a resposta ao sildenafil. Separamos os indivíduos afetados pelo DM dos não afetados e analisamos a função erétil, por meio do score IIEF pós tratamento (figura 2.1.1), delta IIEF (figura 2.1.2) e delta IIEF percentual (figura 2.1.3), e os dados bioquímicos de substâncias relacionadas à via do óxido nítrico (nitrito, figura 2.1.4; ADMA, figura 2.1.5; atividade das arginases, figura 2.1.6; arginase 1, figura 2.1.7, e arginase 2, figura 2.1.8).

Figura 2.1.1: Score IIEF domínio FE pós tratamento com sildenafil nos grupos DEC e DEC com diabetes mellitus

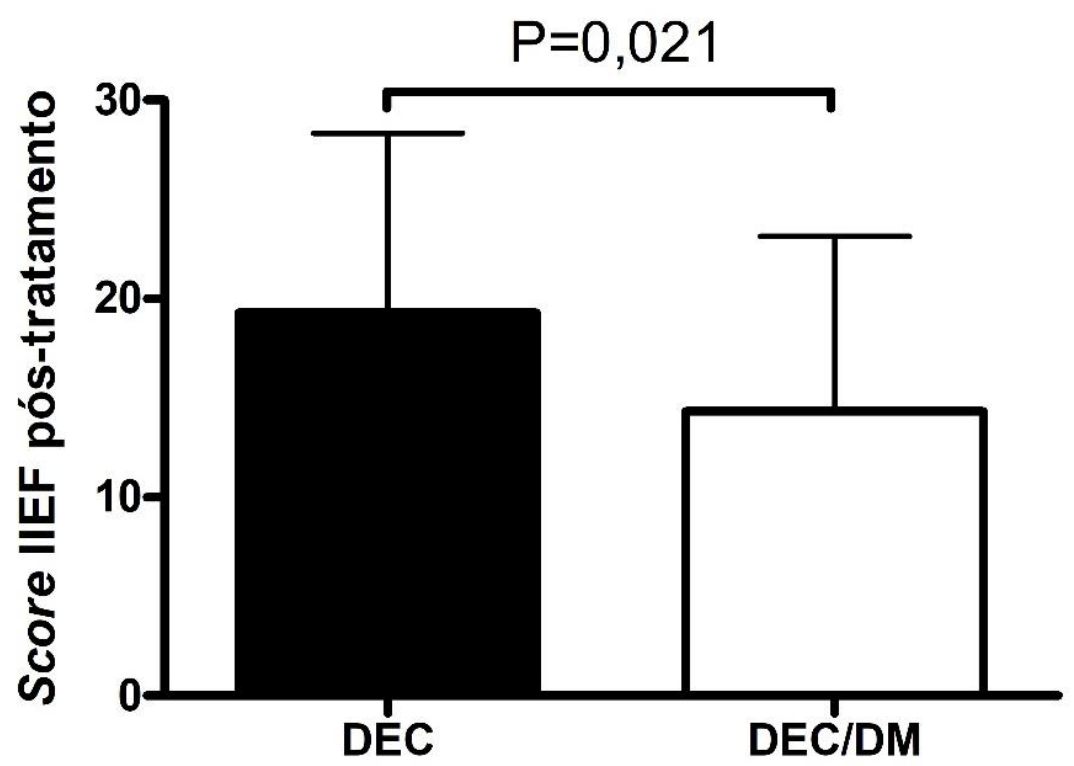

IIEF, Índice Internacional de Função Erétil; DEC, disfunção erétil clínica; DEC/DM, disfunção erétil clínica com diabetes mellitus. $n$ por grupo: $\mathrm{DEC}=44, \mathrm{DEC} / \mathrm{DM}=30$. Teste Mann Whitney. Valores expressos como média \pm desvio padrão. 
Figura 2.1.2: $\triangle \mathrm{IIEF}$ nos grupos DEC e DEC com diabetes mellitus

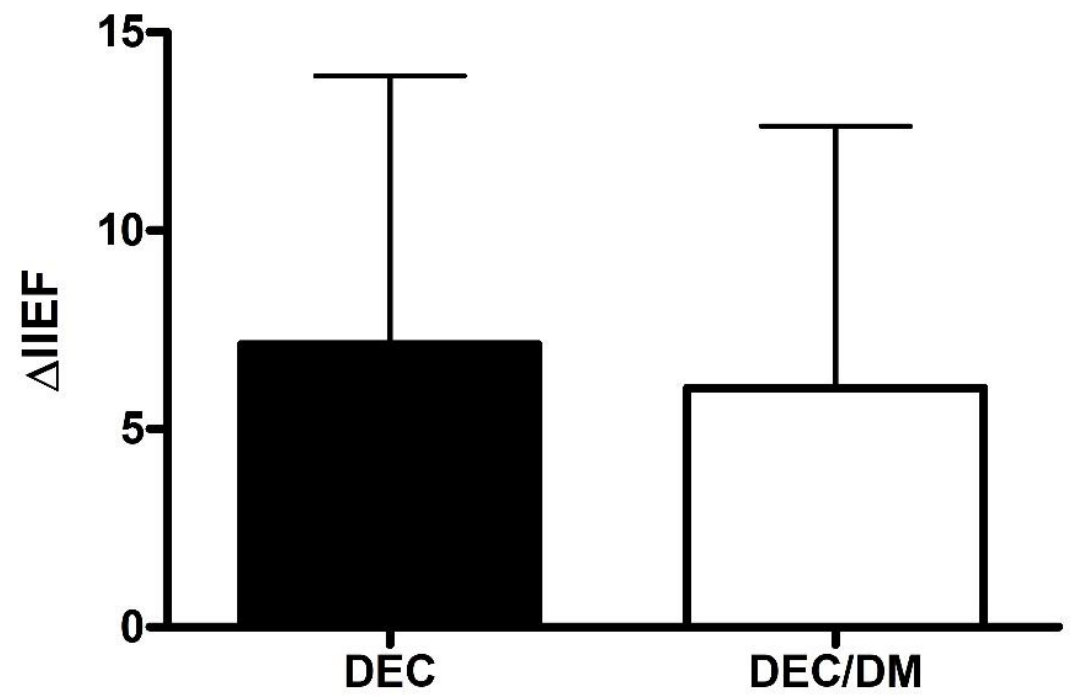

IIEF, Índice Internacional de Função Erétil; $\triangle \mathrm{IIEF}$ = IIEF pós tratamento - IIEF pré tratamento; DEC, disfunção erétil clínica; DEC/DM, disfunção erétil clínica com diabetes mellitus. $\mathrm{n}$ por grupo: $\mathrm{DEC}=44, \mathrm{DEC} / \mathrm{DM}=30$. Teste Mann Whitney. $\mathrm{P}=0,402$. Valores expressos como média \pm desvio padrão.

Figura 2.1.3: $\triangle \mathrm{IIEF} \%$ nos grupos DEC e DEC com diabetes mellitus



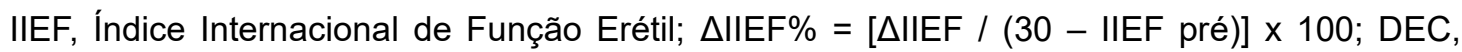
disfunção erétil clínica; DEC/DM, disfunção erétil clínica com diabetes mellitus. $\mathrm{n}$ por grupo: DEC = $44, \mathrm{DEC} / \mathrm{DM}=30$. Teste Mann Whitney. $\mathrm{P}=0,104$. Valores expressos como média \pm desvio padrão. 
Figura 2.1.4: Nitrito nos grupos DEC e DEC com diabetes mellitus

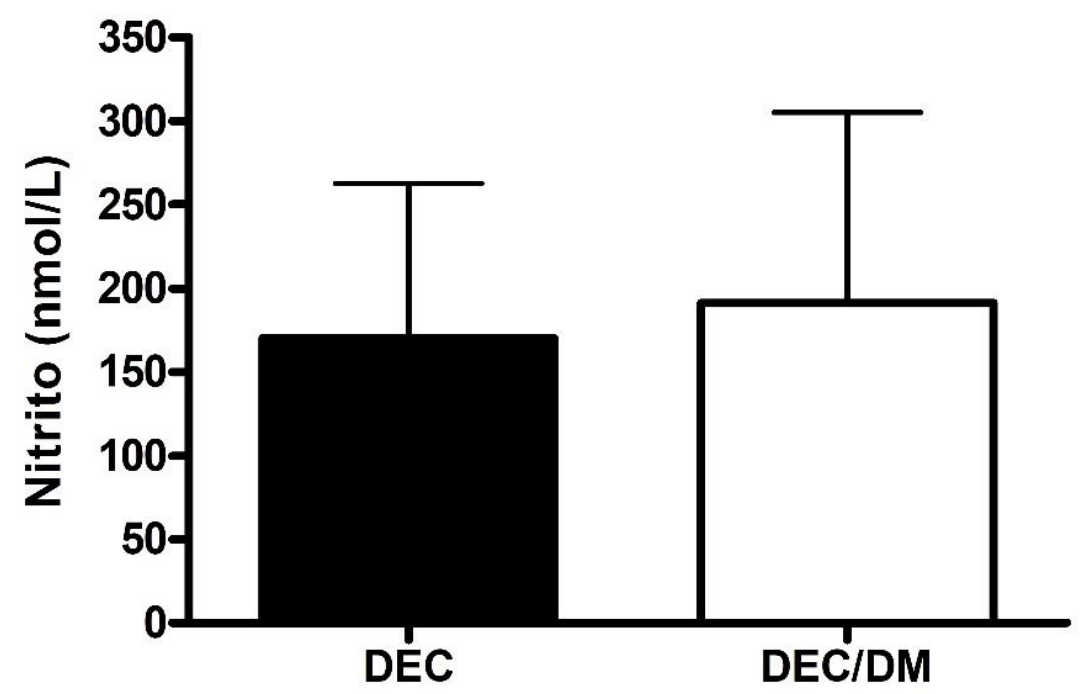

DEC, disfunção erétil clínica; DEC/DM, disfunção erétil clínica com diabetes mellitus. $\mathrm{n}$ por grupo: $\mathrm{DEC}=44, \mathrm{DEC} / \mathrm{DM}=30$. Teste $\mathrm{t}$ não pareado. $\mathrm{P}=0,391$. Valores expressos como média \pm desvio padrão.

Figura 2.1.5: ADMA nos grupos DEC e DEC com diabetes mellitus

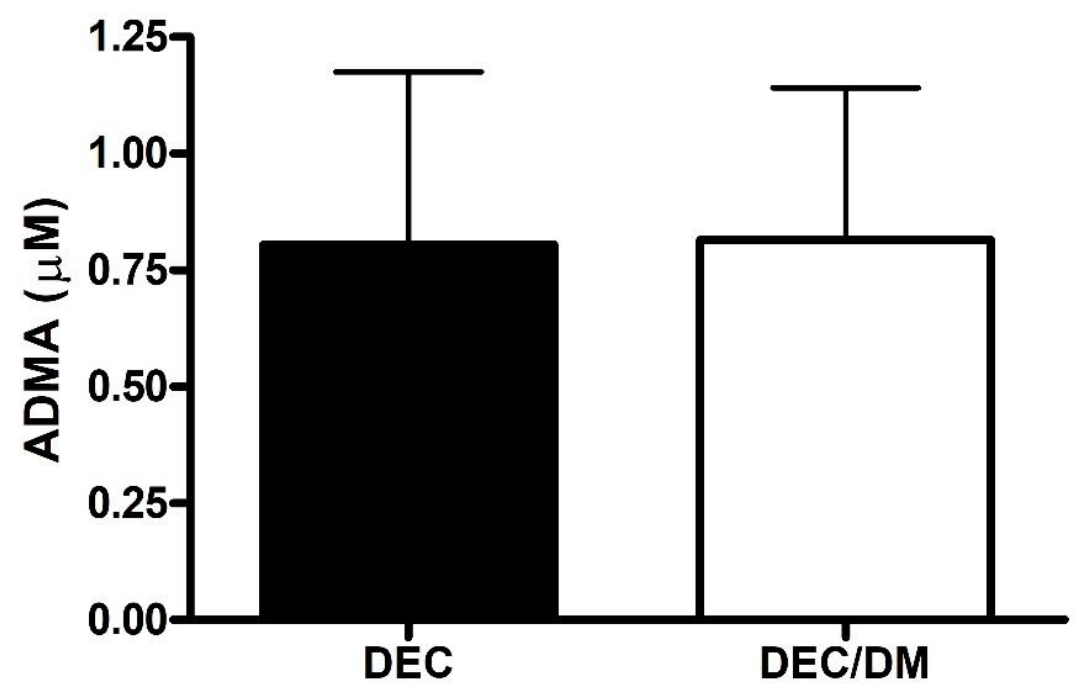

ADMA, dimetilarginina assimétrica; DEC, disfunção erétil clínica; DEC/DM, disfunção erétil clínica com diabetes mellitus. $n$ por grupo: $D E C=35, D E C / D M=28$. Teste $t$ não pareado. $P=0,908$. Valores expressos como média \pm desvio padrão. 
Figura 2.1.6: Atividade das arginases nos grupos DEC e DEC com diabetes mellitus

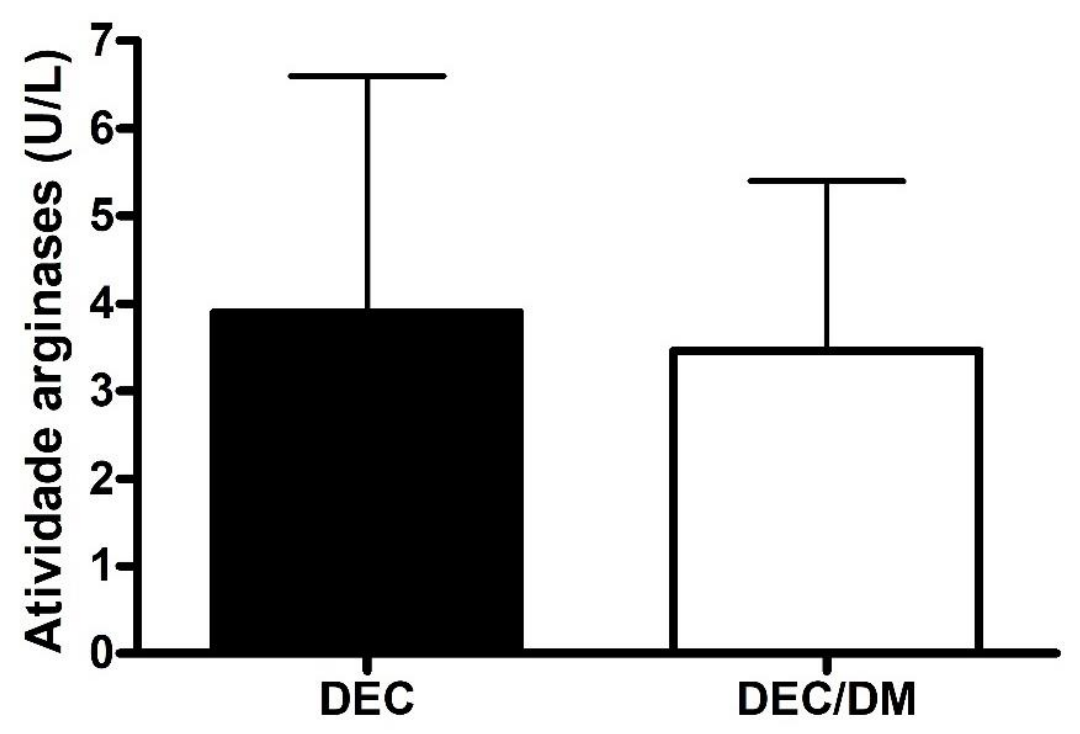

DEC, disfunção erétil clínica; DEC/DM, disfunção erétil clínica com diabetes mellitus. $\mathrm{n}$ por grupo: $\mathrm{DEC}=44$, $\mathrm{DEC} / \mathrm{DM}=30$. Teste Mann Whitney. $\mathrm{P}=0,974$. Valores expressos como média \pm desvio padrão.

Figura 2.1.7: Arginase 1 nos grupos DEC e DEC com diabetes mellitus

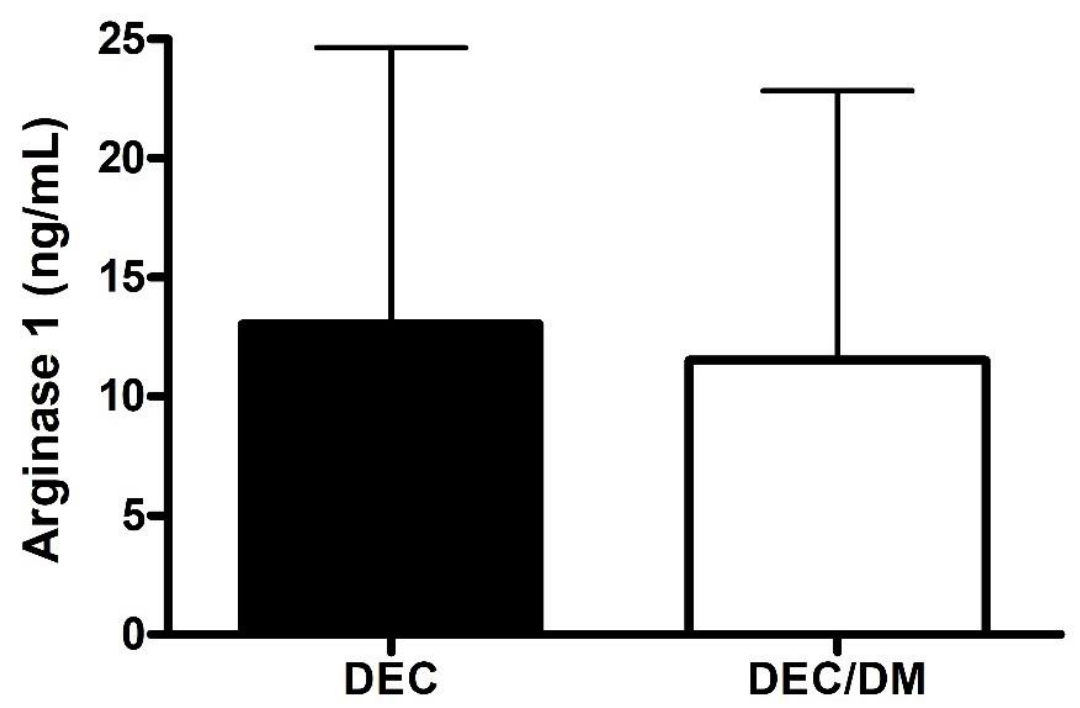

DEC, disfunção erétil clínica; DEC/DM, disfunção erétil clínica com diabetes mellitus. $\mathrm{n}$ por grupo: $\mathrm{DEC}=37, \mathrm{DEC} / \mathrm{DM}=30$. Teste Mann Whitney. $\mathrm{P}=0,641$. Valores expressos como média \pm desvio padrão. 
Figura 2.1.8: Arginase 2 nos grupos DEC e DEC com diabetes mellitus



$D E C$, disfunção erétil clínica; DEC/DM, disfunção erétil clínica com diabetes mellitus. $\mathrm{n}$ por grupo: $\mathrm{DEC}=44, \mathrm{DEC} / \mathrm{DM}=30$. Teste $\mathrm{t}$ não pareado. $\mathrm{P}=0,696$. Valores expressos como média \pm desvio padrão.

O score IIEF pós-tratamento com sildenafil é significativamente maior no grupo DEC do que no grupo DEC diabéticos. Isso mostra que, após o tratamento, o grupo sem DM atingiu maiores níveis de função erétil. Apesar de não ser estatisticamente significativa $(P=0,104)$, é possível observar a tendência dos valores de $\triangle \mathrm{IIEF}$ percentual apresentarem-se maiores nos não diabéticos. Esta forma de resposta leva em consideração o estado inicial de disfunção e avalia a melhora após o tratamento. Idealmente, as três formas de avaliação da resposta, quando consistentes, mostrariam dados mais contundentes; ainda assim, temos indícios que o DM afeta a resposta ao sildenafil. 
Capítulo 2.2

Nesta seção, avaliamos o impacto, nos diabéticos, do uso de insulina na resposta ao sildenafil, comparando a função erétil e os dados bioquímicos das mesmas substâncias relacionadas à via do óxido nítrico analisadas anteriormente (nitrito, ADMA, atividade das arginases, arginase 1 e arginase 2). Para isso, selecionamos os portadores de DE que também possuem diabetes mellitus e os separamos de acordo com o uso ou não de insulina.

Figura 2.2.1: Score IIEF domínio FE pós tratamento com sildenafil nos grupos DEC com diabetes mellitus e DEC com diabetes mellitus tratado com insulina

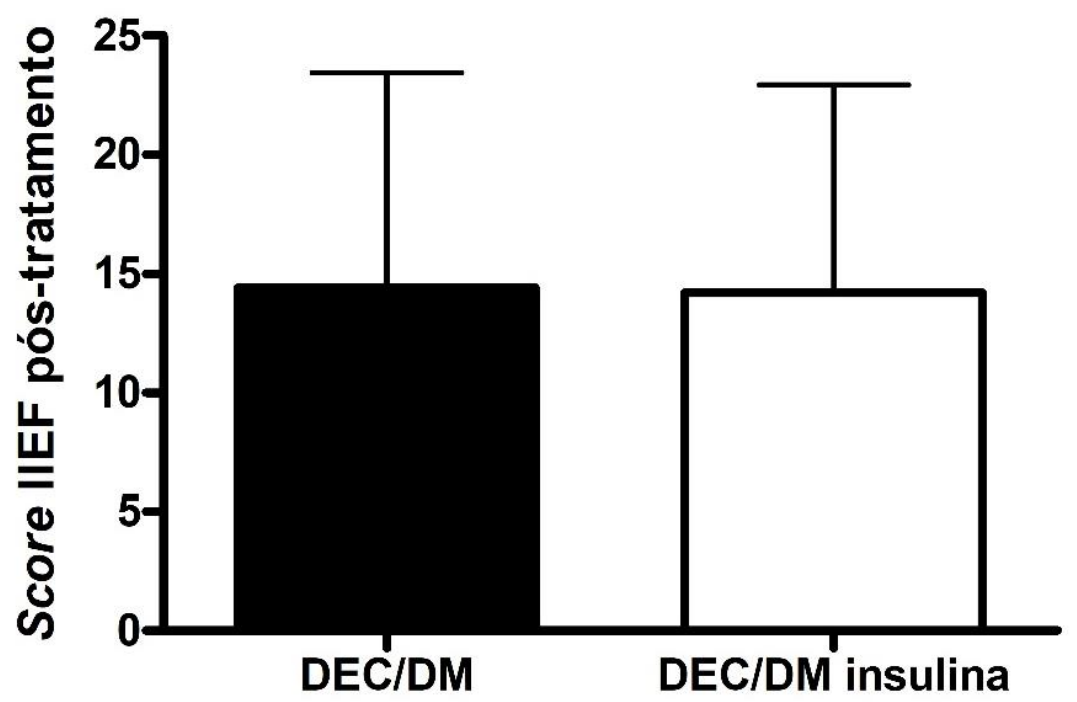

IIEF, Índice Internacional de Função Erétil; DEC/DM, disfunção erétil clínica com diabetes mellitus; $\mathrm{DEC} / \mathrm{DM}$ insulina, disfunção erétil clínica com diabetes mellitus tratado com insulina. $\mathrm{n}$ por grupo: $\mathrm{DEC} / \mathrm{DM}=20, \mathrm{DEC} / \mathrm{DM}$ insulina $=10$. Teste Mann Whitney. $\mathrm{P}=0,930$. Valores expressos como média \pm desvio padrão. 
Figura 2.2.2: $\triangle \mathrm{IIEF}$ nos grupos DEC com diabetes mellitus e DEC com diabetes mellitus tratado com insulina

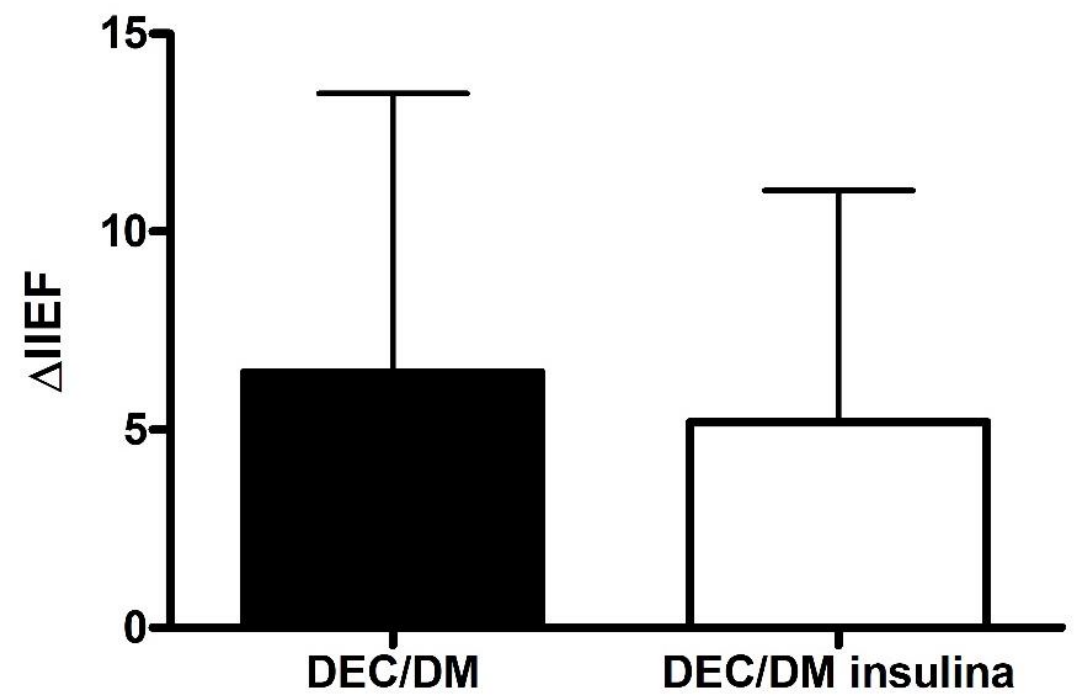

IIEF, Índice Internacional de Função Erétil; $\triangle \mathrm{IIEF}$ = IIEF pós tratamento - IIEF pré tratamento; DEC/DM, disfunção erétil clínica com diabetes mellitus; DEC/DM insulina, disfunção erétil clínica com diabetes mellitus tratado com insulina. $n$ por grupo: $D E C / D M=20, D E C / D M$ insulina $=10$. Teste Mann Whitney. $\mathrm{P}=0,774$. Valores expressos como média \pm desvio padrão.

Figura 2.2.3: $\triangle I I E F \%$ nos grupos DEC com diabetes mellitus e DEC com diabetes mellitus tratado com insulina

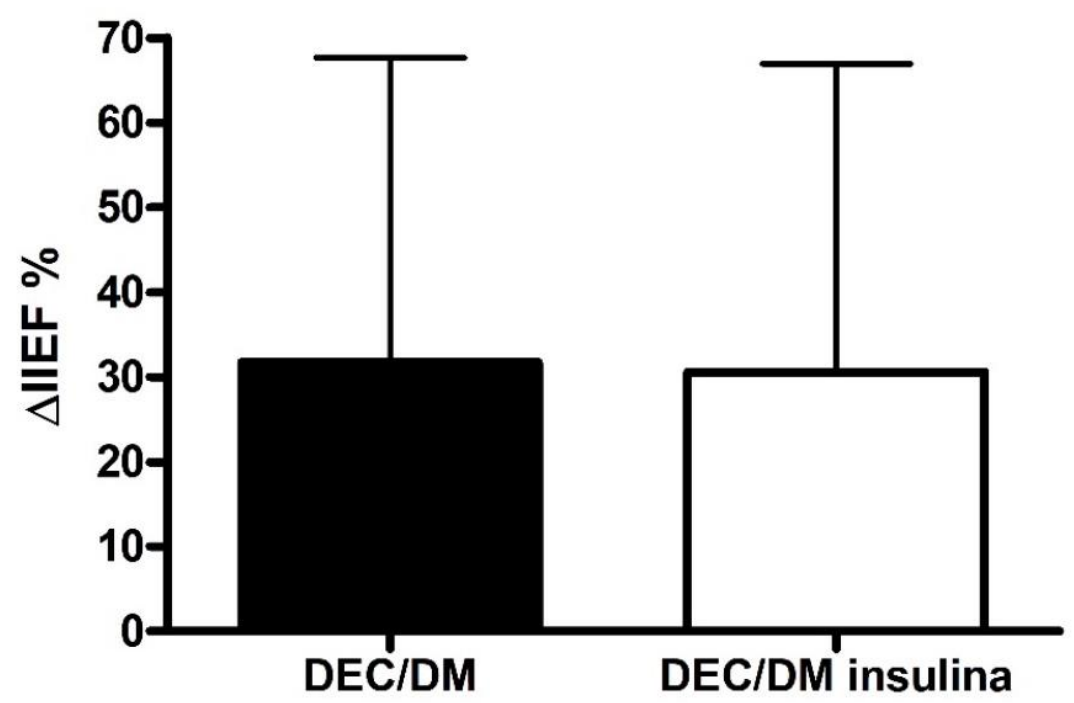

IIEF, Índice Internacional de Função Erétil; $\Delta \mathrm{IIEF} \%=[\Delta \mathrm{IIEF} /(30$ - IIEF pré) $]$ x 100; DEC/DM, disfunção erétil clínica com diabetes mellitus; DEC/DM insulina, disfunção erétil clínica com diabetes mellitus tratado com insulina. $n$ por grupo: $D E C / D M=20, D E C / D M$ insulina $=10$. Teste Mann Whitney. $P=0,930$. Valores expressos como média \pm desvio padrão. 
Figura 2.2.4: Nitrito nos grupos DEC com diabetes mellitus e DEC com diabetes mellitus tratado com insulina

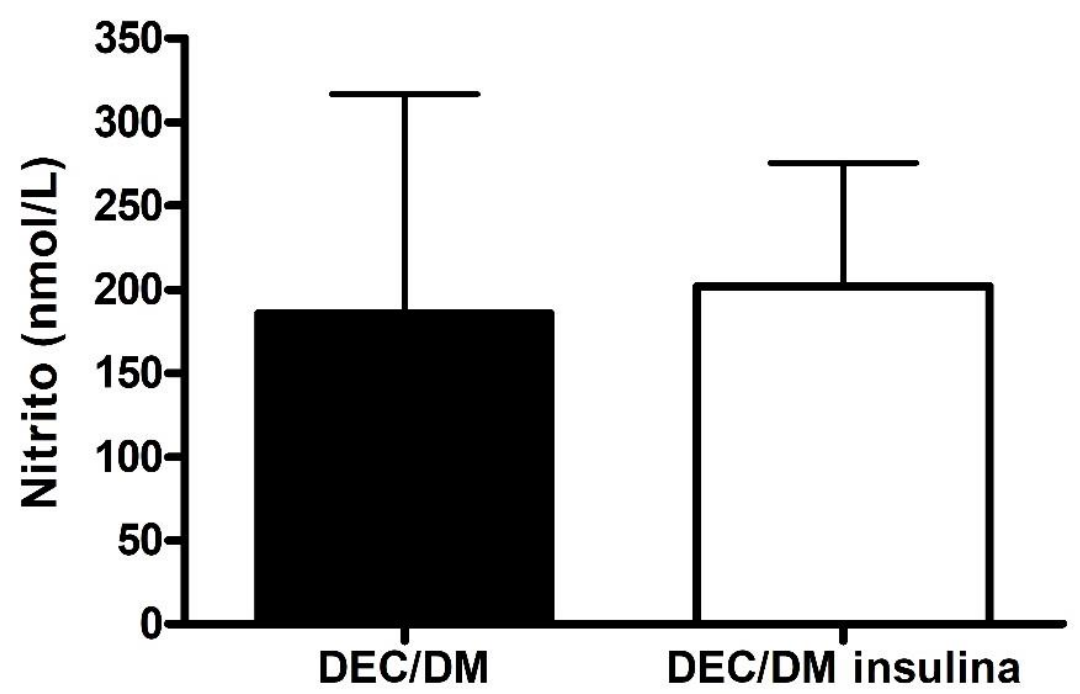

DEC/DM, disfunção erétil clínica com diabetes mellitus; DEC/DM insulina, disfunção erétil clínica com diabetes mellitus tratado com insulina. $n$ por grupo: $D E C / D M=20, D E C / D M$ insulina $=10$. Teste Mann Whitney. $P=0,720$. Valores expressos como média \pm desvio padrão.

Figura 2.2.5: ADMA nos grupos DEC com diabetes mellitus e DEC com diabetes mellitus tratado com insulina

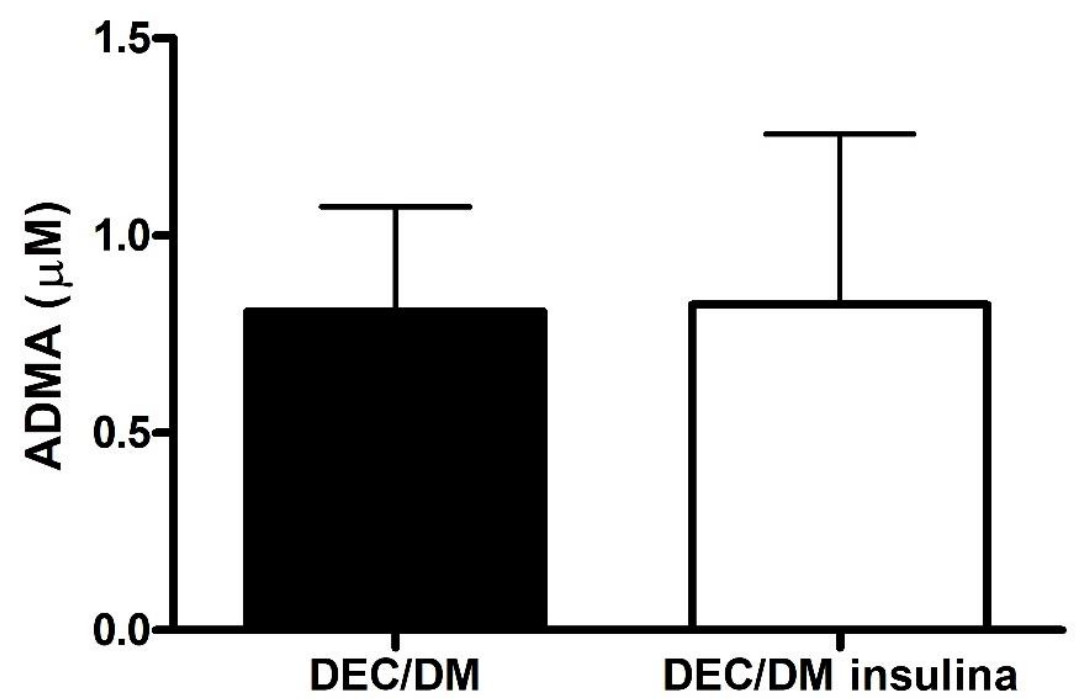

ADMA, dimetilarginina assimétrica; DEC/DM, disfunção erétil clínica com diabetes mellitus; $D E C / D M$ insulina, disfunção erétil clínica com diabetes mellitus tratado com insulina. $\mathrm{n}$ por grupo: $\mathrm{DEC} / \mathrm{DM}=18, \mathrm{DEC} / \mathrm{DM}$ insulina $=10$. Teste $\mathrm{t}$ não pareado. $\mathrm{P}=0,892$. Valores expressos como média \pm desvio padrão. 
Figura 2.2.6: Atividade das arginases nos grupos DEC com diabetes mellitus e DEC com diabetes mellitus tratado com insulina

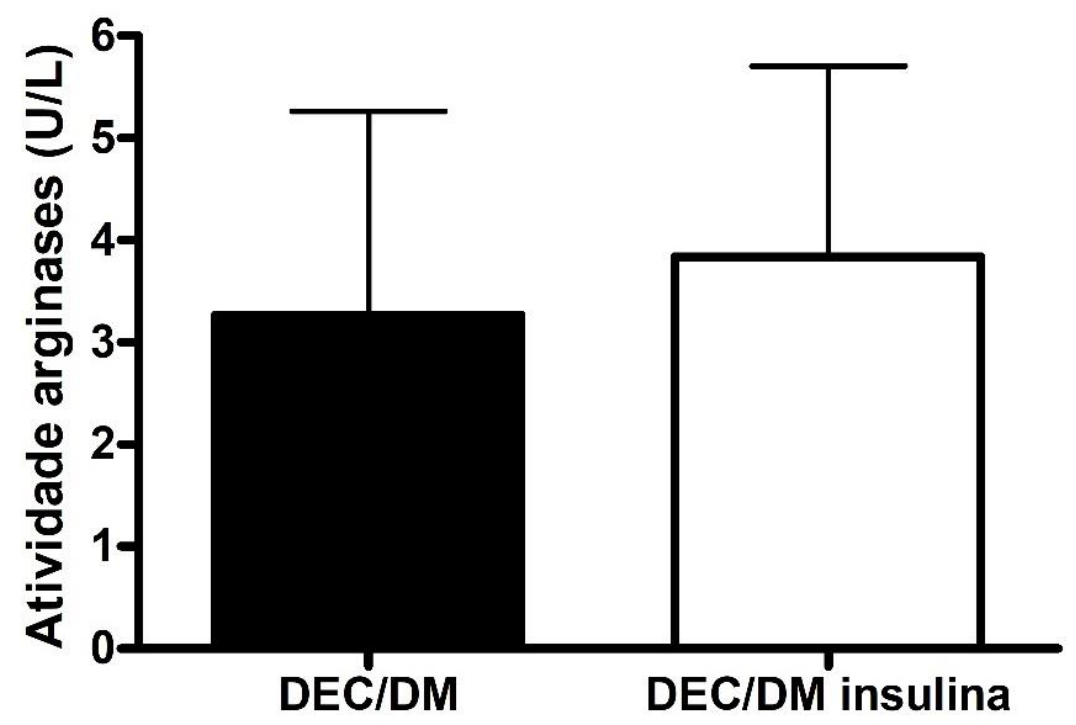

DEC/DM, disfunção erétil clínica com diabetes mellitus; DEC/DM insulina, disfunção erétil clínica com diabetes mellitus tratado com insulina. $n$ por grupo: $D E C / D M=20, D E C / D M$ insulina $=10$. Teste t não pareado. $P=0,457$. Valores expressos como média \pm desvio padrão.

Figura 2.2.7: Arginase 1 nos grupos DEC com diabetes mellitus e DEC com diabetes mellitus tratado com insulina

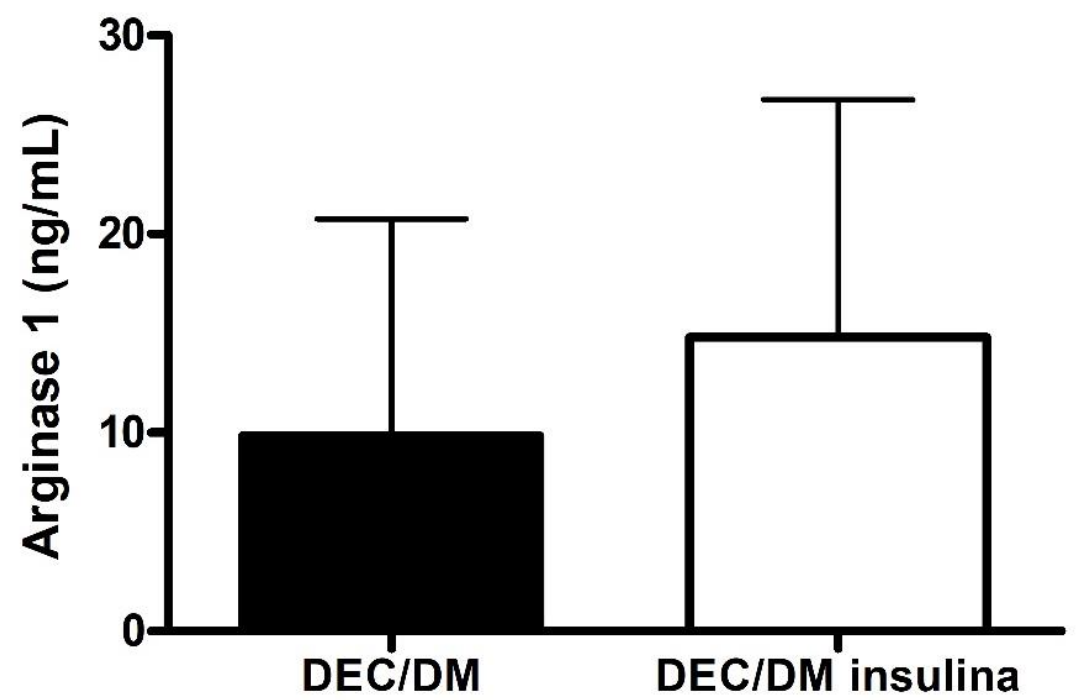

DEC/DM, disfunção erétil clínica com diabetes mellitus; DEC/DM insulina, disfunção erétil clínica com diabetes mellitus tratado com insulina. $n$ por grupo: $D E C / D M=20, D E C / D M$ insulina $=10$. Teste t não pareado. $P=0,265$. Valores expressos como média \pm desvio padrão. 
Figura 2.2.8: Arginase 2 nos grupos DEC com diabetes mellitus e DEC com diabetes mellitus tratado com insulina



DEC/DM, disfunção erétil clínica com diabetes mellitus; DEC/DM insulina, disfunção erétil clínica com diabetes mellitus tratado com insulina. $n$ por grupo: $D E C / D M=20, D E C / D M$ insulina $=10$. Teste $t$ não pareado. $P=0,981$. Valores expressos como média \pm desvio padrão.

Não houve nenhuma associação significativa nesta seção. 


\section{Capítulo 3}

Neste capítulo, os dados apresentados avaliam o impacto do uso de outros fármacos, que afetam a enzima XOR (omeprazol e alopurinol), sobre a terapia da disfunção erétil com sildenafil. Para as próximas análises, agrupamos tanto os sujeitos que têm DE clínica quanto aqueles afetados pela DE pós-prostatectomia, e redividimos os grupos de acordo com o uso ou não do medicamento de interesse (omeprazol, no capítulo 3.1, e alopurinol, no capítulo 3.2). Na terceira parte do capítulo, mostramos um modelo de regressão linear multivariada que leva em conta o uso ou não de omeprazol e alopurinol, assim como a etiologia da disfunção erétil, para análises corrigidas. A decisão de juntar DE clínica e DE pós-prostatectomia num mesmo grupo foi tomada pelo número reduzido de homens que utilizam os fármacos selecionados para as análises (omeprazol e alopurinol). Vale ressaltar que se trata de um estudo retrospectivo que utilizou amostras já coletadas anteriormente, armazenadas em biorrepositório, e que os participantes não foram prospectados procurando ativamente por usuários desses fármacos, apesar do uso ter sido investigado e registrado dentre participantes que tinham, ou não, DE.

Capítulo 3.1

O efeito do uso de omeprazol sobre a resposta ao sildenafil foi avaliado separando os indivíduos que utilizam o medicamento dos que não utilizam. Para tanto, analisamos a resposta ao sildenafil por meio do score IIEF pós tratamento (figura 3.1.1), delta IIEF (figura 3.1.2) e delta IIEF percentual (figura 3.1.3), e dados bioquímicos de substâncias relacionadas à via do óxido nítrico (nitrito, figura 3.1.4; 
ADMA, figura 3.1.5; atividade das arginases, figura 3.1.6; arginase 1, figura 3.1.7, e arginase 2, figura 3.1.8).

Figura 3.1.1: Score IIEF domínio FE pós tratamento com sildenafil nos grupos DE e DE tratado com omeprazol

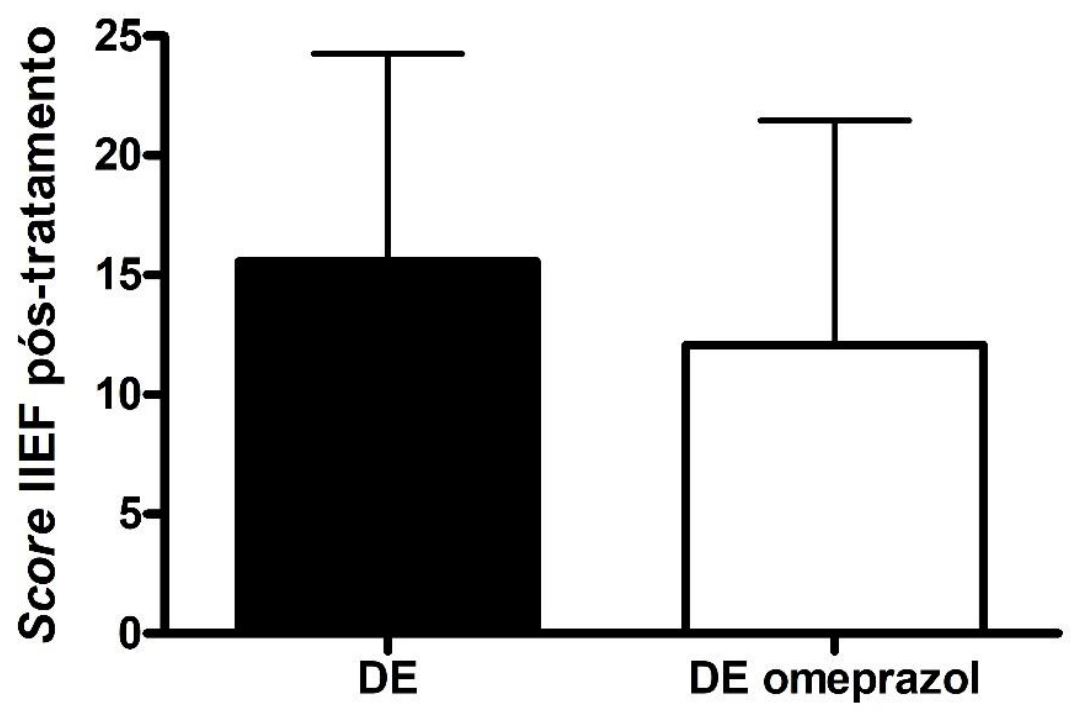

IIEF, Índice Internacional de Função Erétil; DE, disfunção erétil; DE omeprazol, disfunção erétil tratado com omeprazol. $n$ por grupo: $D E=136$, $D E$ omeprazol $=12$. Teste Mann Whitney. $P=$ 0,144 . Valores expressos como média \pm desvio padrão. 
Figura 3.1.2: $\triangle \mathrm{IIEF}$ nos grupos DE e DE tratado com omeprazol



IIEF, Índice Internacional de Função Erétil; $\triangle \mathrm{IIEF}=$ IIEF pós tratamento - IIEF pré tratamento; $\mathrm{DE}$, disfunção erétil; $\mathrm{DE}$ omeprazol, disfunção erétil tratado com omeprazol. $\mathrm{n}$ por grupo: $\mathrm{DE}=136$, $\mathrm{DE}$ omeprazol $=12$. Teste Mann Whitney. $\mathrm{P}=0,474$. Valores expressos como média \pm desvio padrão.

Figura 3.1.3: $\triangle \mathrm{IIEF} \%$ nos grupos DE e DE tratado com omeprazol



IIEF, Índice Internacional de Função Erétil; $\Delta \mathrm{IIEF} \%=[\Delta \mathrm{IIEF} /(30-\mathrm{IIEF}$ pré) $] \times 100 ; \mathrm{DE}$, disfunção erétil; $D E$ omeprazol, disfunção erétil tratada com omeprazol. $n$ por grupo: $D E=136, D E$ omeprazol $=12$. Teste Mann Whitney. $P=0,916$. Valores expressos como média \pm desvio padrão. 
Figura 3.1.4: Nitrito nos grupos DE e DE tratado com omeprazol

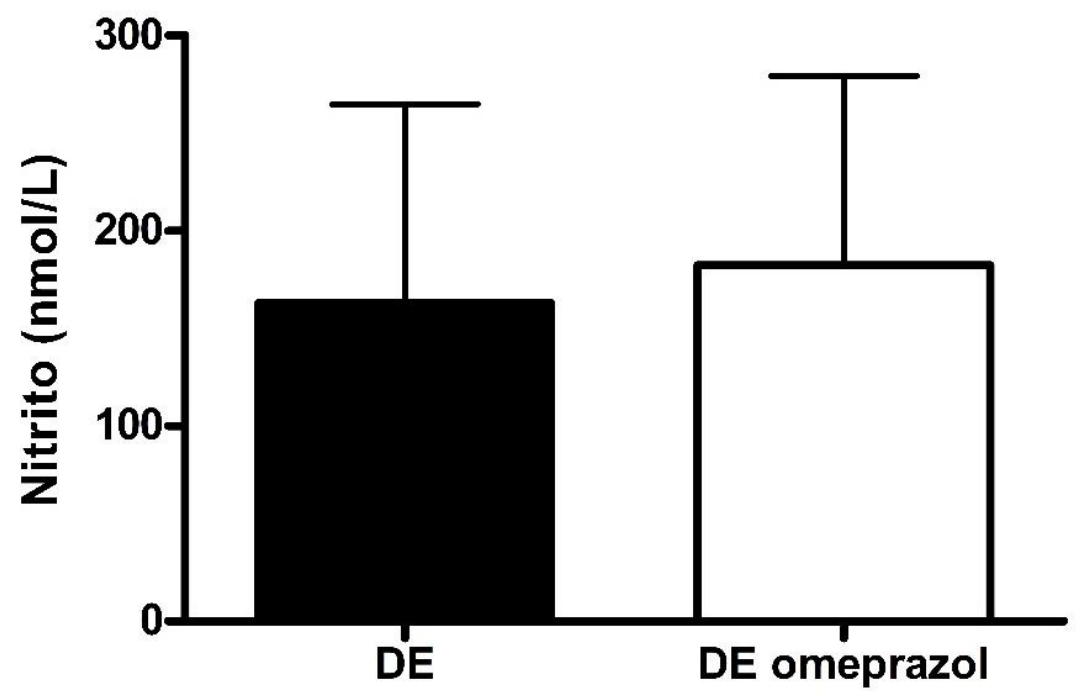

$\mathrm{DE}$, disfunção erétil; DE omeprazol, disfunção erétil tratado com omeprazol. $\mathrm{n}$ por grupo: DE $=136, \mathrm{DE}$ omeprazol $=12$. Teste Mann Whitney. $\mathrm{P}=0,442$. Valores expressos como média \pm desvio padrão.

Figura 3.1.5: ADMA nos grupos DE e DE tratado com omeprazol

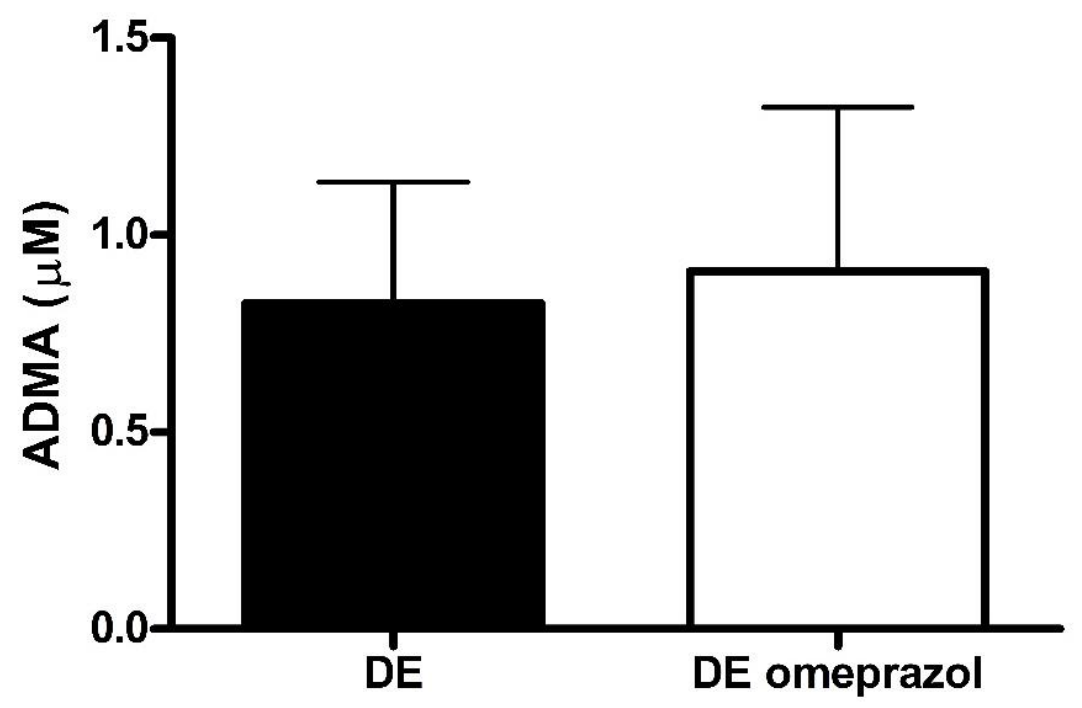

ADMA, dimetilarginina assimétrica; DE, disfunção erétil; DE omeprazol, disfunção erétil tratado com omeprazol. $n$ por grupo: $D E=110$, $D E$ omeprazol $=10$. Teste $t$ não pareado. $P=0,438$. Valores expressos como média \pm desvio padrão. 
Figura 3.1.6: Atividade das arginases nos grupos DE e DE tratado com omeprazol

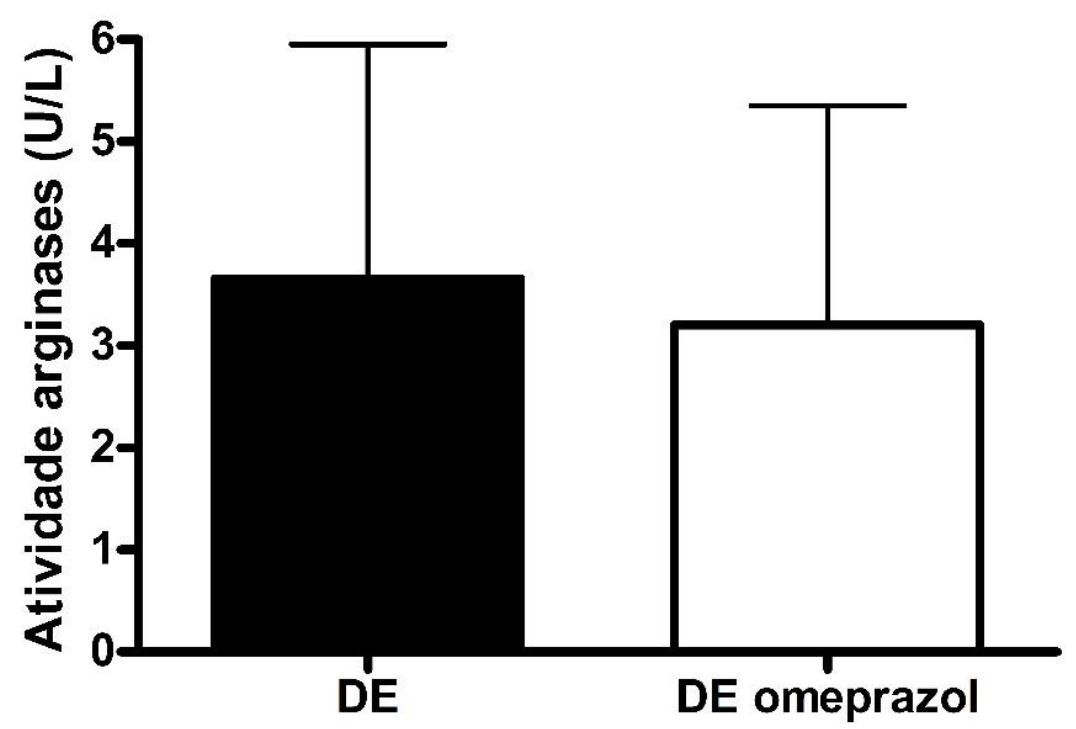

$\mathrm{DE}$, disfunção erétil; $\mathrm{DE}$ omeprazol, disfunção erétil tratado com omeprazol. $\mathrm{n}$ por grupo: $\mathrm{DE}$ $=136, \mathrm{DE}$ omeprazol $=12$. Teste Mann Whitney. $\mathrm{P}=0,411$. Valores expressos como média \pm desvio padrão.

Figura 3.1.7: Arginase 1 nos grupos DE e DE tratado com omeprazol

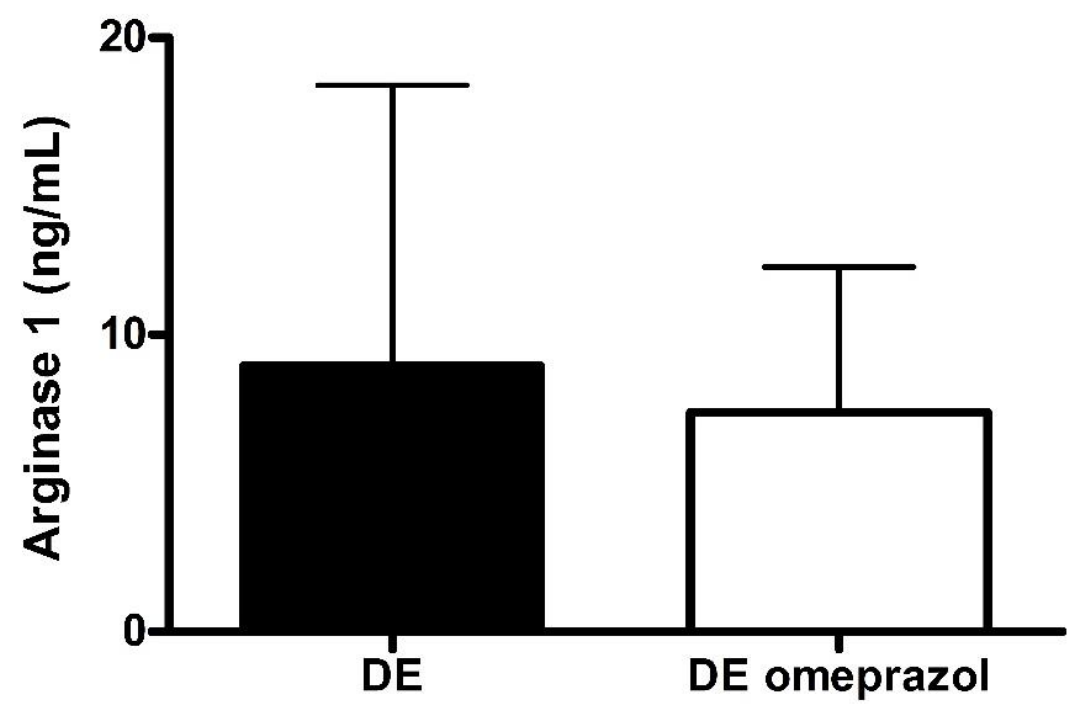

$D E$, disfunção erétil; $D E$ omeprazol, disfunção erétil tratado com omeprazol. $n$ por grupo: $D E$ $=120, \mathrm{DE}$ omeprazol $=10$. Teste Mann Whitney. $\mathrm{P}=0,628$. Valores expressos como média \pm desvio padrão. 
Figura 3.1.8: Arginase 2 nos grupos DE e DE tratado com omeprazol

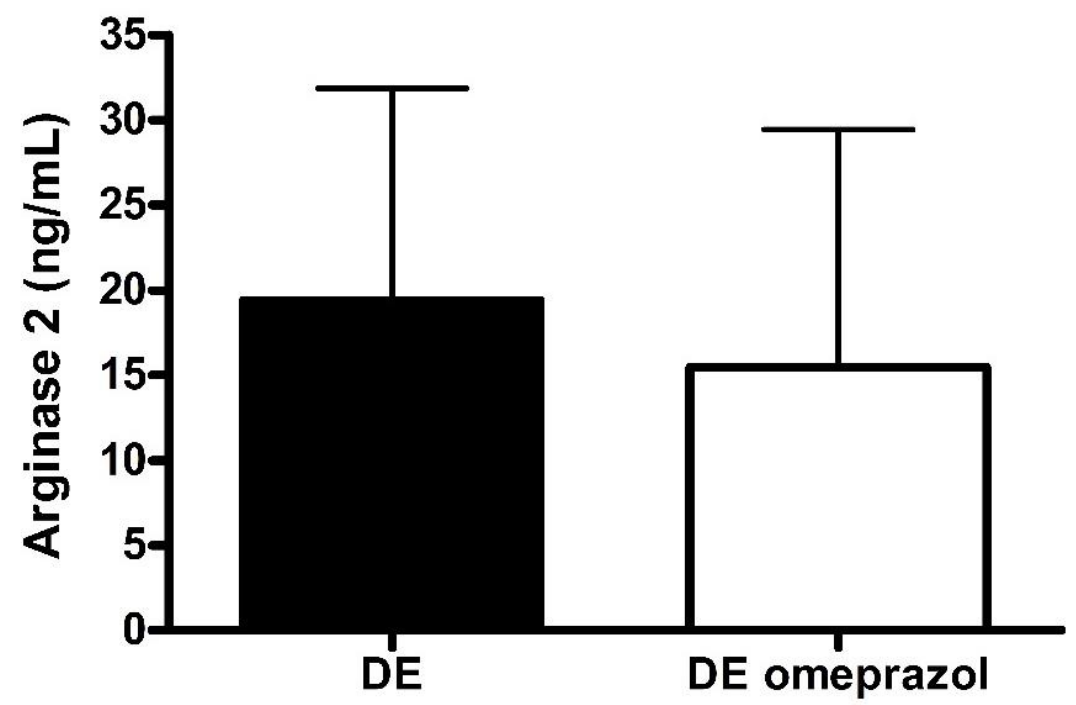

$D E$, disfunção erétil; $D E$ omeprazol, disfunção erétil tratado com omeprazol. $n$ por grupo: $D E$ $=135, \mathrm{DE}$ omeprazol $=12$. Teste Mann Whitney. $\mathrm{P}=0,080$. Valores expressos como média \pm desvio padrão.

Apesar de não terem sido encontradas diferenças estatísticas nesta seção, pode-se notar uma tendência de valores menores tanto para o score IIEF pós tratamento com sildenafil (onde $P=0,144$ ) quanto do $\Delta$ IIEF no grupo que faz uso do omeprazol. Além disso, temos um valor de $\mathrm{P}$ próximo de 0,05 para a análise de arginase $2(=0,080)$, indicando uma tendência para concentrações maiores dessa enzima no grupo que não faz uso do omeprazol. 
Capítulo 3.2

Nesta seção, analisamos o efeito do uso de alopurinol sobre a resposta ao sildenafil, de forma similar ao que foi feito na seção anterior (capítulo 3.1). Os indivíduos que utilizam o medicamento foram separados dos que não utilizam. Para a comparação dos grupos, avaliamos a função erétil, por meio do score IIEF pós tratamento (figura 3.2.1), delta IIEF (figura 3.2.2) e delta IIEF percentual (figura 3.2.3), e dados bioquímicos de substâncias relacionadas à via do óxido nítrico (nitrito, figura 3.2.4; ADMA, figura 3.2.5; atividade das arginases, figura 3.2.6; arginase 1, figura 3.2.7, e arginase 2, figura 3.2.8).

Figura 3.2.1: Score IIEF domínio FE pós tratamento com sildenafil nos grupos DE e DE tratado com alopurinol

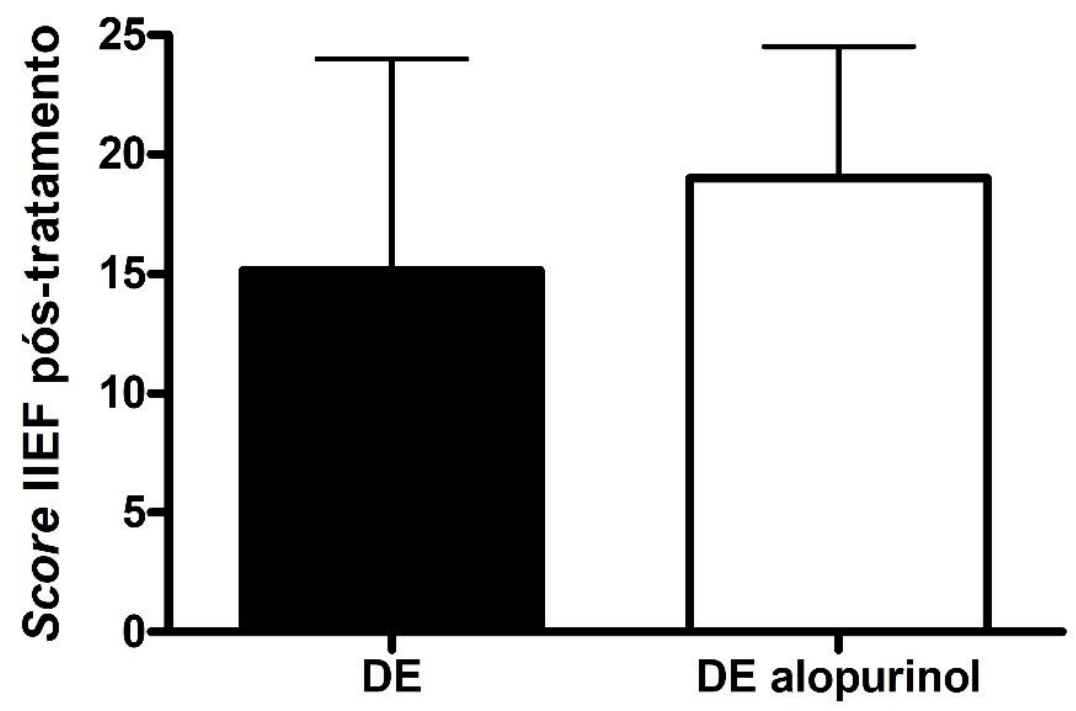

IIEF, Índice Internacional de Função Erétil; DE, disfunção erétil; DE alopurinol, disfunção erétil tratado com alopurinol. $n$ por grupo: $D E=142, D E$ alopurinol $=6$. Teste Mann Whitney. $P=0,185$. Valores expressos como média \pm desvio padrão. 
Figura 3.2.2: $\triangle \mathrm{IIEF}$ nos grupos $D E$ e $D E$ tratado com alopurinol

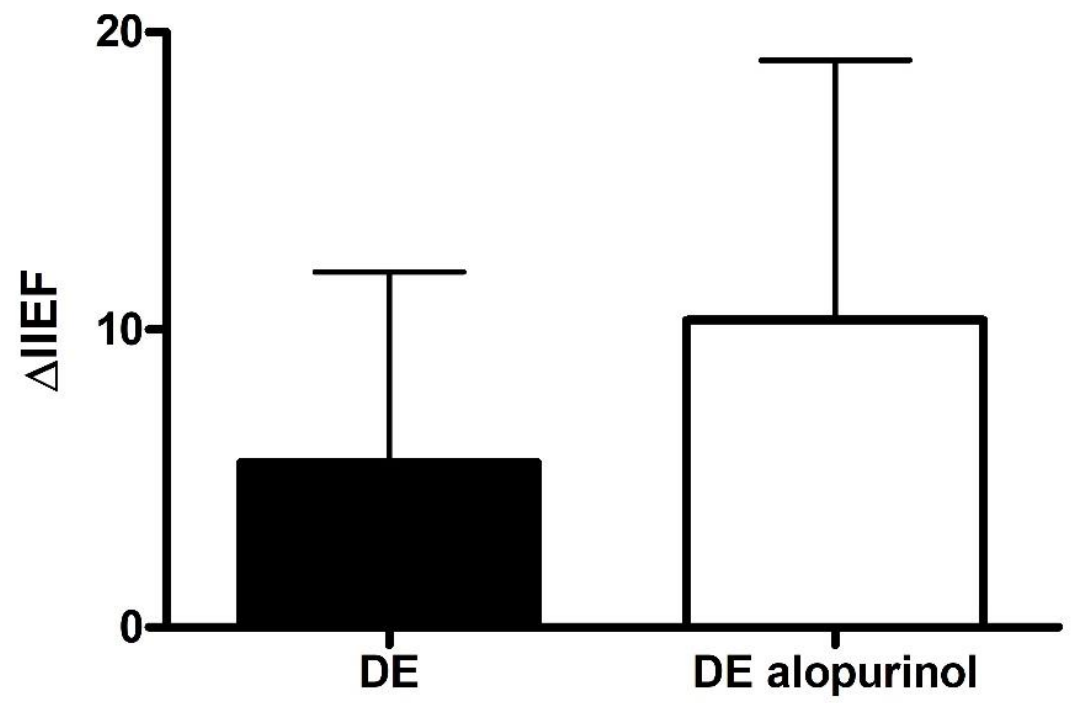

IIEF, Índice Internacional de Função Erétil; $\triangle \mathrm{IIEF}=$ IIEF pós tratamento - IIEF pré tratamento; $\mathrm{DE}$, disfunção erétil; $\mathrm{DE}$ alopurinol, disfunção erétil tratado com alopurinol. $\mathrm{n}$ por grupo: $\mathrm{DE}=142$, DE alopurinol $=6$. Teste Mann Whitney. $P=0,232$. Valores expressos como média \pm desvio padrão.

Figura 3.2.3: $\triangle \mathrm{IIEF} \%$ nos grupos $\mathrm{DE}$ e DE tratado com alopurinol

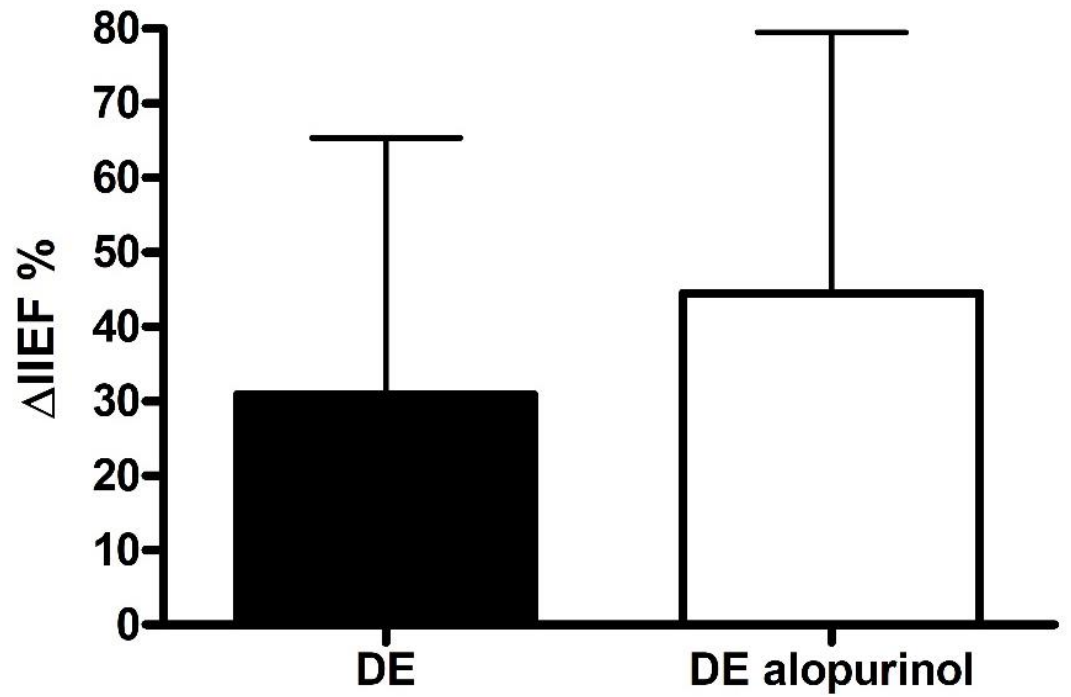

IIEF, Índice Internacional de Função Erétil; $\Delta \mathrm{IIEF} \%=[\Delta \mathrm{IIEF} /(30$ - IIEF pré) $]$ x 100; DE, disfunção erétil; DE alopurinol, disfunção erétil tratada com alopurinol. $n$ por grupo: $D E=142, D E$ alopurinol $=6$. Teste Mann Whitney. $P=0,547$. Valores expressos como média \pm desvio padrão. 
Figura 3.2.4: Nitrito nos grupos DE e DE tratado com alopurinol

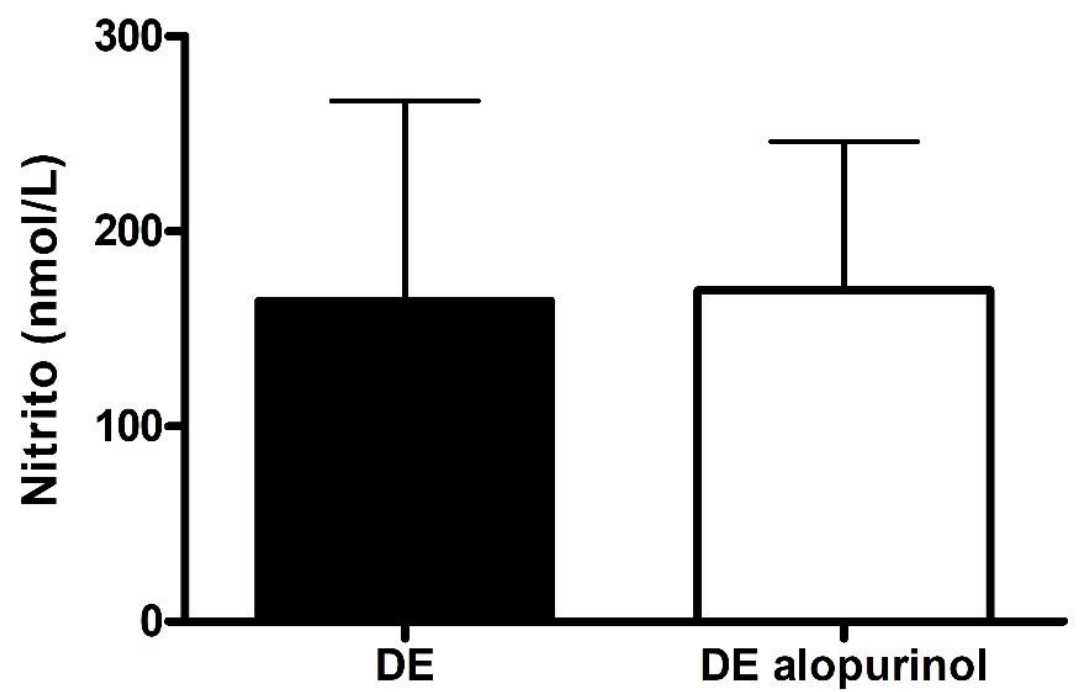

$\mathrm{DE}$, disfunção erétil; $\mathrm{DE}$ alopurinol, disfunção erétil tratada com alopurinol. $\mathrm{n}$ por grupo: $\mathrm{DE}=$ 142 , DE alopurinol $=6$. Teste Mann Whitney. $P=0,644$. Valores expressos como média \pm desvio padrão.

Figura 3.2.5: ADMA nos grupos DE e DE tratado com alopurinol

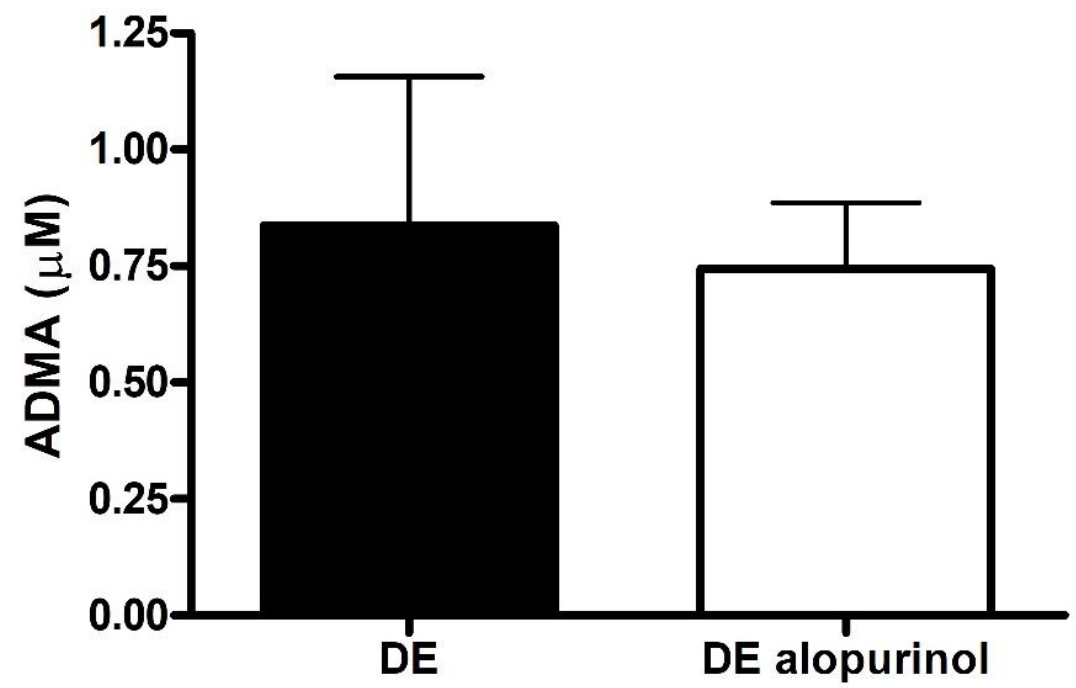

ADMA, dimetilarginina assimétrica; DE, disfunção erétil; DE alopurinol, disfunção erétil tratada com alopurinol. $n$ por grupo: $\mathrm{DE}=116$, $\mathrm{DE}$ alopurinol $=4$. Teste $\mathrm{t}$ não pareado. $\mathrm{P}=0,567$. Valores expressos como média \pm desvio padrão. 
Figura 3.2.6: Atividade das arginases nos grupos DE e DE tratado com alopurinol

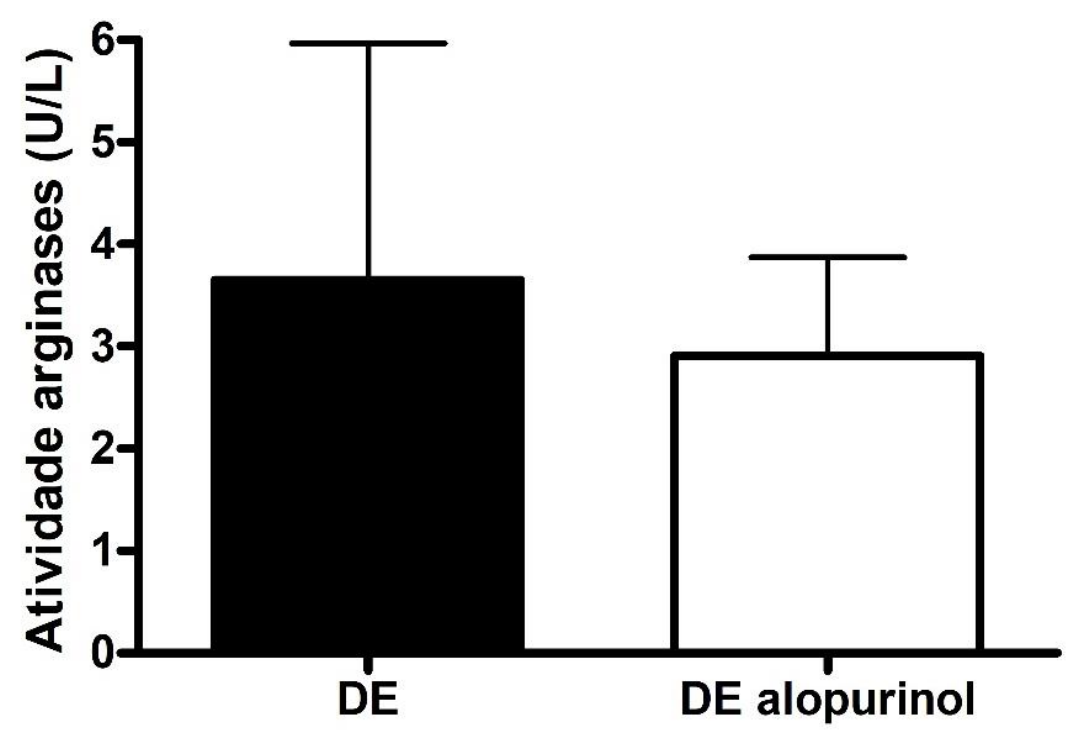

$\mathrm{DE}$, disfunção erétil; DE alopurinol, disfunção erétil tratada com alopurinol. $\mathrm{n}$ por grupo: $\mathrm{DE}=$ 142, $\mathrm{DE}$ alopurinol $=6$. Teste Mann Whitney. $\mathrm{P}=0,563$. Valores expressos como média \pm desvio padrão.

Figura 3.2.7: Arginase 1 nos grupos DE e DE tratado com alopurinol

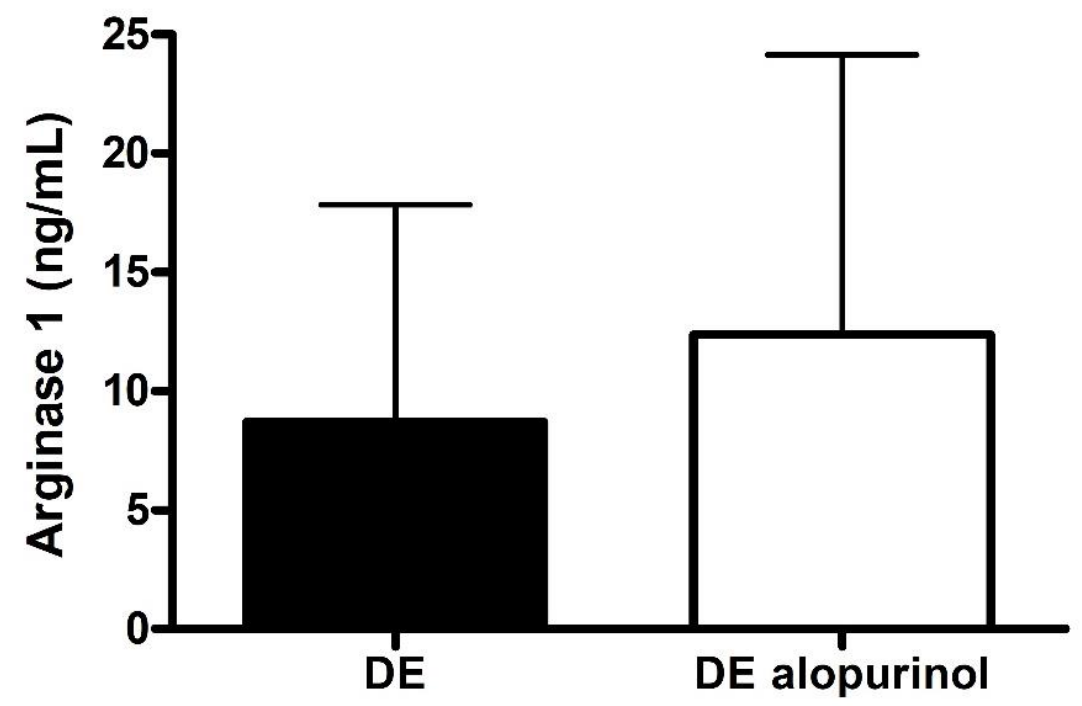

$\mathrm{DE}$, disfunção erétil; $\mathrm{DE}$ alopurinol, disfunção erétil tratada com alopurinol. $\mathrm{n}$ por grupo: $\mathrm{DE}=$ 126, DE alopurinol $=4$. Teste Mann Whitney. $P=0,691$. Valores expressos como média \pm desvio padrão. 
Figura 3.2.8: Arginase 2 nos grupos DE e DE tratado com alopurinol

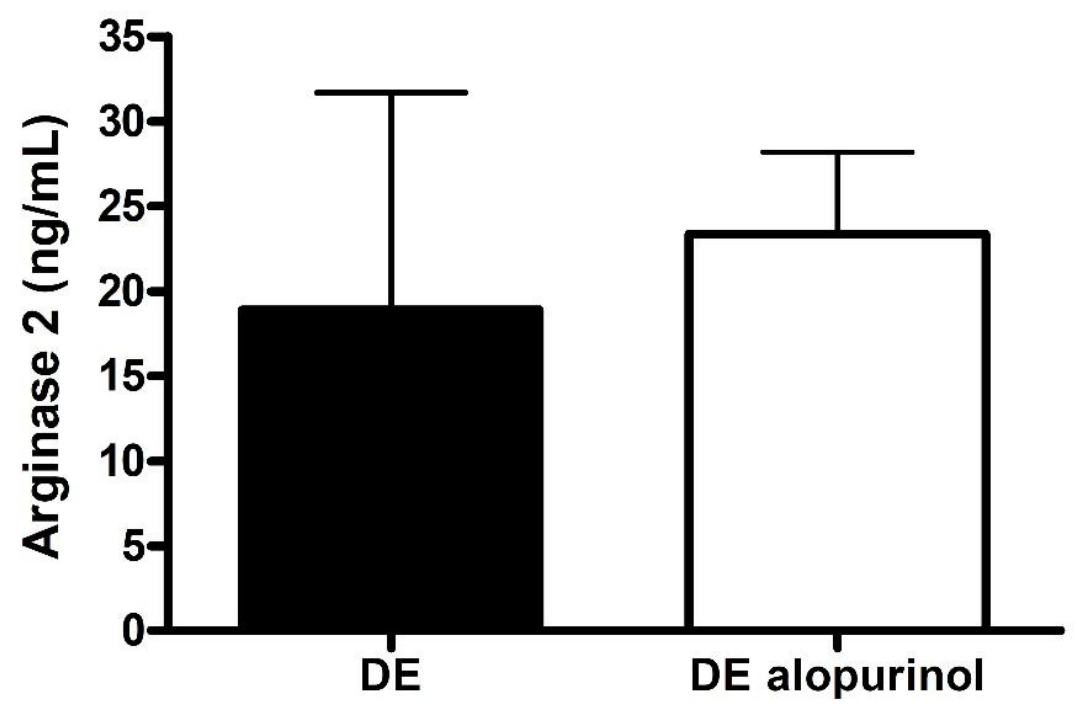

$\mathrm{DE}$, disfunção erétil; $\mathrm{DE}$ alopurinol, disfunção erétil tratada com alopurinol. $\mathrm{n}$ por grupo: $\mathrm{DE}=$ 142, $\mathrm{DE}$ alopurinol $=5$. Teste Mann Whitney. $\mathrm{P}=0,084$. Valores expressos como média \pm desvio padrão.

Assim como nas análises anteriores do capítulo, apesar de não haver diferença estatística nos testes realizados, vale destacar a tendência do $\Delta$ IIEF se apresentar maior em um dos grupos estudados (aqui, ao contrário da seção anterior, os valores parecem estar aumentados no grupo que utiliza o fármaco de interesse alopurinol). No teste para arginase 2 , temos um valor de P próximo a 0,05 $(=0,084)$, indicando uma tendência para concentrações maiores da enzima no grupo que faz uso do alopurinol. 


\section{Capítulo 3.3}

Construímos um modelo de regressão linear multivariada que leva em consideração a etiologia da disfunção erétil (DEC ou DEPP) e o uso tanto do omeprazol quanto do alopurinol, além de outros fatores de confusão, como idade, tabagismo, etilismo, diabetes mellitus e uso de anti-hipertensivos.

Avaliamos o efeito dessas variáveis sobre os parâmetros de responsividade ao sildenafil (score IIEF pós-tratamento, $\triangle \mathrm{IIEF}$ e $\triangle \mathrm{IIEF} \%$; tabela III) e sobre os marcadores bioquímicos estudados anteriormente (nitrito, ADMA, atividade das arginases, arginase 1 e arginase 2; tabela IV). 
Tabela III: Análise de regressão linear multivariada mostrando os efeitos da etiologia da DE e do uso do omeprazol e do alopurinol sobre os parâmetros de responsividade ao sildenafil

\begin{tabular}{|c|c|c|c|c|c|c|}
\hline \multirow[t]{2}{*}{ Modelo } & \multicolumn{2}{|c|}{$\begin{array}{c}\text { Score IIEF pós- } \\
\text { tratamento } \\
R^{2}=0,126 \\
\text { RMSE }=0,289\end{array}$} & \multicolumn{2}{|c|}{$\begin{array}{c}\Delta \text { IIEF } \\
R^{2}=0,077 \\
\text { RMSE }=0,480\end{array}$} & \multicolumn{2}{|c|}{$\begin{array}{c}\Delta \text { IIEF\% } \\
R^{2}=0,080 \\
\text { RMSE }=0,780\end{array}$} \\
\hline & $\beta$ & $\mathbf{P}$ & $\beta$ & $\mathbf{P}$ & $\beta$ & $\mathbf{P}$ \\
\hline Idade & $-0,005$ & 0,061 & 0,002 & 0,675 & $-0,003$ & 0,727 \\
\hline \multicolumn{7}{|l|}{ Tabagismo } \\
\hline Fumante & $-0,027$ & 0,583 & 0,120 & 0,144 & 0,111 & 0,404 \\
\hline Ex-fumante & 0,022 & 0,535 & $-0,106$ & 0,074 & $-0,118$ & 0,219 \\
\hline Não fumante & 0,005 & 0,896 & $-0,013$ & 0,829 & 0,007 & 0,941 \\
\hline Etilismo & 0,011 & 0,807 & 0,056 & 0,455 & 0,090 & 0,464 \\
\hline Ser diabético & $-0,038$ & 0,176 & $-0,056$ & 0,231 & $-0,113$ & 0,134 \\
\hline Uso de anti-hipertensivo & $-0,032$ & 0,197 & $-0,029$ & 0,490 & $-0,048$ & 0,472 \\
\hline \multicolumn{7}{|l|}{ Etiologia da DE } \\
\hline DEC & 0,028 & 0,344 & 0,094 & 0,058 & 0,156 & 0,053 \\
\hline DEPP & $-0,028$ & 0,344 & $-0,094$ & 0,058 & $-0,156$ & 0,053 \\
\hline Uso de omeprazol & $-0,062$ & 0,167 & $-0,001$ & 0,993 & 0,100 & 0,407 \\
\hline Uso de alopurinol & 0,091 & 0,145 & 0,109 & 0,294 & 0,106 & 0,529 \\
\hline
\end{tabular}

DEC, disfunção erétil clínica; DEPP, disfunção erétil pós-prostatectomia; $\triangle I I E F=$ IIEF pós tratamento - IIEF pré tratamento; $\Delta$ IIEF \% = [AIIEF / (30 - IIEF pré) ] x 100; $R^{2}$, fração da variabilidade da variável dependente que é explicada por este modelo; RMSE, raiz quadrada média do erro; $\beta$, estimativa de efeito. Todas as variáveis contínuas, exceto a idade, foram normalizadas. Todos os modelos foram corrigidos por idade, consumo de etanol, tabagismo, diabetes mellitus e uso de anti-hipertensivos. 
Tabela IV: Análise de regressão linear multivariada mostrando os efeitos da etiologia da DE e do uso do omeprazol e do alopurinol sobre os marcadores bioquímicos relacionados à via do óxido nítrico

\begin{tabular}{|c|c|c|c|c|c|c|c|c|c|c|}
\hline \multirow[t]{2}{*}{ Modelo } & \multicolumn{2}{|c|}{$\begin{array}{c}\text { Nitrito } \\
\mathbf{R}^{2}=0,063 \\
\text { RMSE }=0,217\end{array}$} & \multicolumn{2}{|c|}{$\begin{array}{c}\text { ADMA } \\
\mathbf{R}^{2}=0,044 \\
\text { RMSE }=0,163\end{array}$} & \multicolumn{2}{|c|}{$\begin{array}{c}\text { Atividade das } \\
\text { arginases } \\
\mathbf{R}^{2}=0,036 \\
\text { RMSE }=0,305\end{array}$} & \multicolumn{2}{|c|}{$\begin{array}{c}\text { Arginase } 1 \\
R^{2}=0,088 \\
\text { RMSE }=0,469\end{array}$} & \multicolumn{2}{|c|}{$\begin{array}{c}\text { Arginase } 2 \\
\mathbf{R}^{2}=0,399 \\
\text { RMSE = 0,231 }\end{array}$} \\
\hline & $\beta$ & $\mathbf{P}$ & $\beta$ & $\mathbf{P}$ & $\boldsymbol{\beta}$ & $\mathbf{P}$ & $\beta$ & $\mathbf{P}$ & $\beta$ & $\mathbf{P}$ \\
\hline Idade & $-0,002$ & 0,386 & $-0,001$ & 0,452 & 0,002 & 0,517 & 0,004 & 0,385 & $-0,002$ & 0,291 \\
\hline \multicolumn{11}{|l|}{ Tabagismo } \\
\hline Fumante & 0,024 & 0,513 & $-0,037$ & 0,225 & 0,077 & 0,142 & 0,053 & 0,515 & 0,047 & 0,231 \\
\hline Ex-fumante & $-0,002$ & 0,931 & 0,019 & 0,404 & $-0,040$ & 0,290 & $-0,066$ & 0,269 & $-0,021$ & 0,465 \\
\hline Não fumante & $-0,022$ & 0,437 & 0,018 & 0,423 & $-0,037$ & 0,354 & 0,013 & 0,840 & $-0,026$ & 0,378 \\
\hline Etilismo & $-0,012$ & 0,725 & 0,022 & 0,392 & $-0,034$ & 0,482 & $-0,073$ & 0,348 & $-0,070$ & 0,053 \\
\hline Ser diabético & 0,018 & 0,388 & $-0,004$ & 0,810 & $-0,032$ & 0,284 & $-0,010$ & 0,832 & $-0,013$ & 0,561 \\
\hline Uso de anti-hipertensivo & 0,025 & 0,183 & 0,005 & 0,738 & $-0,023$ & 0,373 & $-0,029$ & 0,494 & 0,022 & 0,271 \\
\hline \multicolumn{11}{|l|}{ Etiologia da DE } \\
\hline DEC & 0,023 & 0,296 & $-0,024$ & 0,201 & 0,008 & 0,798 & 0,138 & $0,008^{*}$ & 0,154 & $<0,0001^{*}$ \\
\hline DEPP & $-0,023$ & 0,296 & 0,024 & 0,201 & $-0,008$ & 0,798 & $-0,138$ & $0,008^{*}$ & $-0,154$ & $<0,0001^{*}$ \\
\hline Uso de omeprazol & 0,023 & 0,492 & 0,016 & 0,574 & $-0,029$ & 0,537 & 0,053 & 0,507 & $-0,063$ & 0,080 \\
\hline Uso de alopurinol & 0,008 & 0,859 & 0,003 & 0,937 & $-0,025$ & 0,701 & 0,022 & 0,858 & 0,020 & 0,712 \\
\hline
\end{tabular}

DEC, disfunção erétil clínica; DEPP, disfunção erétil pós-prostatectomia; $\Delta$ IIEF = IIEF pós tratamento - IIEF pré tratamento; $\Delta$ IIEF \% $=[\Delta I I E F /(30-I I E F$ pré)] x 100; $R^{2}$, fração da variabilidade da variável dependente que é explicada por este modelo; RMSE, raiz quadrada média do erro; $\beta$, estimativa de efeito. Todas as variáveis contínuas, exceto a idade, foram normalizadas. Todos os modelos foram corrigidos por idade, consumo de etanol, tabagismo, diabetes mellitus e uso de anti-hipertensivos. 
As análises corrigidas, apresentadas nesta seção, demonstram que a etiologia da disfunção erétil (DE clínica ou DE pós-prostatectomia) influencia as concentrações de arginase 1 e arginase 2. Conforme podemos observar, as concentrações tanto de arginase 1 quanto de arginase 2 são menores no grupo portador de disfunção erétil pós-prostatectomia. 


\section{DISCUSSÃO}

Ao comparar homens sem disfunção erétil com sujeitos portadores da doença, espera-se encontrar diferenças significativas para o score IIEF e as medidas derivadas desta variável, tendo em vista que o questionário avalia tanto a presença quanto o grau de disfunção erétil $[10,11]$. No presente trabalho, além dessa diferença já esperada, pudemos observar uma tendência de valores menores da pontuação IIEF para o grupo de homens com DE que também tem diabetes. Essa tendência é um indicativo de que o grau de disfunção erétil nos homens diabéticos é mais severo do que em homens sem a doença, o que já foi mostrado em diversos outros estudos [65, 92-95]. Além da severidade da disfunção erétil, o diabetes também está implicado em sua prevalência: uma meta-análise publicada em 2017 estimou a prevalência de DE em diabéticos em de cerca de 52,5\% [96]. Outro estudo aponta que até $75 \%$ dos casos de disfunção erétil podem ser consequência direta de prejuízos decorrentes do diabetes [97].

Um estudo conduzido em tecido humano de corpos cavernosos (homens com disfunção erétil submetidos ao implante de prótese peniana) demonstrou uma correlação negativa significativa entre o tempo do diabetes e o relaxamento neurogênico do tecido cavernoso - ou seja, quanto maior a duração dessa comorbidade, menor o relaxamento produzido [95]. Outro achado importante da mesma pesquisa foi a redução pronunciada da vasodilatação mediada por acetilcolina (ou seja, dependente do endotélio) no tecido cavernoso dos diabéticos quando comparados aos não diabéticos [95].

Outro estudo mais recente, também desenvolvido com tecido humano de corpos cavernosos, chegou a resultados similares aos discutidos anteriormente: 
tanto o relaxamento neurogênico quanto o mediado pelo endotélio foram pronunciadamente menores nos diabéticos quando comparados a outros portadores de disfunção erétil [65]. Além disso, observou-se que o prejuízo causado pelo DM no relaxamento do tecido cavernoso e de artérias penianas de resistência não foi comum a outras situações sabidamente associadas a disfunção endotelial (como hipercolesterolemia e hipertensão arterial), isto é, o grau de relaxamento dos tecidos foi similar em todos os grupos com disfunção erétil, sendo pronunciadamente menor apenas nos diabéticos [65].

Um terceiro estudo sobre o impacto do diabetes na gravidade da DE e na resposta ao tratamento com inibidores de PDE-5 também demonstrou que homens diabéticos com disfunção erétil apresentaram menores valores basais de IIEF [93], o que reforça a tendência observada em nossas análises.

As evidências de prejuízo funcional nos diabéticos nas pesquisas citadas anteriormente ajudam a explicar a alta prevalência de DE nessa população e corroboram a importância da disfunção endotelial na fisiopatologia da doença [15, 95-97].

Assim como no teste anterior, quando avaliamos a função erétil nos grupos controle, DEC/DM e DEC/DM em uso de insulina, também encontramos diferença estatística - já prevista. Apesar do tratamento com insulina estar, de forma geral, atrelado a casos mais graves de diabetes $[68,71]$ e do conhecido papel dessa doença no desenvolvimento da disfunção endotelial [98], não houve associação entre o score IIEF e o uso do hormônio. Há evidências na literatura de que a hiperinsulinemia contribui para o aumento do estresse oxidativo e nitrosativo via NADPH oxidase, culminando no processo de disfunção endotelial [72, 99, 100]. Levando em consideração a gravidade do diabetes nos sujeitos tratados com 
insulina e seu papel na disfunção endotelial, esperávamos encontrar valores menores de IIEF neste grupo em relação àqueles diabéticos que não fazem uso de insulina - o que não se concretizou.

Conforme apresentado na figura 1.1.2, as concentrações de nitrito foram estatisticamente maiores nos grupos DEC e DEC/DM do que nos controles. Este dado, apesar de contraintuitivo, foi reportado também em outro estudo do nosso grupo publicado em 2019: as concentrações de nitrito nos portadores de disfunção erétil foram maiores que as encontradas no grupo controle [101]. A relação entre o óxido nítrico e a função erétil também foi explorada na publicação, e encontrou-se uma correlação negativa entre as concentrações plasmáticas de nitrito e a função erétil nos portadores de DE (quanto menor a pontuação no IIEF e, portanto, maior a gravidade da doença, maior a concentração de nitrito) [101]. Concentrações aumentadas de nitrito também estão relacionadas a piores respostas no tratamento da disfunção erétil com inibidores de PDE-5 (o que será discutido posteriormente) $[64,102]$

De forma semelhante, as concentrações de nitrito foram significativamente maiores tanto no grupo DEC/DM quanto no grupo DEC/DM que faz uso de insulina, quando comparados aos controles. Esses resultados são coerentes com os dados apresentados anteriormente e o estudo do grupo supracitado [101]. Apesar de não significativa, nota-se que a concentração média de nitrito nos usuários de insulina é maior do que aquela no grupo DE que não utiliza o fármaco. Essa tendência está de acordo com a hipótese de que ao induzir o estresse oxidativo, a insulina gera disfunção endotelial $[72,99,100]$ e culmina num prejuízo ainda mais pronunciado da função erétil. 
O grupo DEC/DM, quando comparado aos controles, apresentou concentrações maiores de arginase 2. Níveis aumentados de ARG2 em portadores de disfunção erétil foram descritos num estudo do grupo publicado em 2015; entretanto, os sujeitos não foram divididos entre diabéticos e não diabéticos [56]. No mesmo estudo, os níveis dessa isoforma da enzima também foram associados positivamente ao risco para disfunção erétil (ou seja, maiores concentrações de ARG2 estão relacionadas a um risco aumentado para desenvolvimento de DE) [56]. Considerando os resultados aqui encontrados, é provável que essa associação encontrada por Lacchini e colaboradores seja resultado da presença de diabéticos no grupo disfunção erétil, que tornaram as concentrações de arginase 2 nesse grupo significativamente maiores que nos controles. Um estudo realizado em amostras de tecido cavernoso humano reforça essa hipótese: os testes mostraram que a expressão de ARG2 estava aumentada nos diabéticos (que também eram portadores de DE), quando comparados aos controles [103]. Diferentemente de $A R G 1$, a isoforma ARG2 parece desempenhar como principal função o controle da homeostase de L-arginina [55]. Por sua presença no tecido cavernoso, foi proposto que a inibição da atividade de ARG2 seria capaz de melhorar o fluxo sanguíneo peniano sem alterações significativas na pressão arterial sistêmica, constituindo um possível alvo terapêutico para o tratamento da disfunção erétil [55].

No que diz respeito à resposta ao sildenafil, encontramos uma diferença significativa nos valores de IIEF pós-tratamento entre os grupos DEC e DEC/DM, tendo o primeiro apresentado valores maiores, o que se traduz numa resposta melhor à terapia da disfunção erétil. Essa diferença também era esperada, levando em conta as análises do IIEF e das concentrações de nitrito discutidas anteriormente, e os estudos já citados, que relacionaram o diabetes com uma piora 
na função endotelial (e, como consequência, na função erétil) [65, 92-95], assim como aquele que associa maiores concentrações de nitrito a uma pior função erétil [101]. Junta-se a isso os estudos que comprovam a existência de uma correlação negativa entre os níveis de nitrito e a resposta à terapia com inibidores de PDE-5 em disfunção erétil $[64,102]$. Apesar do mecanismo desse efeito não ser conhecido, supõe-se que a síntese reduzida de NO, traduzida em concentrações menores de óxido nítrico biodisponível, acarrete na sensibilização da enzima guanilato ciclase solúvel (que passaria então a responder mais pronunciadamente a menores concentrações de NO,) e que outros mecanimos adjacentes possam estar envolvidos no aumento do NO, como processos inflamatórios (com indução da isoforma iNOS) [64, 102]. Esses estudos também demonstram que as concentrações de nitrito e de ADMA estão negativamente correlacionadas, o que significa que níveis maiores de nitrito indicam a presença de concentrações menores de ADMA $[64,102]$. Apesar de não significativa, observamos que os níveis de ADMA nos controles parecem maiores que no grupo DEC/DM, que, por sua vez, parece ter médias ligeiramente maiores que as do grupo DEC/DM tratado com insulina. Vale ressaltar que essa tendência é inversa ao que ocorre com o nitrito, o que parece estar de acordo com a correlação entre ambas as substâncias nos estudos supracitados $[64,102]$. Ainda que não haja diferença significativa, nota-se que o grupo DEC apresenta valores maiores de $\triangle \mathrm{IIEF}$ percentual quando comparado ao grupo DEC/DM - caso houvesse diferença estatística nessa análise, esse dado também estaria de acordo com a evidência existente de que o diabetes está relacionado a maior comprometimento da função endotelial, e, consequentemente, a uma piora da função erétil e da resposta ao sildenafil [23, 65]. 
Fica claro, de acordo com as análises discutidas até este ponto, que os portadores de DM respondem menos ao tratamento com sildenafil. Contudo, os parâmetros bioquímicos avaliados não justificam essa associação. Levando em consideração a evidência existente na literatura, a pior resposta ao sildenafil pode ser justificada por processos adjacentes, como por exemplo, inflamação ativa, ou alterações estruturais que possam causar fibrose tecidual [104, 105]. De fato, há descrita na literatura uma associação entre marcadores inflamatórios e a ocorrência de complicações relacionadas ao diabetes [104].

Conforme explicitado na seção "Resultados", grande parte dos homens portadores de disfunção erétil clínica estudados são ex-tabagistas e deixaram de fumar há mais de 10 anos. Estudos demonstram que cessar prolongadamente o hábito de fumar diminui tanto a mortalidade quanto o risco cardiovascular [107-109]. Além disso, outras publicações mostram que interromper o hábito de fumar leva a uma reversão considerável da disfunção endotelial em períodos menores que 10 anos [110-117] e à diminuição tanto do estresse oxidativo quanto inflamatório [116118], o que corrobora a ideia de que esse tempo decorrido minimiza os efeitos maléficos do tabagismo que possam estar associados à DE.

Finalmente, levando em consideração a importância da XOR no estresse oxidativo e nitrosativo (pela produção de espécies reativas de oxigênio e de nitrogênio) [74, 83], e os efeitos dos fármacos omeprazol e alopurinol sobre essa enzima especificamente (que são antagônicos) [77, 81], esperávamos encontrar diferenças estatísticas entre os parâmetros avaliados nas duas primeiras seções do capítulo 3, o que não ocorreu. De acordo com a evidência existente, o uso do omeprazol teria consequências negativas na função erétil e nos parâmetros bioquímicos analisados [77-80]. Entretanto, pudemos notar certas tendências: na 
seção 3.1, tanto o IIEF pós-tratamento com sildenafil quanto o $\Delta$ IIEF aparentam estar maiores no grupo que não utiliza omeprazol (o que viria de encontro às nossas expectativas, considerando que o omeprazol induz o aumento da atividade da XOR, o que culminaria numa produção maior de espécies reativas de oxigênio e de nitrogênio, e no processo de estresse oxidativo e nitrosativo). Ainda para as análises que levaram em conta o uso de omeprazol, a de concentração de arginase 2 teve um valor de $P$ próximo a 0,05. A tendência dessa análise indica que as concentrações de ARG2 parecem menores no grupo que utiliza o fármaco; no entanto, não foram encontradas evidências na literatura que justifiquem essa tendência.

Em relação ao uso de alopurinol, era esperado um efeito oposto às expectativas para o omeprazol, isto é, melhora tanto nos parâmetros de função erétil quanto nos bioquímicos $[81,84,85]$, o que também não se concretizou. Apesar disso, notamos que para o $\triangle \mathrm{IIEF}$, houve uma tendência de valores maiores para o grupo que utiliza o fármaco - caso a diferença fosse significativa, esse resultado iria de encontro ao esperado, ou seja, que o uso de alopurinol tem consequências positivas na terapia com sildenafil (melhor resposta). Não foram encontradas evidências na literatura que relacionem o alopurinol diretamente à via das NOS.

Entretanto, na terceira parte do capítulo 3, pudemos observar algumas diferenças estatísticas nas análises corrigidas que levaram em consideração tanto a etiologia da DE quanto o uso do omeprazol e do alopurinol, além de outros fatores de confusão (idade, tabagismo, etilismo, diabetes mellitus e uso de antihipertensivos). De acordo com o modelo proposto, a etiologia da disfunção erétil influencia as concentrações de arginase 1 e arginase 2: os homens que pertencem ao grupo DE pós-prostatectomia tiveram redução de ambas isoformas da enzima. 
Apenas um estudo encontrado na literatura avaliou as concentrações de arginase 1 e arginase 2 em portadores de DEC e de DEPP [106]. Nele, são descritas correlações negativas entre as concentrações plasmáticas de ARG1 e a resposta ao sildenafil no grupo DE clínica, e entre a atividade das arginases e a resposta ao sildenafil no grupo DE pós-prostatectomia [106]. Não foram encontrados estudos que associassem as concentrações de ARG1 e ARG2 à etiologia da disfunção erétil. Além disso, os resultados encontrados especificamente nesta seção do nosso estudo devem ser vistos com cautela, tendo em mente o número pequeno de sujeitos nos grupos.

Este trabalho possui algumas limitações, como por exemplo, o número reduzido de sujeitos para algumas das análises realizadas, e a necessidade de agrupar homens com disfunção erétil de diferentes etiologias (DE clínica e DE pósprostatectomia) para os testes das duas primeiras seções do capítulo 3; o fato de não termos critérios objetivos para confirmar as respostas dos participantes no questionário IIEF (algumas respostas podem não condizer exatamente com a realidade); e, por serem amostras oriundas de biorrepositório, uma dificuldade para selecionar grupos atendessem a determinados parâmetros, como, por exemplo, o uso de determinados fármacos, que tiveram um $n$ amostral pequeno. Os aspectos positivos deste trabalho, por outro lado, residem nas relações desenhadas entre os parâmetros escolhidos para análise (como por exemplo, a avaliação de fármacos que tem ações antagônicas sobre uma mesma enzima), na detecção de lacunas do conhecimento científico (como a relação entre omeprazol e arginases, as possíveis ações do alopurinol na via das NO sintases e o impacto da etiologia da DE nas concentrações de arginases), e nas perspectivas futuras de aumentar tanto o número de participantes, para avaliar de forma mais fidedigna a influência do uso de 
omeprazol e de alopurinol sobre a terapia da disfunção erétil, como o próprio escopo do estudo, com a possibilidade de avaliarmos dados de polimorfismos genéticos da XOR, por exemplo, dentre outros ensaios adicionais que podem ser incluídos. Além disso, para as análises bioquímicas, temos um número de indivíduos que nos possibilita resultados robustos. Tendo em vista todos esses aspectos, os dados aqui gerados e as lacunas a serem preenchidas, é provável que haja uma continuidade deste trabalho no projeto de doutorado, ampliando essa linha de pesquisa. 
Os principais achados da nossa pesquisa foram as concentrações maiores de nitrito nos grupos formados por portadores de disfunção erétil quando comparados aos controles (tanto na análise com controles $x$ DEC não diabéticos $x$ DEC diabéticos, quanto na análise com controles $x$ DEC diabéticos $\times$ DEC diabéticos que utilizam insulina), as concentrações aumentadas de arginase 2 no grupo DEC diabéticos quando comparado ao grupo controle, e o score IIEF pós tratamento com sildenafil maior no grupo DEC quando comparado ao grupo DEC diabéticos. Esses dados reforçam as evidências de que níveis elevados de nitrito estão relacionados a piores desfechos (concentrações maiores nos pacientes que nos controles, e relacionadas a piores respostas ao sildenafil) e do impacto negativo do diabetes na função erétil. 


\section{REFERÊNCIAS}

1. Association, A.P., Diagnostic and statistical manual of mental disorders (DSM5). 2013: American Psychiatric Pub.

2. Corona, G., et al., Age-related changes in general and sexual health in middle-aged and older men: results from the European Male Ageing Study (EMAS). J Sex Med, 2010. 7(4 Pt 1): p. 1362-80.

3. Hackett, G., et al., British Society for Sexual Medicine Guidelines on the Management of Erectile Dysfunction in Men-2017. J Sex Med, 2018. 15(4): p. 430-457.

4. Abdo, C.H., et al., [Erectile dysfunction: results of the Brazilian Sexual Life Study]. Rev Assoc Med Bras (1992), 2006. 52(6): p. 424-9.

5. Latini, D.M., et al., Clinical and psychosocial characteristics of men with erectile dysfunction: baseline data from ExCEED. J Sex Med, 2006. 3(6): p. 1059-1067.

6. Huri, H.Z., et al., Association of psychological factors, patients' knowledge, and management among patients with erectile dysfunction. Patient Prefer Adherence, 2016. 10: p. 807-23.

7. Feldman, H.A., et al., Impotence and its medical and psychosocial correlates: results of the Massachusetts Male Aging Study. J Urol, 1994. 151(1): p. 54-61.

8. Yafi, F.A., et al., Erectile dysfunction. Nat Rev Dis Primers, 2016. 2: p. 16003.

9. Hatzimouratidis, K., et al., Guidelines on male sexual dysfunction: erectile dysfunction and premature ejaculation. Eur Urol, 2010. 57(5): p. 804-14. 
10. Rosen, R.C., et al., The international index of erectile function (IIEF): $a$ multidimensional scale for assessment of erectile dysfunction. Urology, 1997. 49(6): p. 822-30.

11. Gonzáles, A.I., et al., Validation of the International Index of Erectile Function (IIFE) for use in Brazil. Arq Bras Cardiol, 2013. 101(2): p. 176-82.

12. Tortora, G.J. and M.T. Nielsen, Principles of human anatomy. 12th ed. ed. 2012 Wiley; Chichester: John Wiley [distributor].

13. Anatomy and physiology of erection: pathophysiology of erectile dysfunction. Int J Impot Res, 2003. 15 Suppl 7: p. S5-8.

14. Mulcahy, J.J., Male sexual function : a guide to clinical management. 2001: Humana Press.

15. Gratzke, C., et al., Anatomy, physiology, and pathophysiology of erectile dysfunction. J Sex Med, 2010. 7(1 Pt 2): p. 445-75.

16. El-Sakka, A.I. and T.F. Lue, Physiology of penile erection. ScientificWorldJournal, 2004. 4 Suppl 1: p. 128-34.

17. Christ, G.J. and T. Lue, Physiology and biochemistry of erections. Endocrine, 2004. 23(2-3): p. 93-100.

18. Irwin, G.M., Erectile Dysfunction. Prim Care, 2019. 46(2): p. 249-255.

19. Fazio, L. and G. Brock, Erectile dysfunction: management update. CMAJ, 2004. 170(9): p. 1429-37.

20. Bø, K.e., et al., Evidence-based physical therapy for the pelvic floor : bridging science and clinical practice. Second ed. 2015: Churchill Livingstone. 448.

21. Castiglione, F., D.J. Ralph, and A. Muneer, Surgical Techniques for Managing Post-prostatectomy Erectile Dysfunction. Curr Urol Rep, 2017. 18(11): p. 90. 
22. Salonia, A., et al., Prevention and management of post prostatectomy erectile dysfunction. Transl Androl Urol, 2015. 4(4): p. 421-37.

23. de Tejada, I.S., Therapeutic strategies for optimizing PDE-5 inhibitor therapy in patients with erectile dysfunction considered difficult or challenging to treat. Int J Impot Res, 2004. 16 Suppl 1: p. S40-2.

24. Gava, G., R. Seracchioli, and M.C. Meriggiola, Urogenital and Reproductive Disorders, in Health and gender : resilience and vulnerability factors for women's health in the contemporary society. 2019, Springer Nature.

25. Barrett, K.E. and W.F. Ganong, Ganong's review of medical physiology. 24th ed. ed. 2012: McGraw Hill Medical.

26. Rang, H.P., et al., Rang and Dale's pharmacology. Eight edition. International edition. ed. 2015. xv, 760 pages.

27. Oliveira-Paula, G.H., R. Lacchini, and J.E. Tanus-Santos, Inducible nitric oxide synthase as a possible target in hypertension. Curr Drug Targets, 2014. 15(2): p. $164-74$.

28. Palmer, R.M., D.S. Ashton, and S. Moncada, Vascular endothelial cells synthesize nitric oxide from L-arginine. Nature, 1988. 333(6174): p. 664-6.

29. Schmidt, H.H., et al., Arginine is a physiological precursor of endotheliumderived nitric oxide. Eur J Pharmacol, 1988. 154(2): p. 213-6.

30. Chin, D. and A.R. Means, Calmodulin: a prototypical calcium sensor. Trends Cell Biol, 2000. 10(8): p. 322-8.

31. McCabe, T.J., et al., Enhanced electron flux and reduced calmodulin dissociation may explain "calcium-independent" eNOS activation by phosphorylation. J Biol Chem, 2000. 275(9): p. 6123-8. 
32. Förstermann, U. and W.C. Sessa, Nitric oxide synthases: regulation and function. Eur Heart J, 2012. 33(7): p. 829-37, 837a-837d.

33. Ignarro, L.J., et al., Endothelium-derived relaxing factor produced and released from artery and vein is nitric oxide. Proc Natl Acad Sci U S A, 1987. 84(24): p. 9265-9.

34. Zhao, Y., P.M. Vanhoutte, and S.W. Leung, Vascular nitric oxide: Beyond eNOS. J Pharmacol Sci, 2015. 129(2): p. 83-94.

35. Liu, Z., et al., Critical role of vascular peroxidase 1 in regulating endothelial nitric oxide synthase. Redox Biol, 2017. 12: p. 226-232.

36. Li, H., S. Horke, and U. Förstermann, Vascular oxidative stress, nitric oxide and atherosclerosis. Atherosclerosis, 2014. 237(1): p. 208-19.

37. Lundberg, J.O., E. Weitzberg, and M.T. Gladwin, The nitrate-nitrite-nitric oxide pathway in physiology and therapeutics. Nat Rev Drug Discov, 2008. 7(2): p. $156-67$.

38. Cantu-Medellin, N. and E.E. Kelley, Xanthine oxidoreductase-catalyzed reduction of nitrite to nitric oxide: insights regarding where, when and how. Nitric Oxide, 2013. 34: p. 19-26.

39. Maia, L.B. and J.J.G. Moura, Putting xanthine oxidoreductase and aldehyde oxidase on the NO metabolism map: Nitrite reduction by molybdoenzymes. Redox Biol, 2018. 19: p. 274-289.

40. Oliveira-Paula, G.H., R. Lacchini, and J.E. Tanus-Santos, Endothelial nitric oxide synthase: From biochemistry and gene structure to clinical implications of NOS3 polymorphisms. Gene, 2016. 575(2 Pt 3): p. 584-99.

41. Sriram, K., et al., Shear-Induced Nitric Oxide Production by Endothelial Cells. Biophys J, 2016. 111(1): p. 208-21. 
42. Nagassaki, S., et al., eNOS genotype is without effect on circulating nitrite/nitrate level in healthy male population. Thromb Res, 2005. 115(5): p. 375-9.

43. Yuyun, M.F., L.L. Ng, and G.A. Ng, Endothelial dysfunction, endothelial nitric oxide bioavailability, tetrahydrobiopterin, and 5-methyltetrahydrofolate in cardiovascular disease. Where are we with therapy? Microvasc Res, 2018. 119: p. 7-12.

44. Palmer, R.M., et al., L-arginine is the physiological precursor for the formation of nitric oxide in endothelium-dependent relaxation. Biochem Biophys Res Commun, 1988. 153(3): p. 1251-6.

45. Rees, D.D., R.M. Palmer, and S. Moncada, Role of endothelium-derived nitric oxide in the regulation of blood pressure. Proc Natl Acad Sci U S A, 1989. 86(9): p. 3375-8.

46. Closs, E.I., et al., Interference of L-arginine analogues with L-arginine transport mediated by the $y+$ carrier hCAT-2B. Nitric Oxide, 1997. 1(1): p. 6573.

47. Leineweber, K., S. Moosmang, and D. Paulson, Genetics of NO Deficiency. Am J Cardiol, 2017. 120(8S): p. S80-S88.

48. Tain, Y.L. and C.N. Hsu, Toxic Dimethylarginines: Asymmetric Dimethylarginine (ADMA) and Symmetric Dimethylarginine (SDMA). Toxins (Basel), 2017. 9(3).

49. Schwedhelm, E., Quantification of ADMA: analytical approaches. Vasc Med, 2005. 10 Suppl 1: p. S89-95.

50. El-Khoury, J.M., et al., A simple and fast liquid chromatography-tandem mass spectrometry method for measurement of underivatized $L$-arginine, symmetric 
dimethylarginine, and asymmetric dimethylarginine and establishment of the reference ranges. Anal Bioanal Chem, 2012. 402(2): p. 771-9.

51. Martens-Lobenhoffer, J. and S.M. Bode-Böger, Chromatographic-mass spectrometric methods for the quantification of L-arginine and its methylated metabolites in biological fluids. J Chromatogr B Analyt Technol Biomed Life Sci, 2007. 851(1-2): p. 30-41.

52. Martens-Lobenhoffer, J. and S.M. Bode-Böger, Mass spectrometric quantification of L-arginine and its pathway related substances in biofluids: the road to maturity. J Chromatogr B Analyt Technol Biomed Life Sci, 2014. 964: p. 89-102.

53. Caldwell, R.B., et al., Arginase: an old enzyme with new tricks. Trends Pharmacol Sci, 2015. 36(6): p. 395-405.

54. Durante, W., F.K. Johnson, and R.A. Johnson, Arginase: a critical regulator of nitric oxide synthesis and vascular function. Clin Exp Pharmacol Physiol, 2007. 34(9): p. 906-11.

55. Cama, E., et al., Human arginase II: crystal structure and physiological role in male and female sexual arousal. Biochemistry, 2003. 42(28): p. 8445-51.

56. Lacchini, R., et al., Relationship between Arginase 1 and Arginase 2 levels and genetic polymorphisms with erectile dysfunction. Nitric Oxide, 2015. 51: p. 36-42.

57. Wobst, J., H. Schunkert, and T. Kessler, Genetic alterations in the NO-cGMP pathway and cardiovascular risk. Nitric Oxide, 2018. 76: p. 105-112.

58. Osterloh, I.H., The discovery and development of Viagra® (sildenafil citrate), in Sildenafil. 2004: Birkhäuser Basel. 
59. Paulis, L., R. Rajkovicova, and F. Simko, New developments in the pharmacological treatment of hypertension: dead-end or a glimmer at the horizon? Curr Hypertens Rep, 2015. 17(6): p. 557.

60. Yugar-Toledo, J.C., et al., Cyclic guanosine monophosphate phosphodiesterase-5 inhibitor promotes an endothelium NO-dependent-like vasodilation in patients with refractory hypertension. Nitric Oxide, 2007. 16(3): p. 315-21.

61. Milenkovic, U., et al., An update on emerging drugs for the treatment of erectile dysfunction. Expert Opin Emerg Drugs, 2018. 23(4): p. 319-330.

62. Goldstein, I., et al., Efficacy and Safety of Sildenafil by Age in Men With Erectile Dysfunction. J Sex Med, 2016. 13(5): p. 852-9.

63. Glina, S., et al., Efficacy and safety of flexible-dose oral sildenafil citrate (Viagra) in the treatment of erectile dysfunction in Brazilian and Mexican men. Int J Impot Res, 2002. 14 Suppl 2: p. S27-32.

64. Muniz, J.J., et al., Low nitric oxide bioavailability is associated with better responses to sildenafil in patients with erectile dysfunction. Naunyn Schmiedebergs Arch Pharmacol, 2013. 386(9): p. 805-11.

65. Angulo, J., et al., Diabetes exacerbates the functional deficiency of NO/cGMP pathway associated with erectile dysfunction in human corpus cavernosum and penile arteries. J Sex Med, 2010. 7(2 Pt 1): p. 758-68.

66. Petersmann, A., et al., Definition, Classification and Diagnosis of Diabetes Mellitus. Exp Clin Endocrinol Diabetes, 2019. 127(S 01): p. S1-S7.

67. Guthrie, R.A. and D.W. Guthrie, Pathophysiology of diabetes mellitus. Crit Care Nurs Q, 2004. 27(2): p. 113-25. 
68. Skyler, J.S., et al., Differentiation of Diabetes by Pathophysiology, Natural History, and Prognosis. Diabetes, 2017. 66(2): p. 241-255.

69. Bertoluci, M.C., et al., Brazilian guidelines on prevention of cardiovascular disease in patients with diabetes: a position statement from the Brazilian Diabetes Society (SBD), the Brazilian Cardiology Society (SBC) and the Brazilian Endocrinology and Metabolism Society (SBEM). Diabetol Metab Syndr, 2017. 9: p. 53.

70. Balakumar, P., K. Maung-U, and G. Jagadeesh, Prevalence and prevention of cardiovascular disease and diabetes mellitus. Pharmacol Res, 2016. 113(Pt A): p. 600-609.

71. Tan, S.Y., et al., Type 1 and 2 diabetes mellitus: A review on current treatment approach and gene therapy as potential intervention. Diabetes Metab Syndr, 2019. 13(1): p. 364-372.

72. Meza, C.A., et al., Endothelial Dysfunction: Is There a Hyperglycemia-Induced Imbalance of NOX and NOS? Int J Mol Sci, 2019. 20(15).

73. Cryer, M.J., T. Horani, and D.J. DiPette, Diabetes and Hypertension: A Comparative Review of Current Guidelines. J Clin Hypertens (Greenwich), 2016. 18(2): p. 95-100.

74. Battelli, M.G., et al., The role of xanthine oxidoreductase and uric acid in metabolic syndrome. Biochim Biophys Acta Mol Basis Dis, 2018. 1864(8): $\mathrm{p}$. 2557-2565.

75. Freeland, B. and M.S. Farber, A Review of Insulin for the Treatment of Diabetes Mellitus. Home Healthc Now, 2016. 34(8): p. 416-23.

76. Hostalek, U., M. Gwilt, and S. Hildemann, Therapeutic Use of Metformin in Prediabetes and Diabetes Prevention. Drugs, 2015. 75(10): p. 1071-94. 
77. Pinheiro, L.C., et al., Omeprazole impairs vascular redox biology and causes xanthine oxidoreductase-mediated endothelial dysfunction. Redox Biol, 2016. 9: p. 134-143.

78. Pinheiro, L.C., et al., Increase in gastric $\mathrm{pH}$ reduces hypotensive effect of oral sodium nitrite in rats. Free Radic Biol Med, 2012. 53(4): p. 701-9.

79. Montenegro, M.F., et al., Blood Pressure-Lowering Effect of Orally Ingested Nitrite Is Abolished by a Proton Pump Inhibitor. Hypertension, 2017. 69(1): $\mathrm{p}$. 23-31.

80. Pinheiro, L.C., et al., Gastric S-nitrosothiol formation drives the antihypertensive effects of oral sodium nitrite and nitrate in a rat model of renovascular hypertension. Free Radic Biol Med, 2015. 87: p. 252-62.

81. Day, R.O., et al., Xanthine oxidoreductase and its inhibitors: relevance for gout. Clin Sci (Lond), 2016. 130(23): p. 2167-2180.

82. Battelli, M.G., et al., Xanthine Oxidoreductase in Drug Metabolism: Beyond a Role as a Detoxifying Enzyme. Curr Med Chem, 2016. 23(35): p. 4027-4036.

83. Battelli, M.G., et al., Xanthine Oxidoreductase-Derived Reactive Species: Physiological and Pathological Effects. Oxid Med Cell Longev, 2016. 2016: p. 3527579.

84. Chen, C., J.M. Lü, and Q. Yao, Hyperuricemia-Related Diseases and Xanthine Oxidoreductase (XOR) Inhibitors: An Overview. Med Sci Monit, 2016. 22: p. 2501-12.

85. Maclsaac, R.L., et al., Allopurinol and Cardiovascular Outcomes in Adults With Hypertension. Hypertension, 2016. 67(3): p. 535-40.

86. Dubreuil, M., et al., Allopurinol initiation and all-cause mortality in the general population. Ann Rheum Dis, 2015. 74(7): p. 1368-72. 
87. Hoey, B.M., J. Butler, and B. Halliwell, On the specificity of allopurinol and oxypurinol as inhibitors of xanthine oxidase. A pulse radiolysis determination of rate constants for reaction of allopurinol and oxypurinol with hydroxyl radicals. Free Radic Res Commun, 1988. 4(4): p. 259-63.

88. Das, D.K., et al., Role of xanthine oxidase inhibitor as free radical scavenger: a novel mechanism of action of allopurinol and oxypurinol in myocardial salvage. Biochem Biophys Res Commun, 1987. 148(1): p. 314-9.

89. Vickneson, K. and J. George, Xanthine Oxidoreductase Inhibitors. Handb Exp Pharmacol, 2020.

90. Vicente, F.B., et al., Quantification of Arginine and Its Methylated Derivatives in Plasma by High-Performance Liquid Chromatography Tandem Mass Spectrometry (LC-MS/MS). Methods Mol Biol, 2016. 1378: p. 21-30.

91. Fleszar, M.G., et al., Quantitative Analysis of I-Arginine, Dimethylated Arginine Derivatives, I-Citrulline, and Dimethylamine in Human Serum Using Liquid Chromatography-Mass Spectrometric Method. Chromatographia, 2018. 81(6): p. $911-921$.

92. Trebatický, B., et al., Role of oxidative stress, adiponectin and endoglin in the pathophysiology of erectile dysfunction in diabetic and non-diabetic men. Physiol Res, 2019. 68(4): p. 623-631.

93. Fonseca, V., et al., Impact of diabetes mellitus on the severity of erectile dysfunction and response to treatment: analysis of data from tadalafil clinical trials. Diabetologia, 2004. 47(11): p. 1914-23.

94. Yaman, O., et al., The effect of diabetes mellitus treatment and good glycemic control on the erectile function in men with diabetes mellitus-induced erectile dysfunction: a pilot study. J Sex Med, 2006. 3(2): p. 344-8. 
95. Saenz de Tejada, I., et al., Impaired neurogenic and endothelium-mediated relaxation of penile smooth muscle from diabetic men with impotence. $\mathrm{N}$ Engl J Med, 1989. 320(16): p. 1025-30.

96. Kouidrat, Y., et al., High prevalence of erectile dysfunction in diabetes: a systematic review and meta-analysis of 145 studies. Diabet Med, 2017. 34(9): p. 1185-1192.

97. De Young, L., et al., Oxidative stress and antioxidant therapy: their impact in diabetes-associated erectile dysfunction. J Androl, 2004. 25(5): p. 830-6.

98. Rajapakse, N.W., et al., Insulin-mediated activation of the L-arginine nitric oxide pathway in man, and its impairment in diabetes. PLoS One, 2013. 8(5): p. e61840.

99. Mahmoud, A.M., et al., Nox2 contributes to hyperinsulinemia-induced redox imbalance and impaired vascular function. Redox Biol, 2017. 13: p. 288-300.

100. Goldstein, B.J., et al., Role of insulin-induced reactive oxygen species in the insulin signaling pathway. Antioxid Redox Signal, 2005. 7(7-8): p. 1021-31.

101. Brites-Anselmi, G., et al., DDAH1 and DDAH2 polymorphisms associate with asymmetrical dimethylarginine plasma levels in erectile dysfunction patients but not in healthy controls. Nitric Oxide, 2019. 92: p. 11-17.

102. Azevedo, A.M.M., et al., Relationship between asymmetric dimethylarginine, nitrite and genetic polymorphisms: Impact on erectile dysfunction therapy. Nitric Oxide, 2017. 71: p. 44-51.

103. Bivalacqua, T.J., et al., Increased expression of arginase // in human diabetic corpus cavernosum: in diabetic-associated erectile dysfunction. Biochem Biophys Res Commun, 2001. 283(4): p. 923-7. 
104. Lontchi-Yimagou, E., et al., Diabetes mellitus and inflammation. Curr Diab Rep, 2013. 13(3): p. 435-44.

105. Lin, H., et al., Rapamycin Supplementation May Ameliorate Erectile Function in Rats With Streptozotocin-Induced Type 1 Diabetes by Inducing Autophagy and Inhibiting Apoptosis, Endothelial Dysfunction, and Corporal Fibrosis. J Sex Med, 2018. 15(9): p. 1246-1259.

106. Lacchini, R., et al., Influence of arginase polymorphisms and arginase levels/activity on the response to erectile dysfunction therapy with sildenafil. Pharmacogenomics J, 2018. 18(2): p. 238-244.

107. Shields, M. and K. Wilkins, Smoking, smoking cessation and heart disease risk: A 16-year follow-up study. Health Rep, 2013. 24(2): p. 12-22.

108. Kenfield, S.A., et al., Smoking and smoking cessation in relation to mortality in women. JAMA, 2008. 299(17): p. 2037-47.

109. Gratziou, C., Respiratory, cardiovascular and other physiological consequences of smoking cessation. Curr Med Res Opin, 2009. 25(2): p. 53545.

110. Johnson, H.M., et al., Effects of smoking and smoking cessation on endothelial function: 1-year outcomes from a randomized clinical trial. J Am Coll Cardiol, 2010. 55(18): p. 1988-95.

111. Celermajer, D.S., et al., Cigarette smoking is associated with dose-related and potentially reversible impairment of endothelium-dependent dilation in healthy young adults. Circulation, 1993. 88(5 Pt 1): p. 2149-55.

112. Fukumoto, K., et al., Predictors of the effects of smoking cessation on the endothelial function of conduit and digital vessels. Hypertens Res, 2021. 44(1): p. 63-70. 
113. Athyros, V.G., et al., Effect of tobacco smoking and smoking cessation on plasma lipoproteins and associated major cardiovascular risk factors: a narrative review. Curr Med Res Opin, 2013. 29(10): p. 1263-74.

114. Rehill, N., et al., The effect of chronic tobacco smoking on arterial stiffness. $\mathrm{Br}$ J Clin Pharmacol, 2006. 61(6): p. 767-73.

115. Korneeva, N.V. and B.Z. Sirotin, Microcirculatory Bed, Microcirculation, and Smoking-Associated Endothelial Dysfunction in Young Adults. Bull Exp Biol Med, 2017. 162(6): p. 824-828.

116. Haziza, C., et al., Favorable Changes in Biomarkers of Potential Harm to Reduce the Adverse Health Effects of Smoking in Smokers Switching to the Menthol Tobacco Heating System 2.2 for 3 Months (Part 2). Nicotine Tob Res, 2020. 22(4): p. 549-559.

117. Xue, C., et al., Effects of Smoking Cessation with Nicotine Replacement Therapy on Vascular Endothelial Function, Arterial Stiffness, and Inflammation Response in Healthy Smokers. Angiology, 2019. 70(8): p. 719-725.

118. Puls, M., et al., Effect of smoking cessation on the number and adhesive properties of early outgrowth endothelial progenitor cells. Int J Cardiol, 2011. 152(1): p. 61-9. 